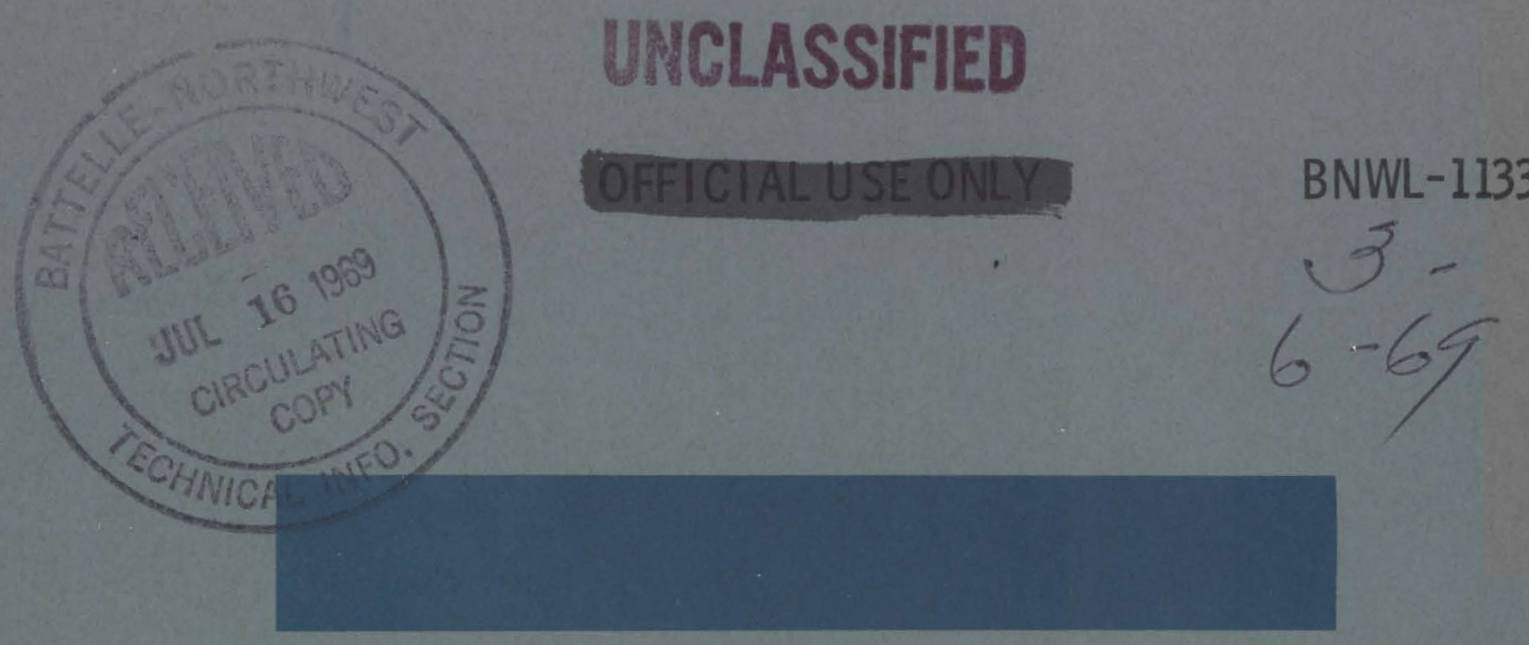

\title{
FAST FLUX TEST FACILITY MONTHLY INFORMAL TECHNICAL PROGRESS REPORT
} JUNE 1969

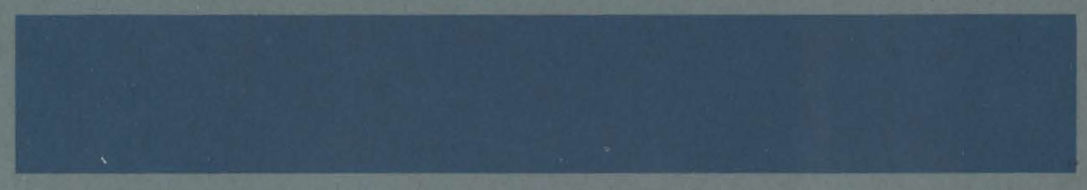

\section{AEC RESEARCH \&} DEVELOPMENT REPORT

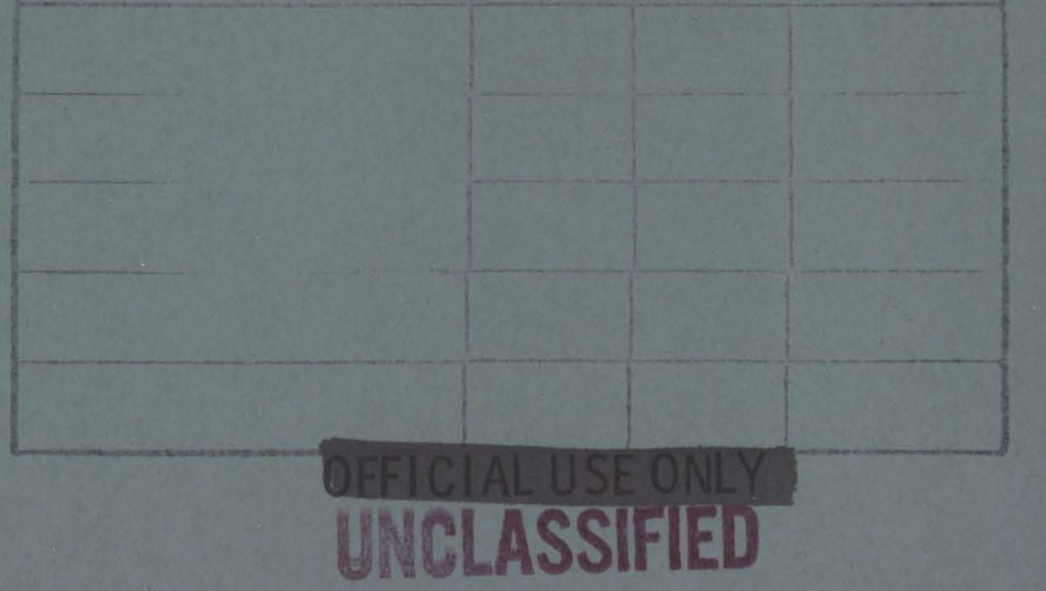




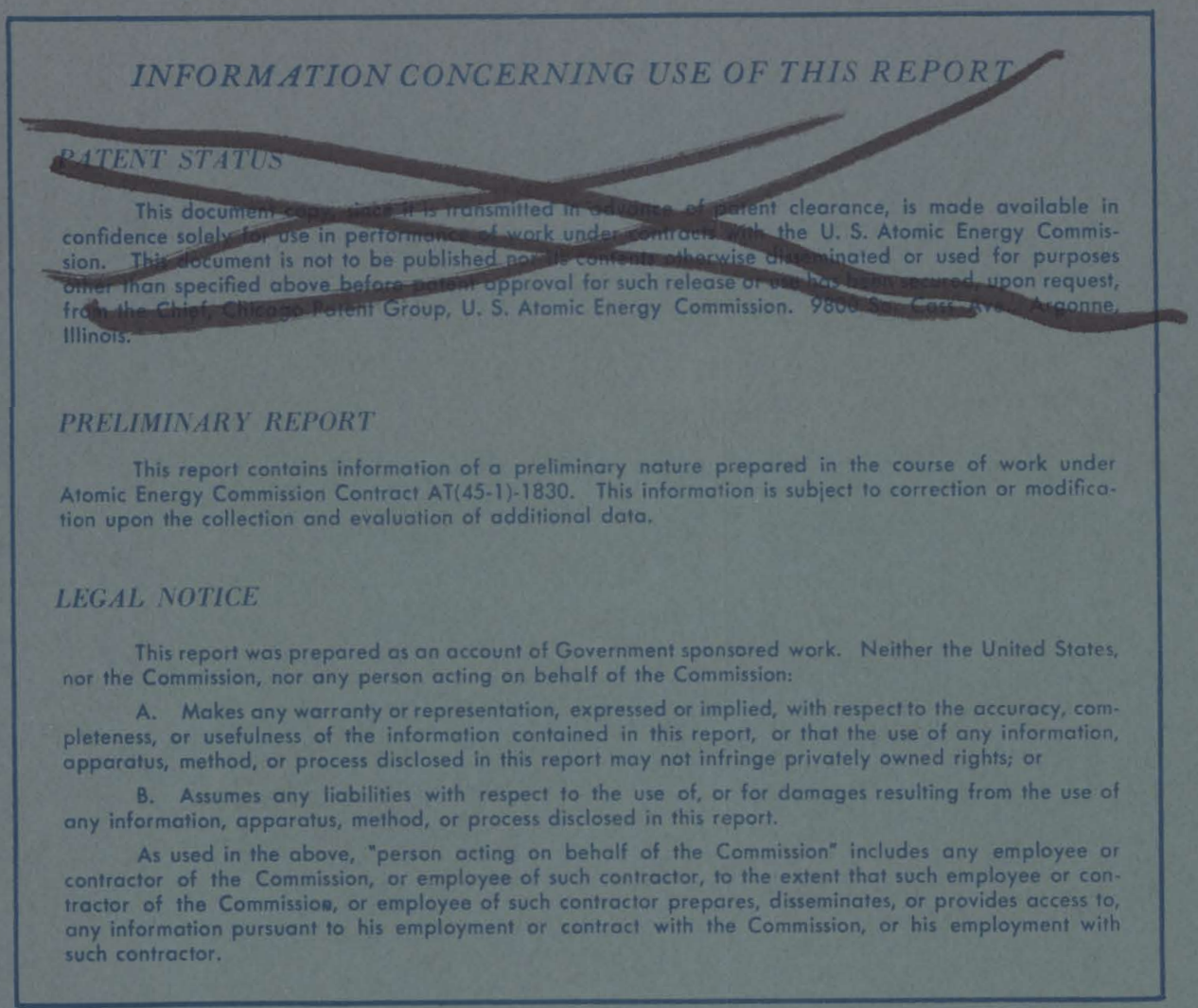

\section{PACIFIC NORTHWEST LABORATORY}

RICHLAND, WASHINGTON

operated by

BATTELLE MEMORIAL INSTITUTE

for the

UNITED STATES ATOMIC ENERGY COMMISSION UNDER CONTRACT AT(45-1)-1830 


\section{FAST FLUX TEST FACILITY \\ MONTHLY INFORMAL TECHNICAL PROGRESS REPORT JUNE 1969}

E. R. Ast 1ey

Project Manager

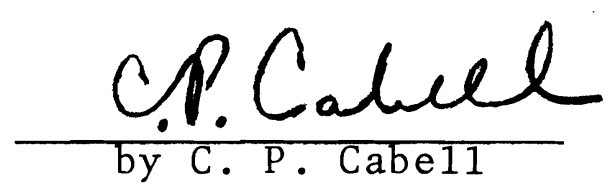

Ju1y 8, 1969

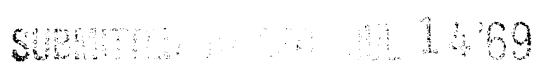

BATTELLE MEMORIAL INSTITUTE PACIFIC NORTHWEST LABORATORY RICHLAND, WASHINGTON 99352 
BNWL -1133

\section{FAST FLUX TEST FACILITY}

MONTHLY INFORMAL TECHNICAL PROGRESS REPORT

June 1969

\section{ABSTRACT}

This report was prepared by Battelle-Northwest under Contract No. AT (45-1)-1830 for the Atomic Energy Commission, Division of Reactor Development and Technology, to summarize technical progress made in the Fast Flux Test Facility Program during June 1969. 


\section{CONTENTS}

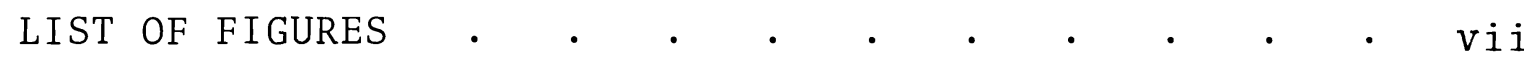

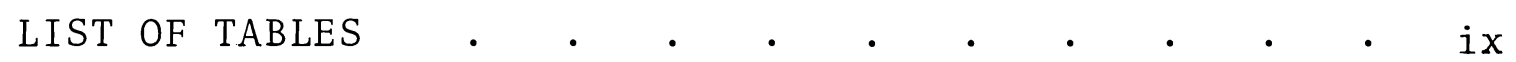

INTRODUCTION

I. OVERALL FFTF PROGRESS .

A. Design Definition Summarization . . . . 1.1

B. Supporting Technology . . . . . . 1.3

C. Development of Fuels and the Fuels

Subassembly . . . . . . . . . . . 1.4

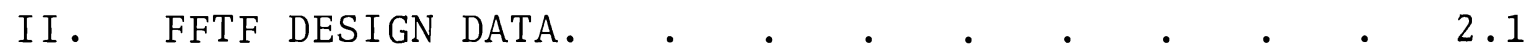

II . GENERAL TECHNOLOGY . . . . . . . . 3.1

A. Reactor and Plant Engineering . . . . 3.1

B. Nuclear and Process Technology . . . . 3.11

C. Safety and Systems Analysis . . . . . 3.37

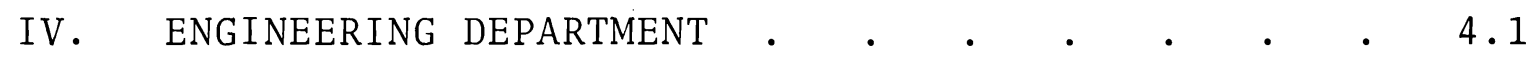

A. Reactor Systems . . . . . . . . . 4.1

B. Fluid Systems . . . . . . . . . . 4.9

C. Plant Systems . . . . . . . . 4.15

D. Instrumentation and Control . . . . . 4.19

E. Sodium and Gas Technology . . . . . 4.23

F. Metals, Materials and Codes. . . . . 4.26

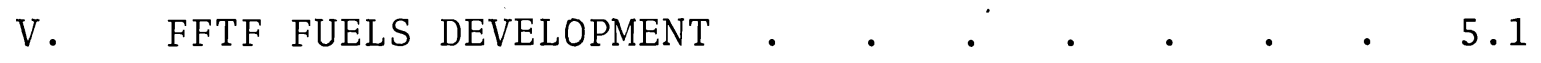

A. Fuel Element Development. . . . . . 5.1

B. Fuels Quality Assurance . . . . . . 5.6

C. Cladding Development . . . . . . 5.10

D. Fuels Evaluation . . . . . . . . 5.17

E. Offsite Fuel Programs . . . . . . 5.25 


\section{LIST OF FIGURES}

3.A.1 Heat Transport System "Y" Equipment Vault Arrangement Plan View

3.A.2 Flux Distributions at the Top of the Receptacles and at the Top of the Grid Plate Versus Distance from Core Centerline

3.B.1 Axial Temperature Profiles for Fully-Inserted Poison Pins

3.16

3.B.2 Radial Temperature Profiles for Poison Pins

3.B.3 Reduction in Cell Inscribed Diameter Induced by Swelling, Distortion, and $100 \%$ Stress Relaxation of Secondary Stresses

3.B.4 Reduction in Grid Cell Inscribed Circle Induced by Relative Swelling in the Grid Lattice

3.B.5 Comparison of Pressure Drop Between WireWrapped and Grid Spaced Bundles

3.B.6 Temperature Peaking Induced by a Local Disturbance of the Heat Transfer Coefficient

3.B.7 Comparison of Enthalpy Peaking Factors Between Grid Spaced and Wire-Wrapped Bundles

3.C.1 HTS Cell Features Included in Mode1 for

Transient Temperature Analysis Following DBA + Loss-of-Coolant Accident

3.C.2 Temperature and Pressure Versus Time Following DBA and Loss of Coolant Accident

3.C.3 Critical Fuel Thickness for Steady State Conditions

3.C.4 Temperature History of Oxide-Fue1 System 3.43

3.C.5 Surface Heat Flux Rates 
BNWL -1133

3.C.6 Pressure History During Cavity Venting

3.46

3.C.7 Core Outlet Temperature Due to $30 \% / \mathrm{sec}$ Flow Reduction with Protective Action

3.51

3.C.8 Maximum Sensor Response in Time Permitted to Prevent Boiling at Core Outlet

3.52

4.F.1 Average Crack Length Versus Load Cycles for 304 SS Specimen

4.30

4.F.2 Crack Growth Rate of 304 SS Plotted Versus Stress Intensity Factor

4.31

5.A.1 Frequency Distribution of Sintered Pellet Diameters

5.3 


\section{LIST OF TABLES}

2-I Summary of Principal Concept Characteristics and Data

3.A.1 Reactor Pressure Drop 3.5

3.A.II Reactor Power and Flow 3.6

3.A.II Available Pressure Drop 3.7

3.A.IV Estimated Number of Individual ${ }^{124} \mathrm{Xe}-{ }^{129} \mathrm{Xe} \quad 3.8$

3.B.I Parameters for $\mathrm{B}_{4} \mathrm{C}$ Poison Pin Thermal Analysis 3.15

3.B.II Heat Generation Rates for Poison Pin Thermal Analys is

3.B.IV Summary of Component Swelling in Radial Dimension

3.B.V FTR I and II Dimensions and Masses

(R-Z Calculation

3.B.VI Centra1 Drawer Exchange Worths 3.33

3.B.VII Peripheral Drawer Exchange Worth 3.33

3.C.1 HTS Ce11 Features Included in Model for Transient Temperature Analysis Following DBA + Loss-of-Coolant Accident

3.C.2 Temperature and Pressure Versus Time Following DBA and Loss of Coolant Accident

4.B.I IHX Design Parameters Resulting from Preliminary Calculations

5.A.I Fuel Pellet Debonding and Sintering Run Data

5.2

5.C.I Biaxial Stress-Rupture Tests on AISI Type 316 SS Irradiated to $20.8 \times 10^{22} \mathrm{n} / \mathrm{cm}^{2}(\mathrm{E}>0.1 \mathrm{MeV})$ in EBR-II. Test Temperature was $1200^{\circ} \mathrm{F}$. The Irradiation Temperature was $815^{\circ} \mathrm{F} \pm 80$

5.C.II Irradiation Induced Swelling in EBR-II Safety Rod Thimble

5.C.III Specimen History and Burst Test Results 5.16

5.D.I PNL-X Cladding Diameters 5.21

5.D.II Gas Measurements on PNL-X Pins 5.21

5.D.III Gas Analysis on PNL-X Pins 5.21 
BNWL -1133

FAST FLUX TEST FACILITY

MONTHLY INFORMAL TECHNICAL PROGRESS REPORT

June 1969

\section{INTRODUCTION}

This Informal Technical Progress Report is divided into five chapters. Chapter I presents a brief summarization of FFTF overall program progress during the reporting period and includes a "Design Definition Summary" which has been compiled by the editors from the report contents. This section summarizes significant design decisions and recommendations made, alternative designs proposed, requirements established, and technical design problems identified.

Chapter II, FFTF Design Data, presents a tabulation of principal concept characteristics.

Chapter III, IV, and $\mathrm{V}$ follow previous practice and describe the work of the various sections of the Engineering, Reactor, and Plant Technology and Fuels Departments respectively. Because of certain limitations of available printing processes used on this report significant amounts of detail may be lost in any photomicrographs presented in this report. AEC or Contractor personnel requiring glossy prints of the photomicrographs may obtain them by writing to the responsible FFTF Department Manager. 
Damage fluence at the top of the receptacles and grid plate were calculated to be $\sim 2 \times 10^{14}$ and $\sim 7 \times 10^{12}$ respectively at the core centerline for concept VA. These fluences are below the damage criteria presently set for these components.

Reactor Nuclear Control. BNW recommended that the roller nut concept be used for the control and secondary safety systems; the magnetic jack concept be used for the primary safety system; and the BNW pneumatic drive be used as the alternative concept in the event that either of the other above drives fails to meet the design requirements.

50. Heat Transport System

Heat Transport System conceptual design modifications are being investigated in an effort to reduce space requirements and thereby to reduce associated size and costs of the containment vesse1. A promising concept reduces the length of the primary piping by $33 \%$.

As a result of Babcock and Wilcox Company work two interim IHX designs were selected as recommended bases for follow-on study. One concept features a helical coil tube bundle with floating lower head. The other concept utilizes a straight tube bundle with floating lower head. In both concepts the tube bundle is removable after cutting secondary inlet and outlet piping.

80. Sodium and Gas Processing and Receiving System

A new vapor trap design has been conceived and a prototype constructed. The new trap design is based on the premise that the bulk of the sodium which escapes concentional traps does so as an aerosol mist which can be trapped through. re-vaporization followed by a second condensation. Initial tests show considerable promise. 


\section{B. SUPPORTING TECHNOLOGY}

This section presents summaries of supporting technology items of wide general interest.

\section{Safety Program}

Arrangements have been made to ensure that the LMFBR safety technology at ANL is applied to its fullest extent in FFTF studies. The areas of immediate application include, for the PSAR and its supporting information, (a) Maximum accident studies which establish the DBA, and (b) Evaluation and specification of the fuel/cladding design bases and, correspondingly, damage criteria for the fuel.

\section{Materials Technology}

In connection with the potential problem of cracking in critical FFTF components, evaluation of the subcritical crack growth properties of Type 304 SS has been initiated. Initial tests are being performed for the purpose of determining the effect of cycle rate and crack orientation on crack growth rates.

It has been found that exposure to sodium vapor produces much more severe degradation in some stainless steels then does exposure to liquid sodium. The causes for this effect are incompletely understood; however, in the case of 201 stainless steel it was found that sodium vapor produces on accelerated surface attack.

\section{Critical Assembly Experiments}

FTR I and II Preanalysis

The critical mass of FTR-II has been computed using the as-built core compositions and assuming a $10 \mathrm{~cm}$ thick $\mathrm{B}_{4} \mathrm{C}$ control ring. This value is $505 \mathrm{~kg}$ fissile mass. 
Pin-Fueled Sodium Void Experiment

Further preplanning calculations have been performed for a pin-fueled sodium void experiment and a proposal for such an experiment has been drafted.

\section{c. DEVELOPMENT OF FUELS AND THE FUELS SUBASSEMBLY}

1. Fue1 Process

Fabrication of the 300 FFTF type fuel pins for criticality studies is continuing in the FFTF fuel pilot line. A total of 98 fuel pins has been assembled. A total of $27 \mathrm{~kg}$ of mixed oxide powder has been processed and $14 \mathrm{~kg}$ of mixed oxide fuel pellets were debonded and sintered. The $0 / M$ results obtained from these sintering runs indicate that the $0 / M$ may be a function of the furnace load mass as well as the sintering temperature.

The capability for sintering fuel pellets to size through control of die size and forming pressure was demonstrated.

A completed draft of the Fuels Quality Assurance Manual was distributed within BNW for comment. This manual (in three volumes) covers the FFTF Fuels Quality Program and FFTF Fuels Quality Assurance Procedures.

Development of a computer method which can be used to select neutron spectra and flux at any radial or axial position in the EBR-II from calculated or measured data has been completed. This will enable rapid evaluation of fuel element behavior for any position in EBR-II.

2. Fue1 Subassemblies

Bending of fuel ducts, as the result of differential swelling of stainless steel in the fuel subassemblies, has been identified as the major lifetime-limiting item for fuel. 
Duct wear pad attachment studies have shown that simultaneous welding of the wear pads to opposite sides of the duct by resistance spot welding is practical with the proper fixtures. The method offers good possibilities for minimizing duct distortion during wear pad attachment.

To identify potential wear problems with wire wrapped fue 1 pins a 7 -pin fuel assembly model ( 3 pins with wire stretched 0.020 in. and 3 pins with wire stretched 0.030 in.) is being tested in the Small Components Test Loop at $30 \mathrm{ft} / \mathrm{sec}$ and temperature of $1150^{\circ} \mathrm{F}$. An interim examination after $800 \mathrm{hr}$ indicated no qualitative evidence of wear on cladding or wire wrap surfaces. 


\section{FFTF DESIGN DATA}

This Chapter presents, as Table 2-I, a current summary of principal FFTF concept characteristics and data.

\section{TABLE 2-I. Summary of Principal Concept Characteristics and Data}

(Compiled by C. W. Higby - June 20, 1969)

$$
\text { Units Values Status (a) }
$$

A. General Plant Data

1. Core arrangement vertical 1

2. Design 1ife years

3. Peak flux

7. Core flow $\mathrm{n} / \mathrm{cm}^{2}-\sec 7.2 \times 10^{15} 2$

4. Total power

5. Reactor coolant $M W_{t}$ $400 \quad 1$

6. Core volume liters sodium $\quad 1$ $\mathrm{lb} / \mathrm{hr}$ 1033 2

8. Core pressure drop $1.5 \times 10^{7} 2$ design maximum

psi

9. Reactor bulk inlet temperature initial

\section{${ }^{\circ} \mathrm{F}$}

${ }^{\circ} \mathrm{F}$

${ }^{\circ} \mathrm{F}$

900

1200

120

2

design maximum

${ }^{\circ} \mathrm{F}$

11. Core temperature rise average initial design maximum

12. Reactor cover gas
${ }^{\circ} \mathrm{F}$

300

2

${ }^{\circ} \mathrm{F}$

400

argon temperature

initial core

(1)

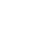

2

(1)

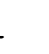

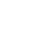
(a) 1 - Firm requirement or definite concept characteristic.
2 - Current reference design value. 
TABLE 2-I. (contd)

Units Values Status(a)

B. Reactor Vesse1

1. Diameter

feet

17

2

2. Height

3. Wall thickness

feet

50

2

4. Wall fluence, total (at $1200^{\circ} \mathrm{F}$ )

inches

2

2

5. Material

nvt

$1.0 \times 10^{21}$

2

304 SS

1

C. Core Design

1. Number of core lattice positions

91

1

2. Number of driver fuel subas semblies

3. Number of closed loops

$76 \quad 2$

4. Number of contact instrumented in-core open test positions

5. Number of proximity instrumented open test positions

6

6. Number of in-core safety rods

7. Number of in-core control rods

8. Number of peripheral control rods

9. Equivalent core diameter inches

inches

$\sim 48$

10. Active core height

36

11. Radial reflector material

nickel

2

12. Reflector thickness

axial

radial

13. Fuel pin heat

transfer area inches

rows

$f t^{2}$
6

3

2980
2

2

2 
BNWL - 1133

TABLE 2-I. (contd)

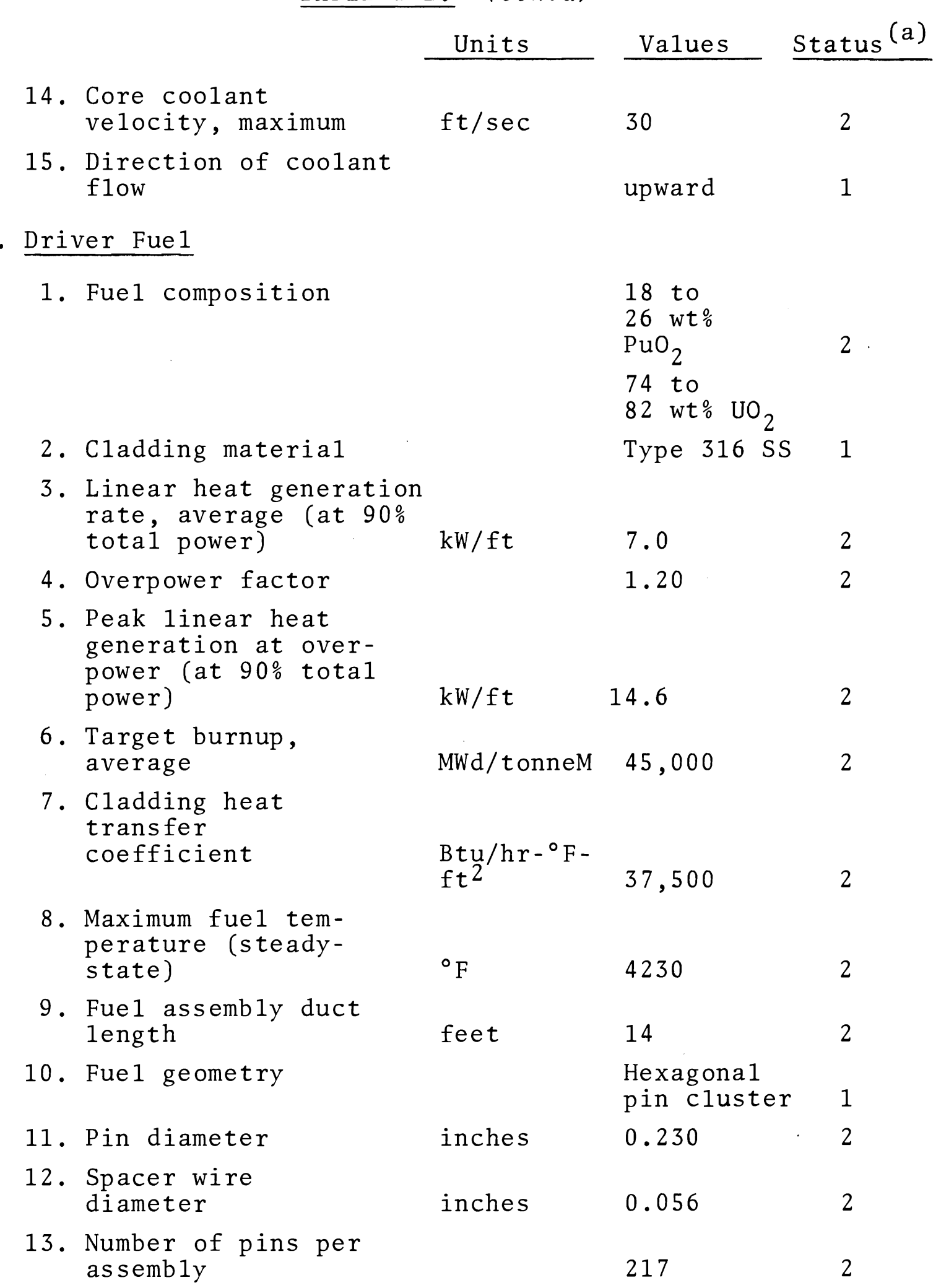


TABLE 2-I. (contd)

Units Values Status (a)

14. Subassembly crosssection outside dimension (across flats) inches 4.615 2

15. Lattice spacing inches

4.715 2

16. Duct wall thickness

inches $\quad 0.140$

E. Physics Data

1. Delayed neutron fraction $\begin{array}{ll} & 0.003 \\ \text { seconds } & 4.0 \times 10^{-7}\end{array}$

2. Neutron lifetime $\mathrm{T}\left(\frac{\mathrm{dk}}{\mathrm{dt}}\right)$ $-0.004$ 2

4. Power density, peak MW/1iter 0.75 2

5. Power distribution (peak/average) radial

axial

total

1.40

1.24

1.74

F. Test Facilities

1. Closed loops

- number

6

2

- location

2 adjacent to core center 2

1 at mid-radius 2

3 at core periphery

- power handling capability

MW 3-5

- test flow rate

$\mathrm{ga} 1 / \mathrm{min} \quad 200-350$

- test section outlet temperature

1400 (bypass flow permitted) 
TABLE 2-I. (contd)

\begin{tabular}{|c|c|c|c|}
\hline & Units & Values & Status (a) \\
\hline test section length & inches & 36 & 2 \\
\hline test section diameter & inches & $2.5-3.0$ & 1 \\
\hline pumping head - primary & $1 \mathrm{~b} /$ in $^{2}$ & 250 & \\
\hline $\begin{array}{l}\text { test section pressure } \\
\text { drop, maximum }\end{array}$ & $1 \mathrm{~b} /$ in $^{2}$ & 90 & 2 \\
\hline $\begin{array}{l}\text { material (in-core } \\
\text { tube) }\end{array}$ & & 316 SS & 1 \\
\hline
\end{tabular}

2. In-core open test positions

- number with contact instrumentation

with proximity instrumentation*

- power

- coolant flow rate

- test assembly length

Same as driver fue 1 subassembly

- test assembly cross section

- coolant

3. Short term irradiation facility

- type trail cable 1

- number 1

- location core periphery 2

- minimum irradiation time at constant flux minutes 1

- sample length inches 24

- sample cross section, maximum inches

2.5

* One open test position will have superior accessibility. Driver fuel positions can be used as open test positions with limited accessibility. 
BNWL - 1133

TABLE 2-I. (contd)

Units Values Status (a)

G. Heat Transport System

1. Primary loops

- number

- primary loop material

3

1

- primary loop flow (per 1oop)

$\mathrm{ga} 1 / \mathrm{min} \quad 14,000$

2

2. Primary pumps

- number

3

1

- design pump head

feet

500

2

- available net positive suction head

feet

51

2

- design temperature

${ }^{\circ} \mathrm{F}$

1200

- speed control

wound rotor motor with

liquid

rheostat

- motor power

brake

HP

1790

2

rated

HP

2500

2

3. Intermediate heat exchangers

- number

3

1

- type

vertical shell and tube 1

- LMTD

initial

ultimate

- capacity

initial

ultimate
${ }^{\circ} \mathrm{F}$

${ }^{\circ} \mathrm{F}$

MW

MW
75

100

133

177

\section{1}

2

2

2

2

H. Shielding

1. Within reactor vesse1

- material

stainless

stee 1 
BNWL - 1133

TABLE 2-I. (contd)

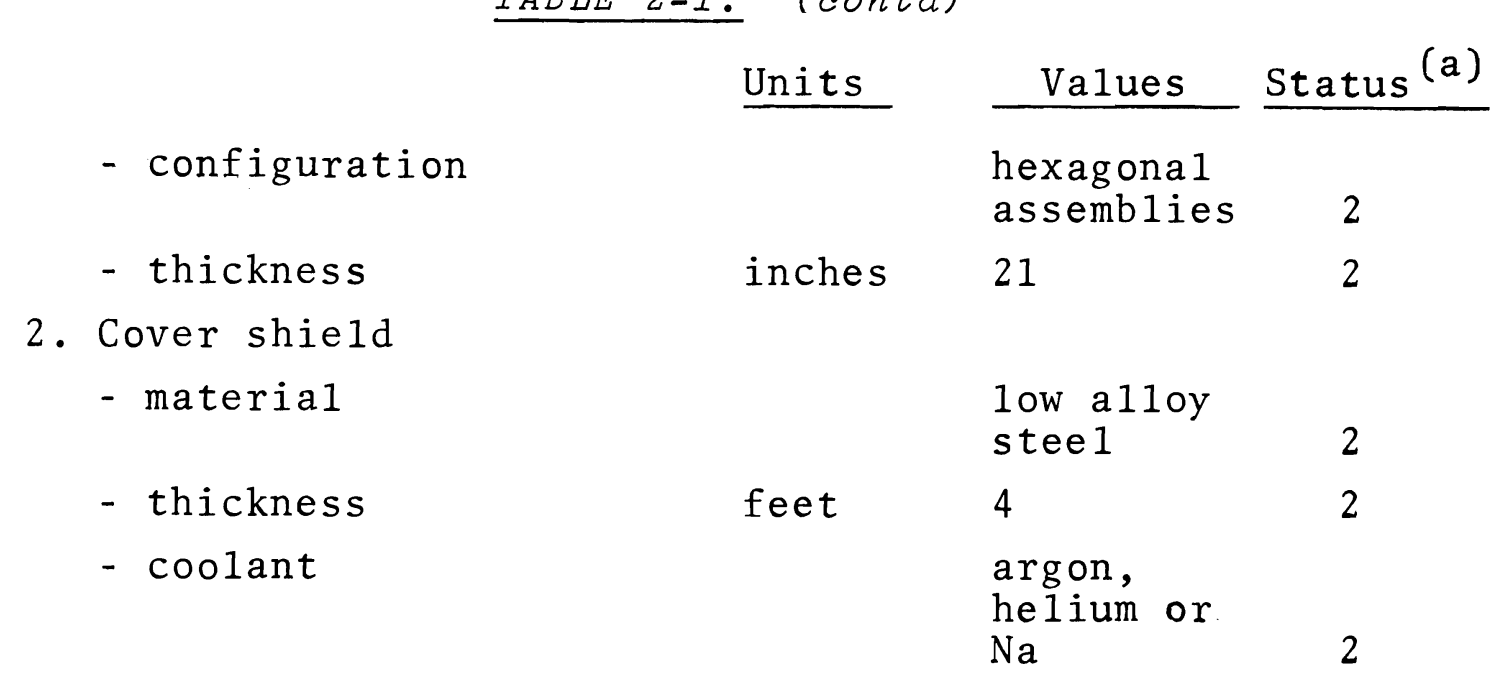




\section{I. GENERAL TECHNOLOGY}

P. L. Hofmann

A. REACTOR AND PLANT ENGINEERING

L. M. Finch

1. Reactor Engineering

D. Marinos

a. Nuclear Control Components

D. Marinos

The CCDD for Nuclear Control Components, CCDD-No. 33, has been approved by the BNW Configuration Control Board after final approval of some changes to the Design Safety Criteria on the same system. The safety criteria were revised to reflect the elimination of the stuck rod criterion from the secondary safetyoperational control system and to insert a reliabilitycriterion for the systems.

b. Core CSDD Preparation

G. R. Waymire

The reactor core CSDD has been approved by the BNW Configuration Control Board. The CCB approved version of the core CSDD was transmitted to RDT for review and approval on June 13 .

\section{c. Radial Restraint G. R. Waymire}

Discussions were conducted with Westinghouse to identify required analysis, design, and development effort which must be performed to complete a preliminary radial restraint design.

A preliminary list of design criteria was generated as well as an identification of analytical work required. An agreed upon development program has not been established pending completion of a detailed development plan from Westinghouse. 
BNWL -1133

d. Movab1e Fue1 Contro1

H. C. F. Ripfe1

A feasibility study is being performed to evaluate the use of movable fuel as a control medium for the FTR. This study is to establish a firm position on this subject as requested recently by RDT. Preliminary results indicate that the reactivity worth of the fuel bundles in place of the existing poison rods are of decidedly less worth than poison as the position moves toward the center of the reactor. Safety rod positions located in the third row radially would only be worth about one third that of the poison rod. The in-core shim rod positions would be worth approximately one half that of a poison rod. Peripheral rod worths of movable fuel approach that of poison rods but the core must be enlarged or the control must replace existing driver element positions to achieve this worth.

The above worths are based on a fuel pin bundle of 169 pins since the outer row of pins must be eliminated from the 217 pin bundle to permit an inner movable structural duct to be placed inside a normal guide duct. Although increasing the number of fuel positions required to control the reactor does not degrade the core as would the poison rods, space for three times as many safety rods or twice as many in-core shim rods (from the standpoint of drive mechanisms) would result in a serious penalty insofar as availability and cost are concerned.

Scram requirements for movable fuel also seem to result in an added penalty because of the high flows required to cool the fuel rods. Insertion forces to propel a rod counter to the flow direction would be much higher than a poison rod where the flow is severely orificed as a result of lower heat generation rates.

Increased rod worths for movable fuel can be achieved by utilizing a poison follower above the fuel consisting of tantalum. 
The gas plenum for the fuel pins must then be located on the bottom of the fuel thus increasing the subassembly length by up to $4 \mathrm{ft}$. This increase is then transmitted to all in-core assemblies, vesse1 clearance heights, fuel handling machine lengths and containment height requirements.

2. Plant Engineering

D. P. Schively

a. FFTF Heat Transport System 51

L. G. Henke

Various piping rearrangements of the basic (BNW, RDT and WARD agreed) FFTF Integral Primary and Emergency Core Coolant System were evaluated to reduce the overall size of the reactor containment below the $200 \mathrm{ft}$ diam and to improve the heat transport system piping by eliminating all vertical expansion U-bends, and by a further reduction in the moments and forces on the vesse1, pump, and IHX nozzles.

The most promising rearrangement reduced the length of the primary piping approximately one third, provided a nearly symmetrical piping layout for all three circuits, and made possible a slight reduction in the containment diameter. This is the Y-type equipment vault concept in which the centerling of all three/pump IHX vaults are spaced at $120^{\circ}$ around the vesse1 cavity.

Further study of this unique concept, as depicted in Figure 3.A.1. (SK-3-14688), wil1 be made to consider the architectural and structural aspects, and the location of ancillary equipment.

b. Structures and Containment

J. R. Samue 1

Drawing SK-3-14677(1) was prepared showing one method of venting the machinery dome into the reactor cavity vault. The drawing shows the venting by means of a pipe attached outside the dome, near the operating floor, passing through the reactor

1. $S K$ drawing not shown in this report. 
BNWL - 1133

RIMARY HEAT TRANSPORT SYSTEM

EQUIPMENT VAULT NO. 2 
support ring into the cavity wall then into the cavity, where a replaceable rupture disk is attached.

Other methods were considered but there are too many reactor oriented items installed directly above the reactor for a simple vent line to be installed directly in a vertical direction.

c. Reactor Flow and Pressure Drop Study

R. E. Keyes

Three tables were prepared to summarize FTR pressure drop studies as follows:

- Table 3.A.I., Reactor Pressure Drop, as based on the maximumflow bundle coolant rate of $2.073 \times 10^{6} \mathrm{lb} / \mathrm{hr}$ with no orifice.

- Table 3.A.II., Reactor Power and Flow for high-flow and lowflow design arrangements and for 76 drivers plus three open loops and for the same plus six closed loops as drivers.

- Table 3.A.III., Available Pressure Drop for the four flow rates of the above table.

TABLE 3.A.I. Reactor Pressure Drop

\begin{tabular}{|c|c|c|c|c|c|}
\hline Item & $\begin{array}{r}\Delta \mathrm{P}, \\
\mathrm{ps} i \\
\end{array}$ & $\begin{array}{l} \pm \Delta \mathrm{P} \\
\mathrm{psi}\end{array}$ & $\begin{array}{l}\text { Ref. Drawings }(1) \\
\text { No., Issue, Date } \\
\end{array}$ & Basis & Remarks \\
\hline In1et P1enum & - & - & $\begin{array}{l}\text { SK-3-14585, 1st, } \\
2 / 18 / 69\end{array}$ & $\begin{array}{l}2100-1 \text { in. dia. Holes, } \\
2 \text { in. Long }\end{array}$ & \\
\hline Receptacle & 1.1 & 0.2 & $\begin{array}{l}\text { SK-3-1440, 1st } \\
10 / 22 / 68\end{array}$ & $\begin{array}{l}\text { Nose Pc Slotted to Match } \\
\text { Receptacle slots; leak } \\
\text { path }=144 ; 0.02 \text {-in. } \\
\text { diam C1. }\end{array}$ & $\begin{array}{l}\text { Leakage }=2.1 \% \\
\text { depend on design }\end{array}$ \\
\hline \multicolumn{6}{|l|}{ Fue 1 Bundle } \\
\hline $\begin{array}{l}\text { Friction Inlet } \\
\text { Inlet \& Outlet } \\
\text { \& Shroud Tube }\end{array}$ & $\begin{array}{r}52.0 \\
3.4\end{array}$ & $\begin{array}{l}8.3 \\
1.0\end{array}$ & $\begin{array}{l}\text { SK-3-14581, 2nd, } \\
2 / 19 / 69\end{array}$ & $\begin{array}{l}\text { 217-pins/0.23 in. diam pin/ } \\
0.056-\text { in. OD wire } @ 12 \text {-in. } \\
\text { pitch/93-in. Long }\end{array}$ & $\begin{array}{l}\text { Temp effect with- } \\
\text { in } 1.3 \mathrm{psi} \text { band } 50 \\
\text { to } 900{ }^{\circ} \mathrm{F}\end{array}$ \\
\hline $\begin{array}{l}\text { Instrument } \\
\text { Probe }\end{array}$ & 15.0 & 2.0 & $\begin{array}{l}\text { SK-3-12896, 2nd, } \\
3 / 14 / 69 \\
\text { SK-3-14581, Modified }\end{array}$ & $\begin{array}{l}4.12 \text { in. diam } \times 0.60 \text { in. } \\
\text { diam } \mathrm{C} 1 \times 1-\text { in. Long Leak } \\
\text { Path; Na at } 900{ }^{\circ} \mathrm{F}\end{array}$ & $\begin{array}{l}\text { Leakage } 7.9 \text { to } 9.6 \% \\
\text { of flow }\end{array}$ \\
\hline Shie1d at In1e & t 6.7 & 1.1 & & $\begin{array}{l}\text { 12-in. Extension of Fue } 1 \\
\text { Bundle }\end{array}$ & \\
\hline Total & 78.2 & 8.7 & & & \\
\hline $\begin{array}{l}\text { Elev } \triangle \mathrm{P} \text { betwee } \\
\text { nozzles }\end{array}$ & n 7.4 & - & SK-3-14541, $1 \mathrm{st}$ & About $20.7 \mathrm{ft} @ 700^{\circ} \mathrm{F}$ & \\
\hline Reactor & 85.6 & \pm 8.7 & & & \\
\hline
\end{tabular}


BNWL - 1133

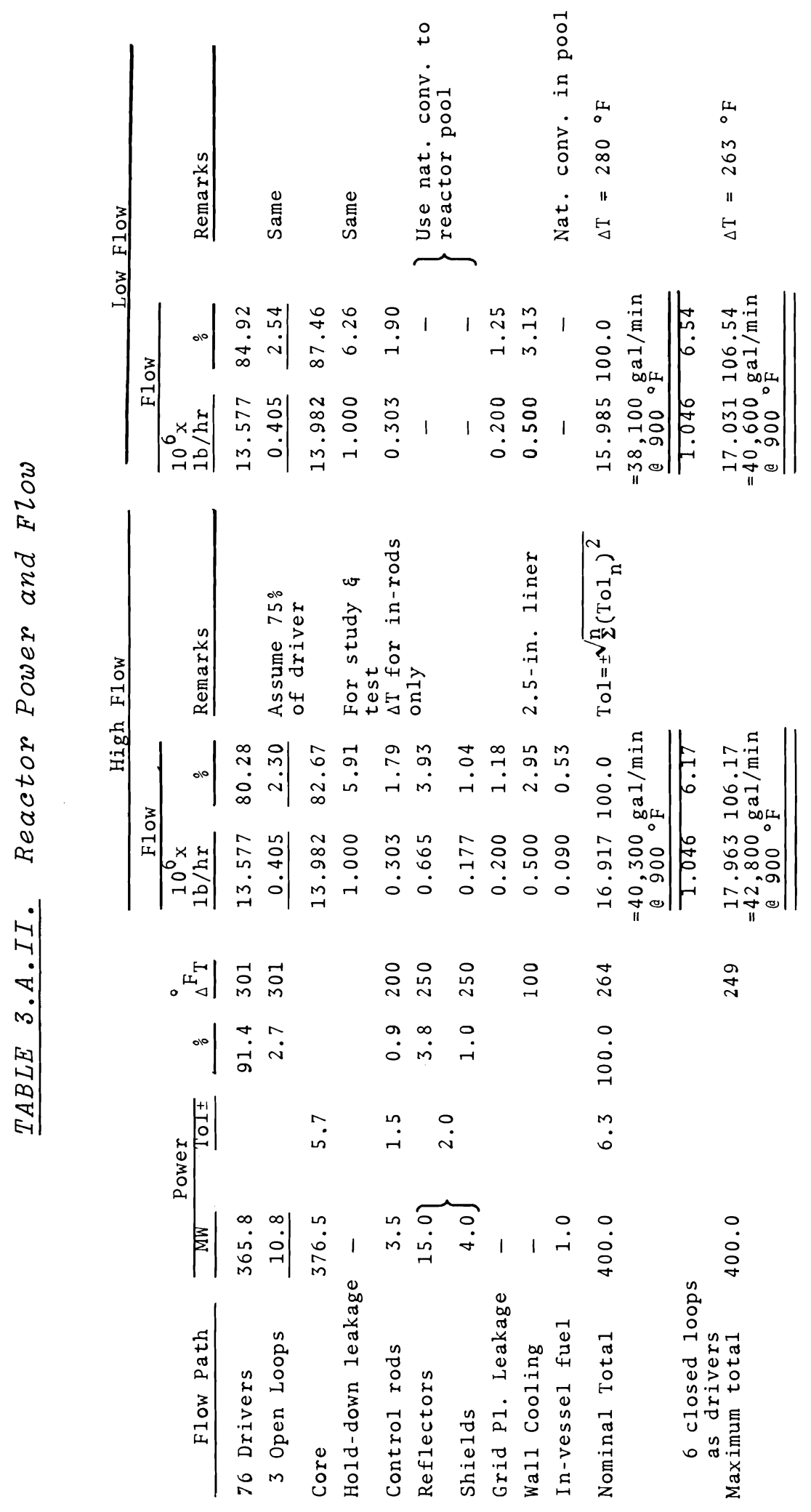




\section{TABLE 3.A.III. Avaizable Pressure Drop}

F1ow

\begin{tabular}{|c|c|c|c|c|}
\hline $\begin{array}{c}\text { Definition, } \\
\text { Table } 2 \\
\end{array}$ & $10^{6} \mathrm{lb} / \mathrm{hr}$ & gal/min & $\begin{array}{c}\text { Norma1 HTS } \\
\text { De1ivery } \Delta \mathrm{P}, \\
\text { psi }\end{array}$ & \begin{tabular}{c}
\multicolumn{2}{c}{ Available $\Delta \mathrm{P}-$} \\
Max Flow Driver \\
psi
\end{tabular} \\
\hline Nominal-High & 16.917 & 40,300 & 152 & 74 \\
\hline Nomina $1-$ Low & 15.985 & 38,100 & 161 & 83 \\
\hline Maximum-High & 17.963 & 42,800 & 142 & 64 \\
\hline Maximum-Low & 17.031 & 40,600 & 151 & 73 \\
\hline
\end{tabular}

These results are intended to serve as interim reference for design evaluation and will be included in a topical report. Revisions will be made when necessary as indicated by test results or design changes initiated during preliminary design.

3. Radiation and Shield Analysis

W. L. Bunch

a. Failed Fuel Element Detection by Xenon Tagging

C. A. Mansius

One method under consideration for the FEDAL system is to monitor the cover gas for the presence of xenon isotopes which had been precharged in the fission gas plenum of the fuel pins. ${ }^{124} \mathrm{Xe},{ }^{126} \mathrm{Xe}$, and ${ }^{129} \mathrm{Xe}$ are the most promising isotopes for tag use because they originate infrequently or not at all as fission products and their burnout characteristics are favorable. A different ratio of these isotopes would be selected as specific tags for each subassembly. Only three different enrichments of these isotopes and natural xenon are available commercially, limiting the ratios that may be realized by mixing. Because the ratios change with exposure and because we require tag uniqueness independent of operating history, the number of specific ratios is limited. Table 3 .A.IV shows the number of specific tags that may be made using ${ }^{124} \mathrm{Xe}$ and ${ }^{129} \mathrm{Xe}$ as a function of the differential burnout of the two isotopes. The best estimate of the 
differential burnout at goal exposure is about 3 to $5 \%$. However, there is a large uncertainty in the burnout calculation because of limited knowledge of the isotopic burnout crosssections. A $10 \%$ differential burnout is believed to be an upper limit providing about 32 individual ${ }^{124}$ Xe, ${ }^{129}$ Xe ratios. Because of mixing constraints, simultaneous consideration of the ${ }^{126} \mathrm{Xe},{ }^{124} \mathrm{Xe}$ ratio has 1 imited value; preliminary investigations show only a small increase in the number of individual tags may be possible.

TABLE 3.A.IV. Estimated Number of Individual ${ }^{124}$ Xe $-{ }^{129}$ Xe Tags

$\begin{array}{cc}\text { Differential } & \\ 124 \mathrm{Xe}-129 \mathrm{Xe} & \begin{array}{r}\text { Number } \\ \text { Burnout, } \%\end{array} \\ 10 & 32 \\ 8 & 40 \\ 5 & 56 \\ 3 & 72\end{array}$

(a) A small increase in the number of individual tags may be made by simultaneous consideration of $124 \mathrm{Xe}$, 126Xe ratio.

b. Axial Below-Core Shielding Calculations

E. T. Boulette

Radiation damage must be considered carefully in designing the below-core shield for the FTR. Two-dimensional diffusion theory calculations in R-Z geometry were made with the 2DBS code based on Concept V-A. Neutron intensities and spectra were calculated throughout the configuration. Total radial flux distributions at the grid plate and at the top of the receptacles are depicted in Figure 3.A.2. The neutron spectra at these elevations do not vary significantly with radial distance. The results indicate that the current total fluence radiation damage criterion at these locations are met by the Concept V-A below-core shield design. 


\section{c. In-Vesse1 Stored Fuel Heat Generation}

E. T. Boulette

The latest conceptual design of the FTR includes in-vessel storage locations in the sodium annulus exterior to the radial shield. Preliminary calculations were made with 2 DBS to estimate the fission heat generated in one stored fuel subassembly. In this calculation, the fuel subassembly and its 8 -in. OD finned storage pot were homogenized into one zone. Based on these calculations, the fission power generated by one stored subassembly is about $85 \mathrm{~kW}$ during full reactor power. This rate is greater than desired; therefore, more detailed investigations will be made to determine methods of reducing the induced fission level in stored fuel.

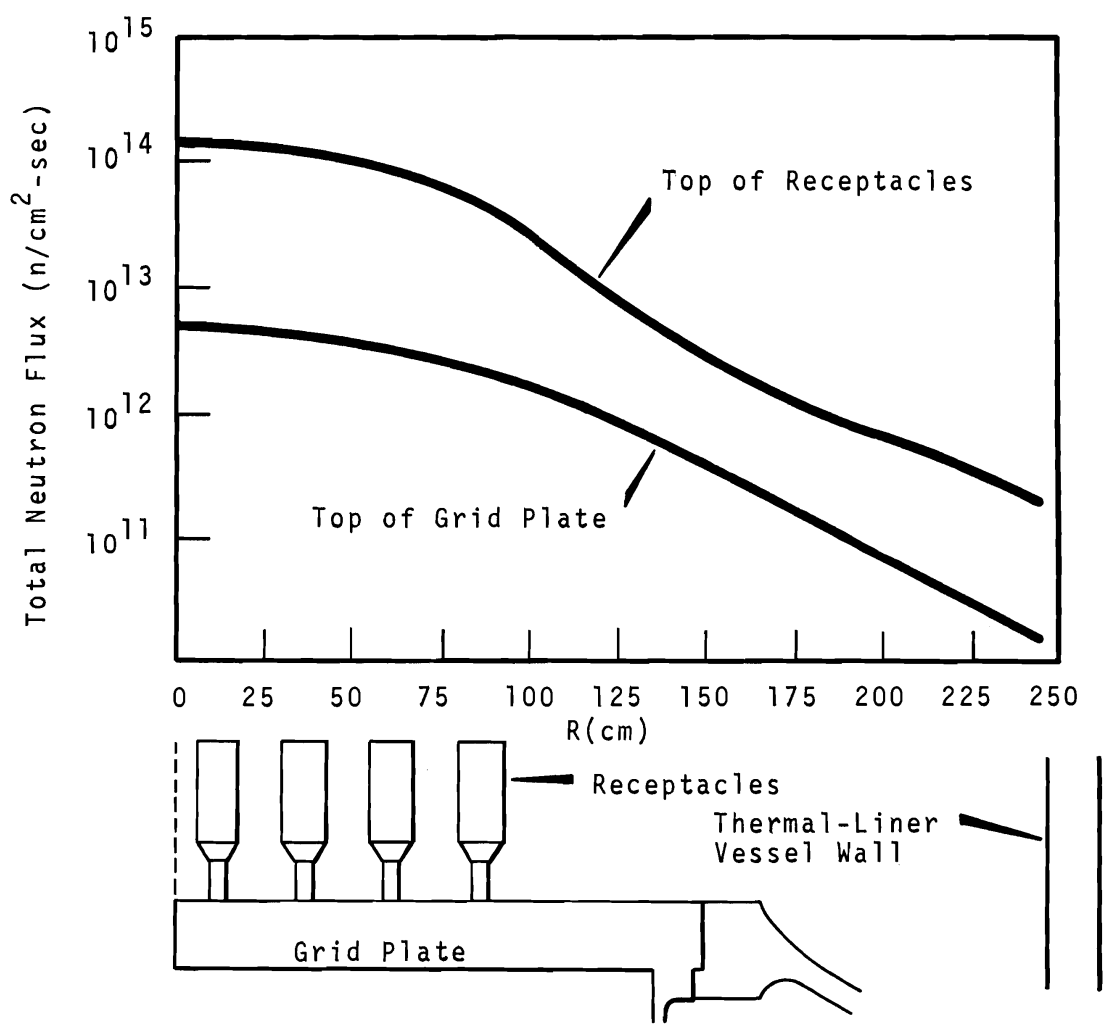
FIGURE 3.A.2. Flux Distributions at the Top of the Receptacles and at the Top of the Grid Plate Versus Distance from core centerline


B. NUCLEAR AND PROCESS TECHNOLOGY

R. E. Heineman

1. Nuclear Analysis Section

W. W. Little, Jr.

a. Criticality Safety - FFTF Fuel Fabrication

D. R. Oden and C. L. Brown

Criticality safety technical limits were approved for the following:

(1) Fabrication of $\leq 31 \% \mathrm{PuO}_{2}-\mathrm{U}(93) \mathrm{O}_{2}$ fuel pins in Line 2, FFTF Fue1 Fabrication Demonstration Facility (Specification 308-2.5 Rev. 1).

(2) Shipment of irradiated FFTF fuel pins in BNW Cask 29 (NCS Memo 69-22).

(3) Storage of $\leq 31 \mathrm{wt} \% \mathrm{PuO}_{2}-\mathrm{UO}_{2}$ in plastic vials in Room 215, B1dg. 308 (NCS Memo 69-30).

(4) Handling and Storage of Special $25 \mathrm{wt} \% \mathrm{PuO}_{2}-\mathrm{U}(\mathrm{N}) \mathrm{O}_{2}$ pins in 305-B and 3731 B1dg. (NCS Memo 69-32).

(5) Grinding mixed oxide fuel pellets in the FFTF Fue1 Fabrication Demonstration Facility (Special Condition $308-3$ ).

(6) Shipment of mixed oxide fuel capsules to EBR-II (Shipping Clearance 78).

(7) Shipment of $25 \mathrm{wt} \% \mathrm{PuO}_{2}-\mathrm{U}(\mathrm{N}) \mathrm{O}_{2}$ FFTF fuel pins in the BNW Mode1 55 container (Request for Amendment 4, DOT SP 4915).

b. $\quad \mathrm{PuO}_{2}=\mathrm{U}(\mathrm{NAT}) \mathrm{O}_{2}$ Fue 1 Pins in Air and Sodium L. C. Davenport and C. L. Brown

Critical parameters have been completed for 31 wt\% $\mathrm{PuO}_{2}-\mathrm{U}(\mathrm{NAT}) \mathrm{O}_{2}$ fuel 1 pins containing no ${ }^{240} \mathrm{Pu}$. Monte Carlo calculations have been used to determine the critical numbers of pins for hexagonal arrays in air and in sodium plus error limits for the cases: (1) pins close-spaced touching claddingto-cladding, and (2) pins close-spaced touching wire-wrapped 
pins. In all four cases, a 24 -in.-thick concrete reflector completely surrounded the fuel bundle providing full reflection. Quoted error limits indicate the statistical precision obtained within the Monte Carlo tracking routines, but do not include any systematic error due to inaccuracies in the cross section set used. The calculated results are presented in the tabulations below:

\section{Critical Number of 31 wt\% FFTF Fuel Pins Fully Reflected, Hexagonal Geometry}

Sodium Coolant

Air Coolant (Pins Unmoderated)
Close Spaced, Touching

Cladding-to-Cladding

Close Spaced, Touching

Wire-Wrap to Wire-Wrap
$1785 \pm 55$

$1862 \pm 78$

Preliminary results were also obtained for pins in air, spaced 0.150-in. between nearest neighbors (no wire wrap). Rough extrapolation indicates the critical number to be approximately 4500 pins. The originally calculated results are presented below:

Effective Multiplication Factor for 31 wt\% FFTF Pins in Air 0.150-in. Between Cladding, Fully Reflected

$\begin{array}{ccc}\frac{\text { Geometry }}{5941} \text { Pins, Hexagonal Geometry } & \frac{k_{\text {eff }}}{1.023 \pm 0.037} \\ 6487 \text { Pins, Hexagonal Geometry } & 1.032 \pm 0.025\end{array}$




\section{Core Analysis Section}

P. D. Cohn

a. $\quad \frac{\text { Poison Pin Temperatures }}{\text { A. Padilla }}$

Axial and radial temperature profiles for the safety, in-core, and reflector control rods have been calculated. Table 3.B.I. shows the parameters used in the analysis. Table 3.B.II. shows the maximum heat generation rates for the $\mathrm{B}_{4} \mathrm{C}$ poison and the cladding which would occur at the outer row of poison pins. A chopped-cosine axial power distribution was assumed.

The results are shown in Figures 3.B.1. and 3.B.2. Figure 3.B.1. shows the axial temperature profiles for the coolant, cladding, and poison for the fully-inserted in-core and reflector control rods. The temperature profiles are almost identical with the reflector control rod except for having slightly higher temperatures at the pellet centerline. The maximum pellet temperatures of about $1180^{\circ} \mathrm{F}$ is reached at a position approximately 6 inches above the core midplane.

Figure 3.B.2. shows the radial temperature profiles for the safety, in-core and reflector control rods at the position of maximum poison temperature. From Figures 3.B.1. and 3.B.2., it is seen that the major portion of the temperature gradient occurs in the helium gap between the $\mathrm{B}_{4} \mathrm{C}$ pellet and the cladding. In actuality, swelling of the $\mathrm{B}_{4} \mathrm{C}$ may close the gap and reduce the temperature drop significantly. However, the cold diametral gap was used in the analysis because of the lack of swelling data for $\mathrm{B}_{4} \mathrm{C}$.

b. Grid Analysis

C. L. Mohr

The grid spacer proposed for the FTR fuel has been analyzed to identify major operational problem areas. The results indicate that uncertainties of material swelling and in-reactor 
creep will have a significant effect upon the success of this design.

Material swelling induced by neutron radiation will cause distortions in the cell lattice dimensions. This distortion would occur in addition to the general growth of the fuel pin and grid structure. This would require that additional space be left between the fuel pin and the inscribed circle within a given grid lattice position. Figure 3.B.3. shows the typical reduction or distortion of the inscribed circle within a grid lattice position. This figure shows the results if stress relaxation is disregarded.

The effect of radiation creep cannot be handled with the analysis methods presently available. An approximation of the effect of the upper limit can be made by assuming $100 \%$ relaxation. From in-reactor stress relaxation and creep data that are available it is apparent that there is certainly a potential for relaxation approaching a large percentage of the initial stress. Using this approach, the grid assembly can be analyzed as a plane truss structure. This allows each grid joint to rotate and would be equivalent to the complete reduction of bending stress in the individual grid segment members.

Figure 3.B.4. shows the results of this analysis for a typical cell. Cell distortion in localized areas of the grid, such as is in the extreme corners, would display more distortion than that shown in Figure 3.B.4.

The result of this analysis is to point out the potential effect of in-reactor creep and relative material swelling on the distortion of the grid cell. The resultant effect is that in order to prevent contact and seizure of the fuel pin by the grid support dimples, 0.003 in. must be added to the fuel pin clearance. 
TABLE 3.B.I. Parameters for ${ }_{4}{ }_{4}$ Poison Pin Thermal Analysis

$P$ in $O D$, inches

0.453

Cladding thickness, inches

0.040

Pellet-clad diametral gap, inches

0.005

Pellet density, : TD 88

B-10 enrichment, 35

Coolant inlet temperature, ${ }^{\circ} \mathrm{F}$ 600

Coolant outlet temperature, ${ }^{\circ} \mathrm{F}$ 900

$\mathrm{B}_{4} \mathrm{C}$ thermal conductivity

Variable

Cladding thermal conductivity (BNWL-891)

Variable (BNWL - 891)

Helium gap thermal conductivity

Variable (LA-2316) TABLE 3.B.II. Heat Generation Rates for Poison Pin Thermal
Analysis

Position

Fully-inserted in-core control rod at core midplane

Ful1y-inserted reflector control rod at core midplane

Safety rod cocked $10 \mathrm{~cm}$ above core
$\mathrm{B}_{4} \mathrm{C}$ W/ $\mathrm{cm}^{3}$

223

12.6

226

6.2

130
Stainless Stee1, W/g

This means that early in 1 ife the fue 1 pin would then have a potential maximum clearance of 0.007 to 0.008 inch. Clearances of 0.007 to 0.008 in. between the fue 1 pin and grid would provide the potential for fuel pin cladding damage caused by vibration. Stress relaxation of residual bending stresses in the fuel pin would increase the potential for vibration and damage of the fuel pin. 
BNWL - 1133

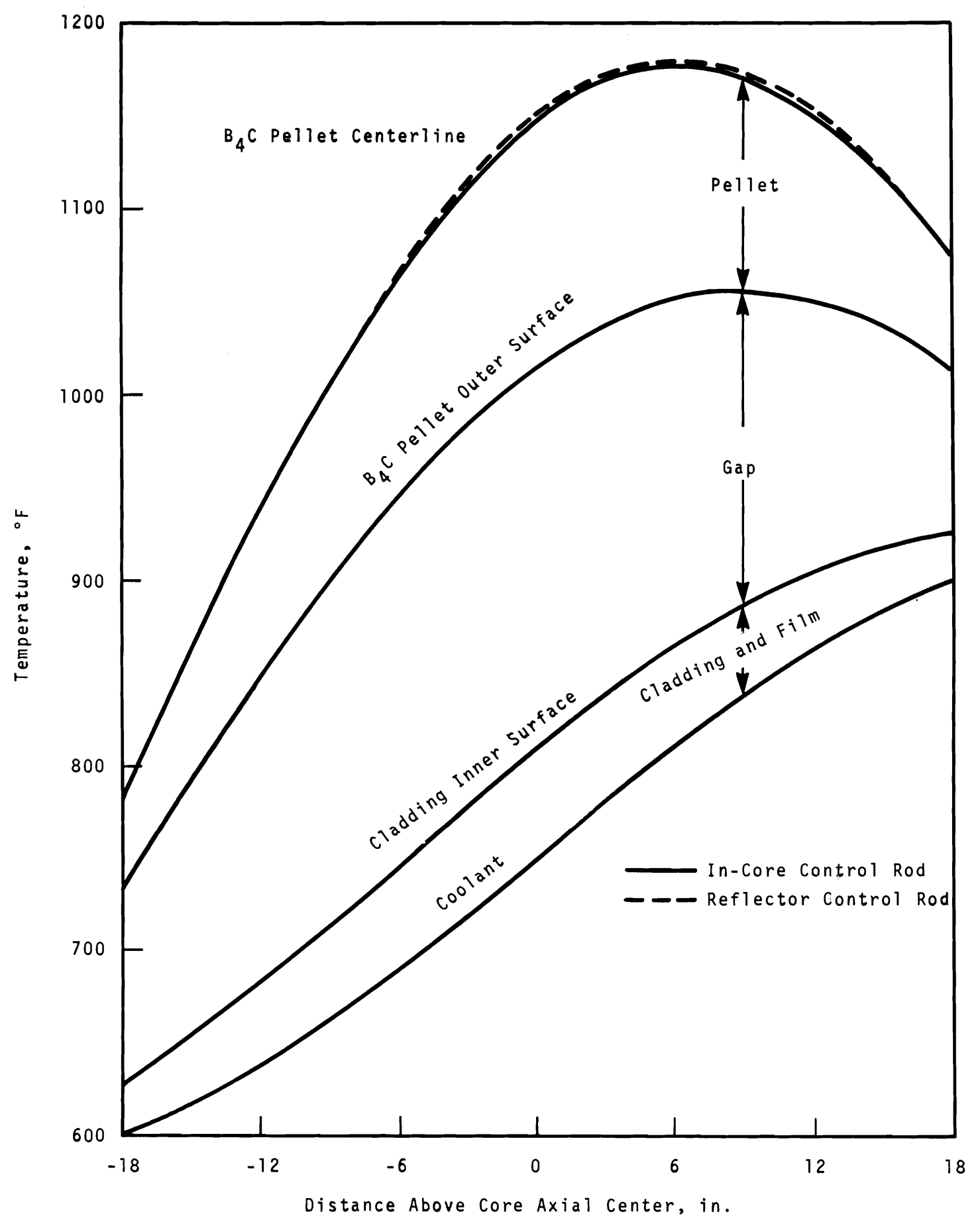

FIGURE 3.B.1. Axial Temperature Profiles for Fully-Inserted Poison Pins 


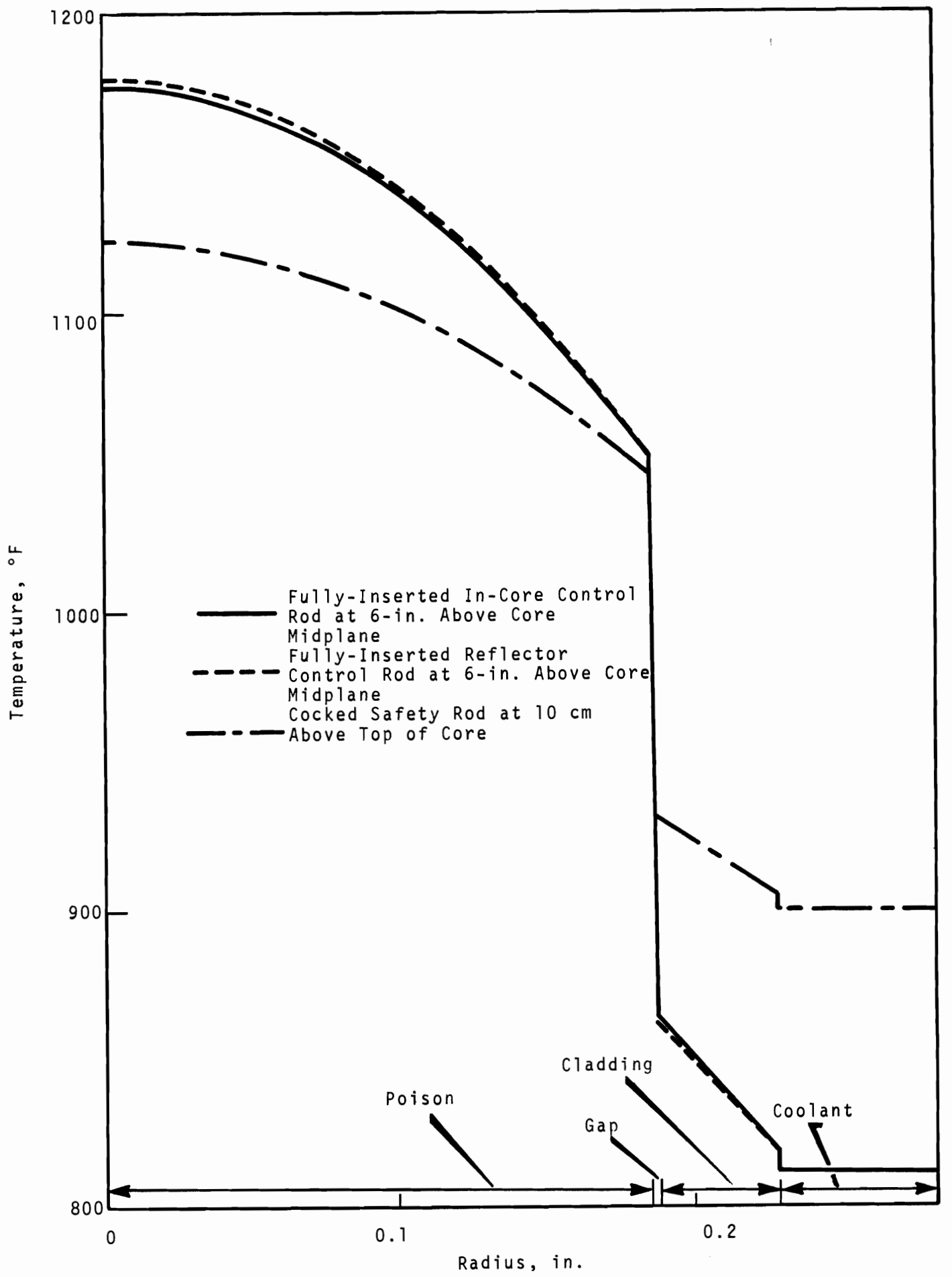

FIGURE 3.B.2. Radial Temperature Profiles for Poison Pins 
BNWL - 1133

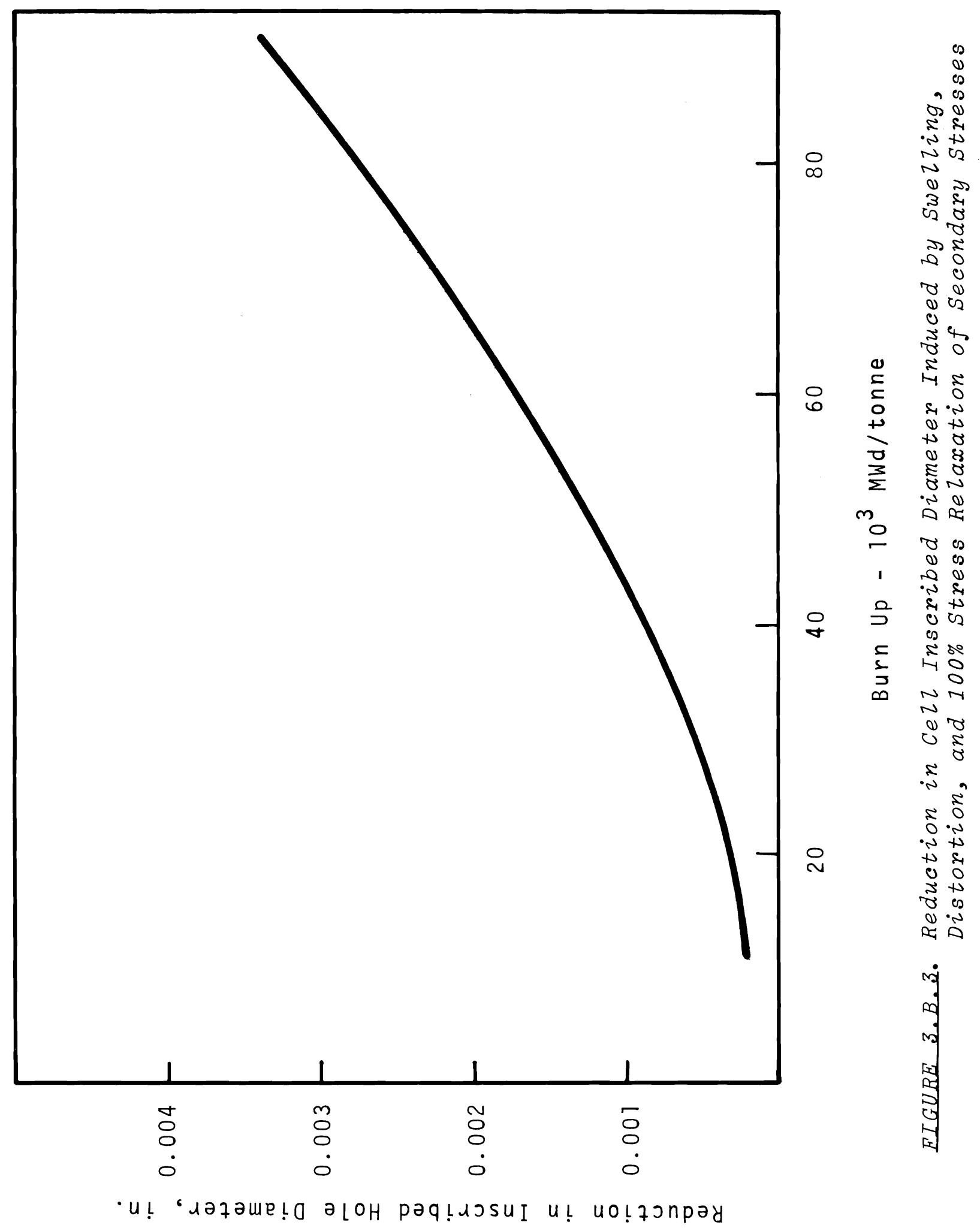




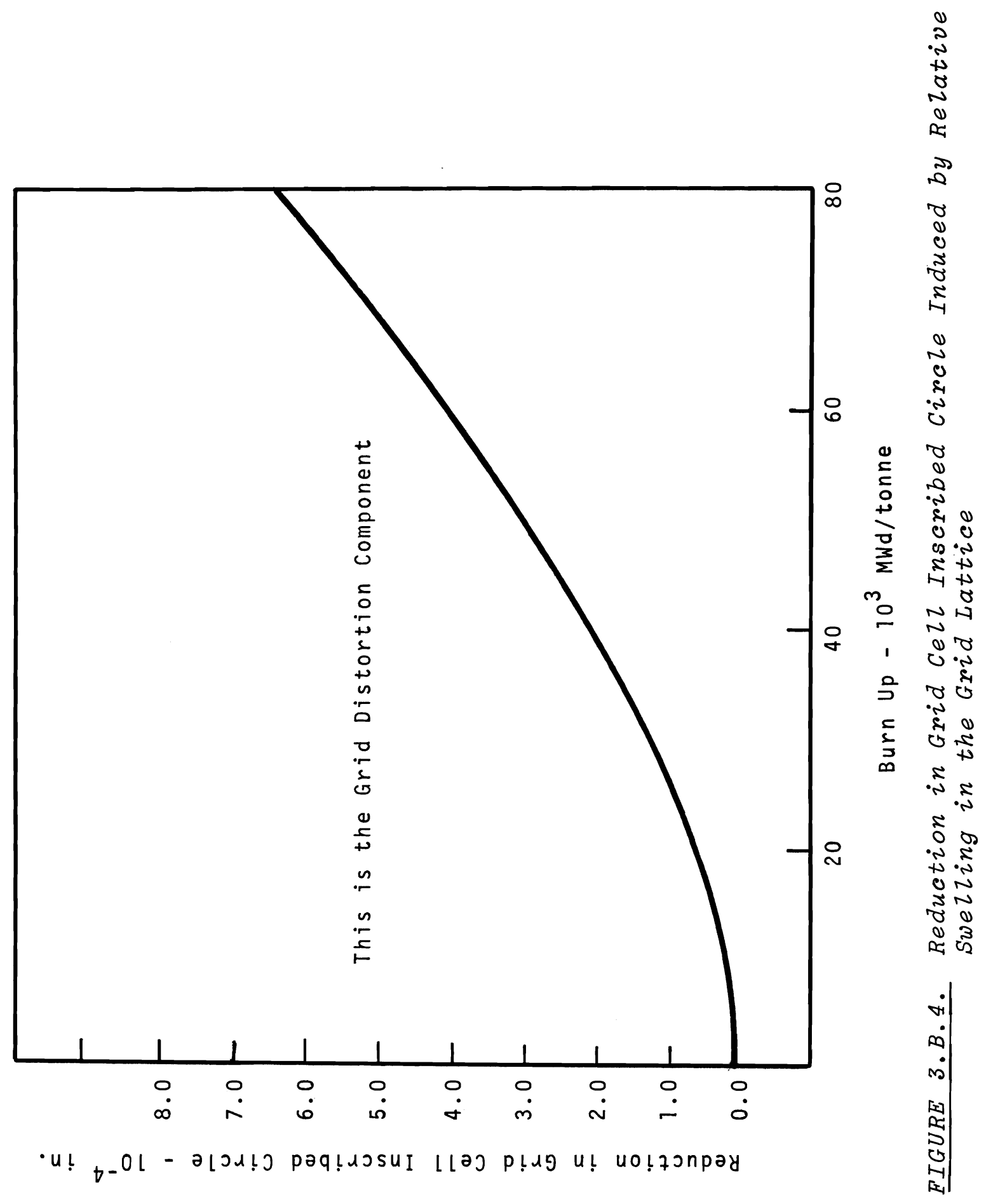




\section{c. Impact of Swelling Mode1 on FTR Core Design \\ R. J. Jackson}

Interim guidance was provided to FTR driver fuel designers in the form of equations describing the relationship among metal swelling, fast neutron fluence and operating temperature. These equations are

$$
\begin{aligned}
& \text { for }\left\{\begin{array}{l}
\text { AISI Type } 304 \text { SS, solution treated } \\
\text { AISI Type } 316 \text { SS, solution treated }
\end{array}\right. \\
& \Delta \mathrm{V} / \mathrm{V}=5.0 \times 10^{-36}(\phi \mathrm{t})^{1.66}\left[\mathrm{e}^{\frac{-6800}{\mathrm{RT}}}-\left(1.87 \times 10^{4}\right) \mathrm{e}^{-\frac{27,000}{\mathrm{RT}}}\right] \\
& \text { for AISI Type } 316 \text { SS, cold worked } \\
& \Delta \mathrm{V} / \mathrm{V}=9.4 \times 10^{-33}(\phi \mathrm{t})^{1.48}\left[\mathrm{e}^{-\frac{5600}{\mathrm{RT}}}-\left(1.78 \times 10^{5}\right) \mathrm{e}^{-\frac{30,000}{\mathrm{RT}}}\right] \\
& \text { to a volume change } \leq 1 \% \\
& \text { and at } \mathrm{T} \leq 500^{\circ} \mathrm{C}
\end{aligned}
$$

Preliminary analyses were performed to determine the impact of the interim metal swelling equations, and the impact of current quantitative uncertainty of swelling on the FTR core design. The principally affected components are the fuel pin bundle with its associated spacer system, the subassembly flow ducts and the core radial restraint mechanism. The analyses considered duct bending and core packing. It is impractical to separate the effects of creep from analysis of duct bending so some creep effects are considered in that analysis. The results are summarized in Tables 3.B.III. and 3.B.IV. The conclusions of the analyses are these:

(1). Differential swelling resulting in duct bending is the major fuel lifetime limiting item in the present design. More analysis of the duct bending problem is required. This must consider both the fuel shuffling schemes and a parametric study of the effects of creep, because no conservative assumption regarding creep rate is posible. 
(2). Potential limitations to fuel exposure include:

(a) duct bending caused by thermal camber if significant creep occurs in-reactor

(b) duct bending caused by differential volume increase if no creep occurs in-reactor

(c) core packing (occupying of all available core space by swollen ducts)

(d) duct packing (occupation of all available duct space by swollen fuel pins).

(3) The uncertainty in extrapolating irradiationinduced swelling to goal burnup is very large and can change the predicted burnup limitation within the range of from 30,000 to 80,000 (or greater) MWd/ tonneM, if duct packing becomes the limitation.

d. Pressure Drop C. L. Wheeler

The pressure drop in the grid and wire-wrapped bundles were compared using both the COBRA computer code and standard flow area hydraulic diameter considerations. Koo's smooth-tube correlation for the friction factor was used in both cases.

For the current design of 19 grids for an 86.6-in. bundle the computed ratios of (grid/wire-wrap) pressure drop are 1.92 and 2.7. (See Figure 3.B.5.) For the maximum flow rate of $2.1 \times 10^{5} \mathrm{lb} / \mathrm{hr}$ the wire-wrapped bundle pressure drop is $50 \pm 8$ psi. Experimental data are not available for the grid design. However, the same bundle incorporating a grid spacer yields values of 96 psi (COBRA calculation) and 135 psi for the two methods of computation. These results point out the need for experimental data on the grid design and show that the grid bundle pressure drop could exceed the allowable pressure drop. 
BNWL - 1133
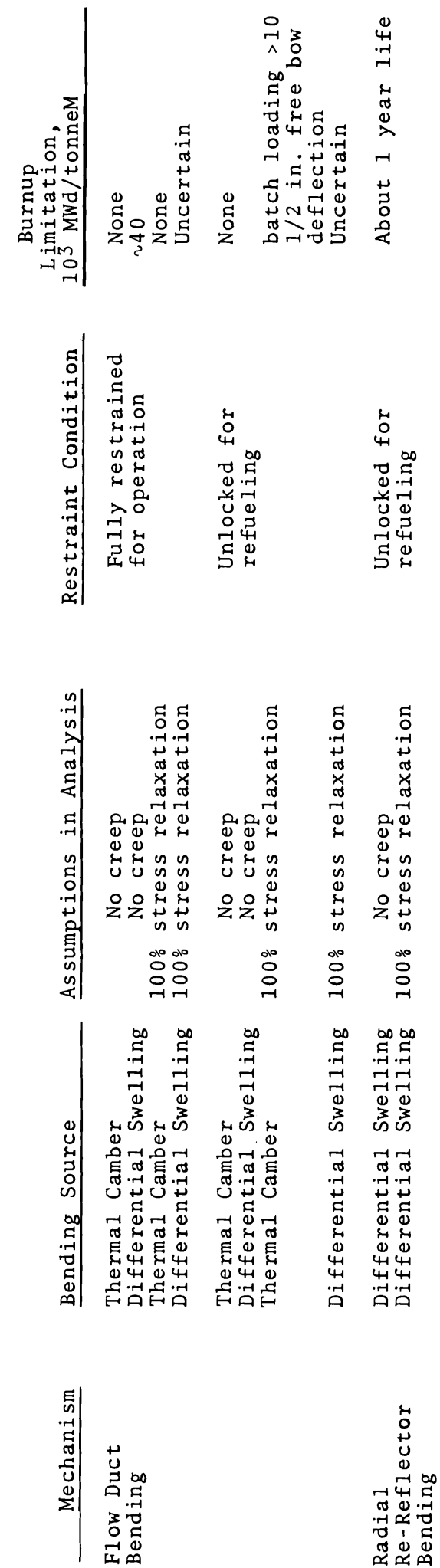


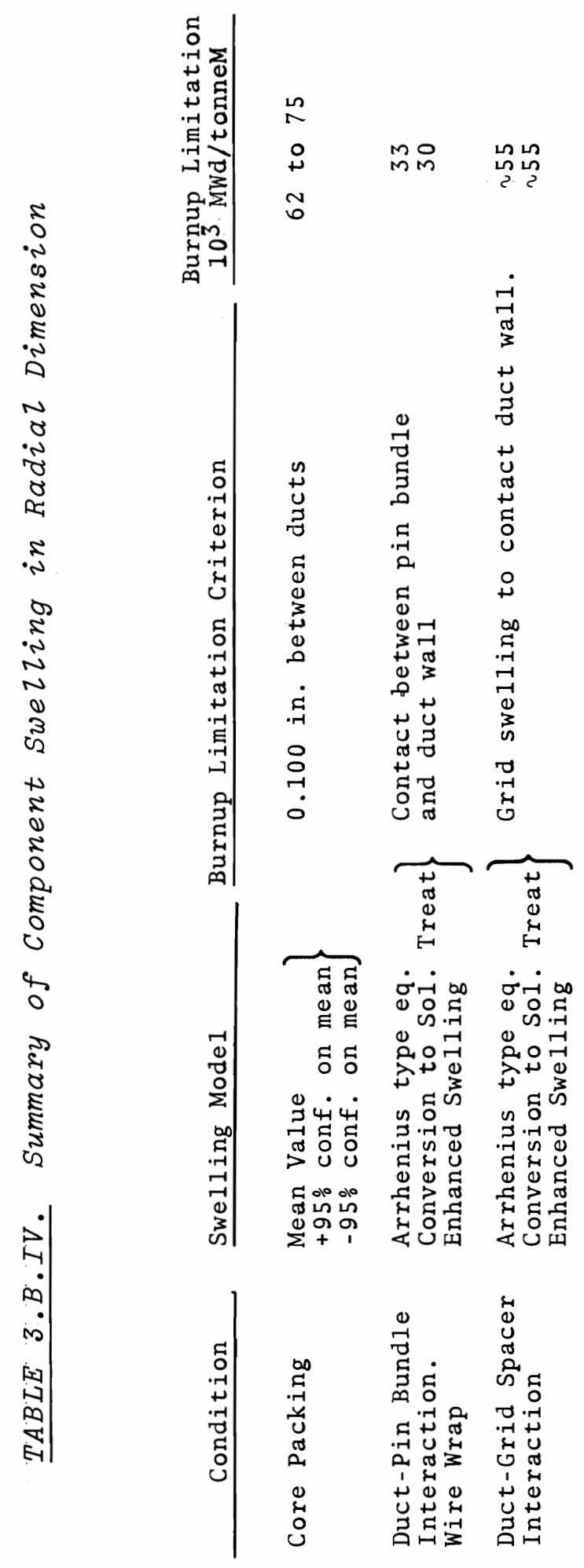




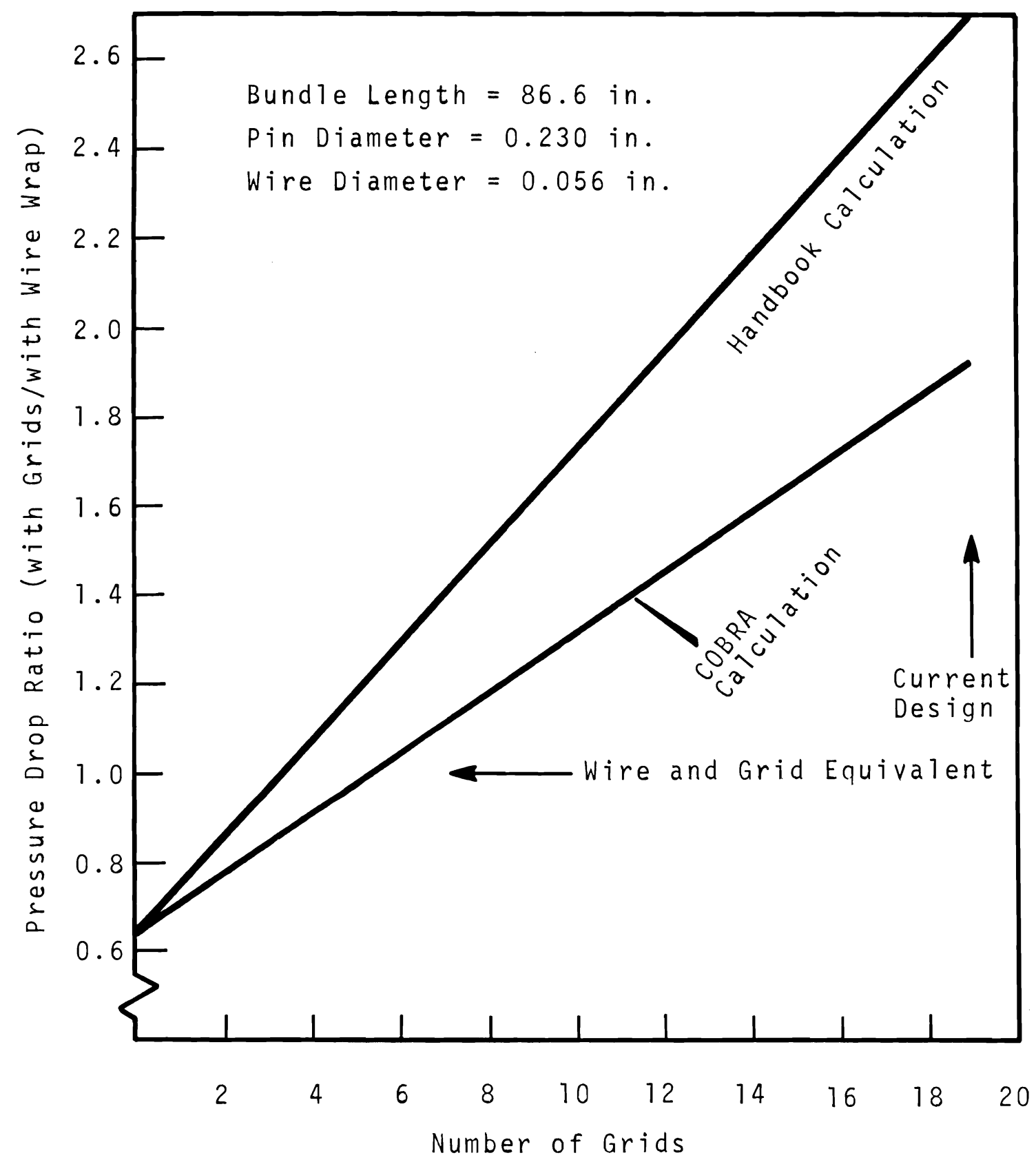

FIGURE 3.B.5. Comparison of Pressure Drop Between Wire-Wrapped and Grid Spaced Bundles 


\section{e. Local Temperature Peaking \\ D. C. Kolesar}

The local reduction of the energy transfer rate induced by geometric asymmetries can result in local hot spots. For the wire spacer it is the region near the wire, particularly as the wire passes into the gap between pins, that constitutes a dangerous peaking problem. For the honeycomb grid it is the region adjacent to and downstream from points of grid-pin contact.

The local effect of 30-mil wire in an infinite array of pins with the wire always in the pin-pin gap has been considered. The method of solution involved a graphical approach created by Dwyer (1) and modified to incorporate a wire in a manner similar to a technique employed by Deisler and Taylor. (2) A range of 25 to $60^{\circ} \mathrm{F}$ was predicted in the cladding with the uncertainty a result of the unknown eddy diffusivity. The validity of the model is dependent upon the wire pitch being at least 12 in. A 56-mil wire will reduce the temperature peaking by perhaps $20 \%$ Local peaking would no longer be accentuated by the presence of the wire in the gap.

The local effect of a grid is not expected to be too dissimilar from the wire-wrap. A 1-dimensional analysis which hypothesizes a step change in heat transfer coefficient provides a model for grid peaking. Figure 3.B.6. provides a parameterized representation of this analysis for various depressions of the heat transfer coefficient and disturbance sizes. The experimental work of Kattchee and Machewicz(3) provide a means of identifying

(1) O. E. Dwyer, "Analytical Study of Heat Transfer to Liquid Metals Flowing In-Line Through Closely Packed Rod Bundles," NUCLEAR SCIENCE AND ENGINEERING, 24, 347, 1966.

(2) R. C. Deissler and M. F. TayZor, "Analysis of FulZy Developed Heat Transfer and Flow in an Annulus with Various Eccentricities," INACA Tech. Note 3451, May 1955.

(3) N. Kattchee and W. V. Machewicz, "Effects of Boundary Layer Turbulence Promoters on the Local Film Coefficients of ML-1 Fuel Elements," NUCLEAR SCIENCE AND ENGINEERING, 16, 31, 1963. 


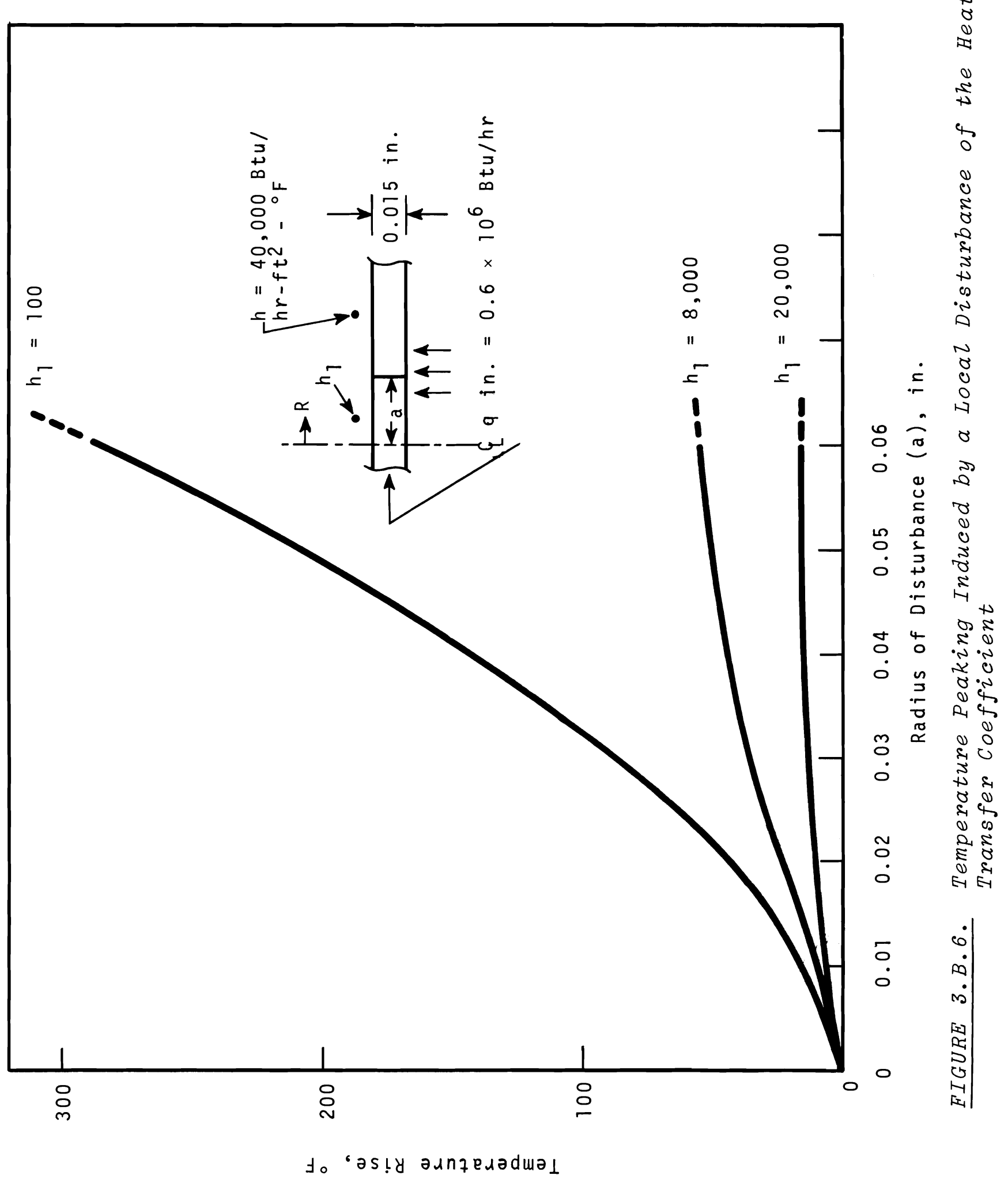


the heat transfer coefficient with the disturbance. A reduction of the heat transfer coefficient by a factor of 2 is reasonable in the wake of a protuberance. It is observed that no serious problem results for all disturbance size. However, if a bubble were to form or to be trapped behind a protuberance the problem could be severe. First, little mechanism is available to sweep the bubble away. Second, the resulting drop in heat transfer coefficient, here assumed to be $100 \mathrm{Btu} / \mathrm{hr}-\mathrm{ft}{ }^{2}-{ }^{\circ} \mathrm{F}$, influences local energy transfer seriously. Thus, the point of contact between grid and pin should be kept small to avoid or minimize the effects of bubbles.

\section{f. Subassembly Enthalpy Peaking}

C. L. Wheeler

The amount of enthalpy peaking in a subassembly is dependent upon the relative areas of the interior and peripheral channels and on the amount of energy and mass transport which occurs between channels. Wire wrap lowers the enthalpy peaking factor by increasing the intra-subassembly mass transport. (See Figure 3.B.7.) The Westinghouse spacers reduce enthalpy peaking by reducing the difference in peripheral and interior channel areas at each grid location.

The COBRA computer code was used to determine the amount of enthalpy peaking for both spacing methods. Values of 1.10 and 1.20 were determined for the loose and tight packed models of the wire-wrapped bundle. These values bracket the actual enthalpy peaking factor that will occur in the standard wire-wrapped bundle. The wire wrap enthalpy peaking factor can be reduced further by the use of peripheral flow suppressors. The computed enthalpy peaking factor for a grid spaced bundle with grids located on 4 -in. increments in the active core region is 1.12 . 
It is difficult to place confidence limits on this value because of the limited amount of experimental data. However, this value is reasonable and it can be concluded that both spacer systems are comparable as far as enthalpy peaking is concerned.

If the current model of duct-bundle swelling is correct, the enthalpy peaking factor will remain essentially constant for grid spacers and decrease with burnup for the wire-wrapped bundle, but if the duct dimensions increase at a faster rate than the bundle dimensions the wrapped bundle enthalpy peaking factor will increase significantly. 


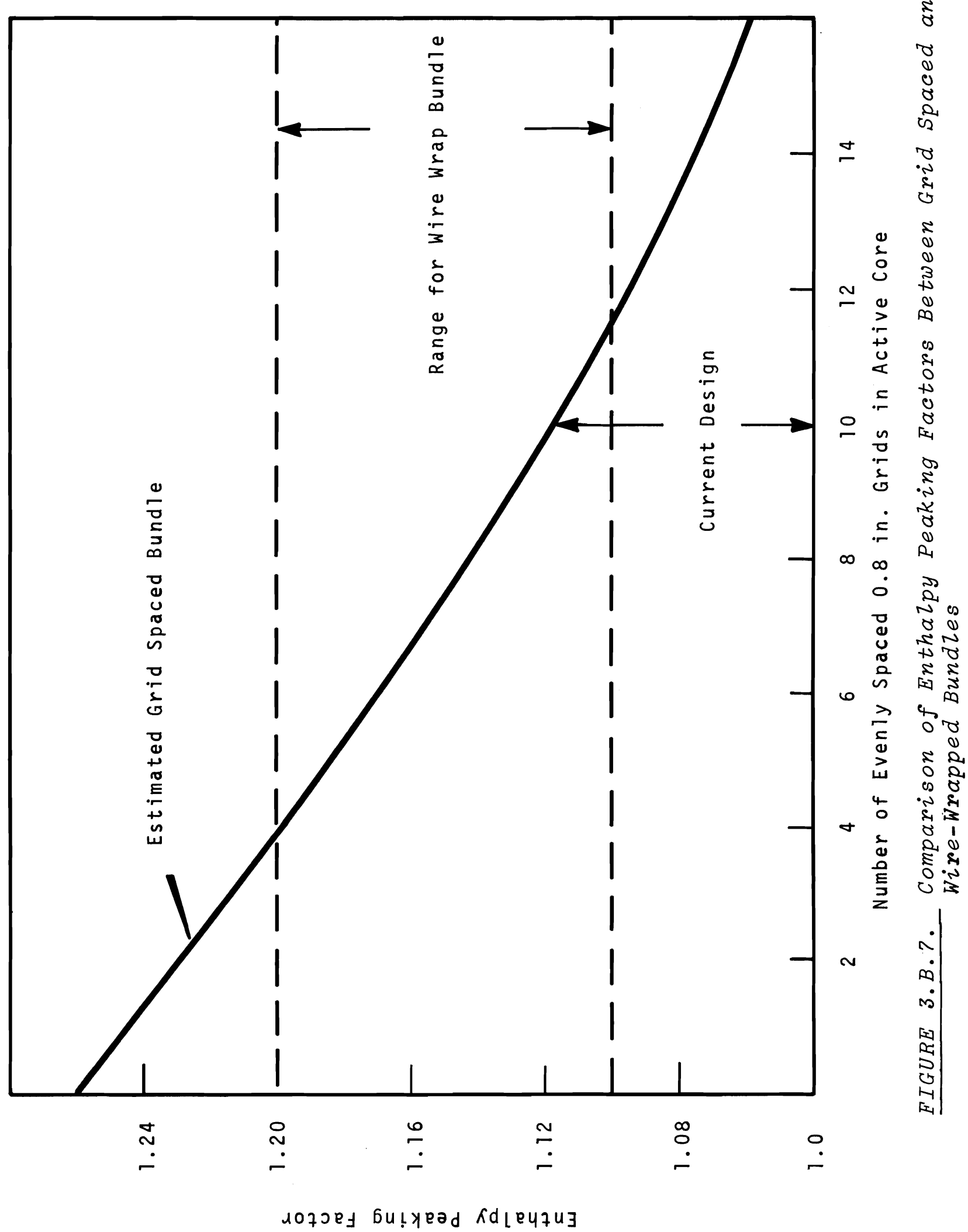


3. Experimental Physics

R. A. Bennett

a. Status of Phase B Experiments

R. A. Bennett

Following the critical loading of ZPPR Assembly I, repeated measurements were made to improve statistics for the source determination. The core profile was reduced to the matrix profile of Assembly 56b, as built in ZPR III, to assess reactivity differences between ZPPR and ZPR-III due in part to the different void fractions. A full control ring has been added in the reflector of ZPPR Assembly I at a position anticipated to yield a critical configuration when the enclosed reflector drawers are replaced with fuel. This control ring is approximately two columns wide, and the loading is the same as the drawer loading used for measurements in the radial reflector of Assembly 56b in the ZPR-III, reported in the April 1969, ANL FFTF Informal Monthly Report. A subscritical measurement of $\mathrm{k}_{\text {eff }}$ has been made with the control ring in place. Presently, the reflector drawers enclosed by the ring are being exchanged for fuel to achieve criticality.

b. FTR I and II Pre-Analysis

J. V. Nelson

As reported last month, planning calculations are being performed for FTR I, II, and III, in the ZPPR. Tabulated in Table 3.B.V. are the dimensions and critical masses for FTR I and II. The results listed here were obtained using the twodimensional diffusion code, $2 \mathrm{DB}$ in $\mathrm{R}-\mathrm{Z}$ geometry. The worth of the control ring in FTR-II has been computed to be $5 \% \Delta \mathrm{k} / \mathrm{k}$. 


\section{TABLE 3.B.V. FTR I and II Dimensions and Masses* (R-Z Calculation)}

FTR I

Core height (cm)

Radial reflector thickness (cm)

Axial reflector thickness (cm)

$\mathrm{B}_{4} \mathrm{C}$ control ring thickness (cm)

Calculated core radius $(\mathrm{cm})$

Calculated core volume (l)

Calculated fissile mass (kg)

$k$ eff **
91.4

30

30.5

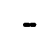

49.5

706

367

0.98
FTR I I

91.4

20

30.5

10

58.1

970

505

*The compositions of the core are those reported in May 1969, ANL FFTF Informal Monthly Report.

**k values have not been corrected for core heterogeneity or coffe gap. They are also subject to a transport theory correction. (Based upon ZPR-III Assembly $56 b$ results the resultant fissile mass for this $k_{\text {eff }}$ should be essentially the critical mass.)

c. Pin-fueled Sodium Void Experiment

Q. L. Baird and J. V. Nelson

A proposal has been drafted for a pin-fueled sodium void experiment as discussed in the May Progress Report. It appears appropriate that the experiment be made a part of the FTR II sequence following the shielding experiment.

As a part of the planning for the experiment, a series of calculations have been done in $R-Z$ geometry using $2 \mathrm{DB}$ code. The reactivity worth of converting a $26 \mathrm{~cm}$ radius central zone of FTR II to Modification A composition (cf May 1969, FFTF Month1y Informa1 Technical Progress Report, BNWL-1097) has been computed to be $+1.01 \%$. The $\Delta \mathrm{k} / \mathrm{k}$ for substitution of a $3 \times 3$ drawer array 
of pin-fueled calandria at the center of this two-zone core is $-0.14 \%$. The reactivity worth of voiding a $42 \mathrm{~cm}$ central segment of the central drawer of this $3 \times 3$ array has also been computed and is nominally 5 inhours. Further calculations are underway to support this planning.

d. Analysis of ZPR-III Assemb1y 56b

S. L. DeMyer

Analysis of large substitution experiments, both at the core center and on the core periphery, have been completed. The central worths were calculated in both $R-Z$ and $x-y$ geometries in the diffusion theory code, 2DB. The peripheral rod worths were calculated in $x-y$ geometry, only, in $2 \mathrm{DB}$.

Table 3.B.VI. compares the measured and calculated worths of the central drawer exchanges. Table 3.B.VII. compares the calculated peripheral control rod worths with four measured values. The locations of the four counters in the assembly are given in the April 1969, ANL FFTF Informal Monthly Report. The measured worths derived from the data of counter 1 are thought to be the most accurate. 
TABLE 3.B.VI. Central Drawer Exchange Worths

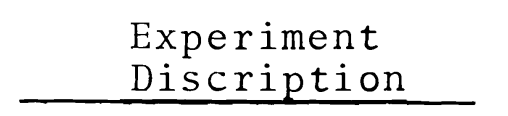

Replace Fuel with Axial Reflector

Replace Fuel with $\mathrm{B}_{4} \mathrm{C}$ Control Rod

Replace Axial Reflector with $\mathrm{B}_{4} \mathrm{C}$ Control Rod

\section{Experimental Worth, \% $\Delta \mathrm{k} / \mathrm{k}$}

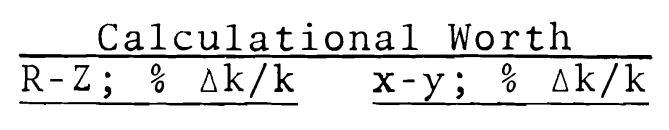

$-0.430$

$-0.578$

$-0.591$

$-1.758$

$-1.188$

$-1.086$

$-1.516$

$-1.748$

$-1.163$

1.34

1.16

1.15

TABLE 3.B.VII. Peripheral Drawer Exchange Worth

$\omega$

$\omega$

\begin{tabular}{l} 
Experiment \\
Description \\
\hline
\end{tabular}

\begin{tabular}{ll} 
Experimental Worth \\
\hline Counter & $\frac{\circ \mathrm{k} / \mathrm{k}}{0}$
\end{tabular}

Replace 4 Reflector

Columns with $\mathrm{B}_{4} \mathrm{C}$
Rods

$\begin{array}{lllll}1 & & & & -0.932 \\ 2 & & & & -0.890 \\ 3 & & & & -0.939 \\ 4 a & \& & b & & -0.962 \\ & & & & \\ 1 & & & -1.736 \\ 2 & & & & -1.700 \\ 3 & & & & -1.727 \\ 4 a & \& & b & & -1.945\end{array}$

Calculational Worth, $\% \Delta \mathrm{k} / \mathrm{k}$

$-0.928$

$-0.928$

$-0.928$

$-0.928$

$-1.749$

$-1.749$

$-1.749$

$-1.749$
$\mathrm{C} / \mathrm{E}$

$$
\begin{aligned}
& 0.996 \\
& 1.043 \\
& 0.988 \\
& 0.965 \\
& 1.007 \\
& 1.029 \\
& 1.013 \\
& 0.899
\end{aligned}
$$


e. Subscritical Reactivity Measurements

V. 0. Uotinen

Experimental rod worths, inferred from measurements of reaction rates in subcritical assemblies, depend upon the location of the detector. For example, the worth of four large peripheral $\mathrm{B}_{4} \mathrm{C}$ rods was measured in ZPR III Assembly 56b, and the worths translated by four detectors varied by as much as 14\% (cf Section 3, above).

This difference is significant and suggests doubts about the validity of other measured large sample worths that have been reported. Such "measured" worths are being used by analysi: groups to check calculational methods, although the measurements may, in fact, contain significant systematic errors.

The problem is also relevant to the FTR, since subcritical flux-monitoring will be used in the FTR to monitor the reactivity status, and to measure reactivity worths.

Calculations are being performed with the two-dimensional diffusion theory code $2 \mathrm{DBS}$ to investigate this problem.

f. Analysis of ZPR-III Assembly 51

W. R. Young

Small sample reactivity worths in Assembly 51 are overcalculated in absolute value for ${ }^{239} \mathrm{Pu}$ and $238 \mathrm{U}$. The values obtained from a 24 -energy group PERT IV calculation with fluxes from $2 \mathrm{DB}$ core calculation are shown in the tabulation on page page 3.33. It should be noted that when ${ }^{239} \mathrm{Pu}$ and ${ }^{238_{U}}$ are removed simultaneously, the effect is a partial cancellation of the calculated-experiment discrepancy because the worth of ${ }^{239} \mathrm{Pu}$ is positive and ${ }^{238} \mathrm{U}$ is negative. Integration of the worths along the axis of the core enhances the cancellation effect for mutual removal. 
BNWL -1133

\section{Sma11 Sample Fue1 Worths}

\begin{tabular}{|c|c|c|c|c|}
\hline & $\begin{array}{l}\text { Measured Small } \\
\text { Central Sample } \\
\text { Worth, Ih } / \mathrm{kg} \\
\end{array}$ & $\mathrm{c} / \mathrm{e}$ & $\begin{array}{l}\text { Measured Small Sample } \\
\text { Worth Integrated Along } \\
\text { Core Axis, Ih/kg } \\
\end{array}$ & $\mathrm{c} / \mathrm{e}$ \\
\hline${ }^{239} \mathrm{Pu}$ & 580 & 1.31 & 392 & 1.28 \\
\hline $238_{U}$ & -23 & 1.52 & -12 & 1.72 \\
\hline
\end{tabular}

The calculated worth for combined removal can be compared with two experiments in Assembly 51. In the first experiment $2.076 \mathrm{~kg}$ of ${ }^{239} \mathrm{Pu}, 5.978 \mathrm{~kg}$ of ${ }^{238} \mathrm{U}$, and small amounts, negligible for this discussion, of other materials were removed from the central core drawer, P-16. The worth of this removal was evaluated by integrating the PERT IV results as well as by a pair of $2 \mathrm{DB}, \mathrm{R}-\mathrm{Z}$ reactor calculations. In the reactor calculations the cross sections for the removed materials were flux-volume weighted. These results are listed in the subsequent tabulation. Note that the whole reactor calculation, $2 \mathrm{DB}$, gives a result more consistent with the measurement.

In the second experiment, the worth of replacing the entire contents of the central column with sodium cans was measured. These results are compared with calculations in the tabulation concerning Central Fuel Column Worth in Assembly 51. The calculations were both done with $2 \mathrm{DB}$, using 8 -energy groups. The $x-y$ calculations used an axial buckling value of $6.82 \mathrm{M}^{-2}$ for the core and radial reflector region and $4.255 \mathrm{M}^{-2}$ for the sodium filled central column. These values were inferred from the results of the critical measurements on ZPR III Assemblies $52 \mathrm{a}, \mathrm{b}, \mathrm{c}$, and $f$. A comparison was obtained of results from flux-volume weighted core cross sections and those from a calculation using homogeneous, non-flux-volume weighted cross sections. A c/e ration of 1.26 resulted for the latter case. 
These results are a partial explanation as to why critical mass calculations are much better than small sample fuel worth calculations. That is, the overcalculation of the negative contribution of ${ }^{238} \mathrm{U}$, in part, cancels the large ${ }^{239} \mathrm{Pu}$ worth overcalculation. The magnitude of this effect on Assembly 51 is fairly clear and it will be necessary to consider its effect on the FTR design calculations.

Reactivity Change for ${ }^{239} \mathrm{Pu}$ and ${ }^{238_{\mathrm{U}}}$

Removal from Central Column of Assembly 51

Worth of Fuel in P-16

Inferred from measurement, Ih

741

$$
\mathrm{c} / \mathrm{e}
$$

PERT IV

1.24

1.15

Worth of Central Fuel Column in Assemb1y 51

Measured Worth, Ih

763

$$
\mathrm{c} / \mathrm{e}(2 \mathrm{DB}, \mathrm{R}-\mathrm{Z})
$$

1.17 $\mathrm{c} / \mathrm{e}(2 \mathrm{DB}, \mathrm{x}-\mathrm{y})$

1.17 


\section{SAFETY AND SYSTEMS ANALYSIS}

R. E. Peterson

1. Safety Analysis

D. D. Stepnewski

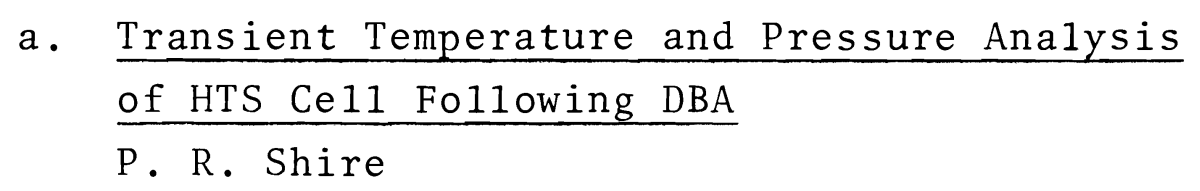

The DBA may involve a primary pipe rupture which results in the release of sodium coolant and core fission products to a heat exchanger cell. A Model of the HTS Cell and its environs was described by the TAP-3F code to evaluate temperature and pressure conditions following the accident.

The HTS Ce11 mode1, Figure 3.C.1, represented the nitrogen plus $2 \%$ oxygen at one atmosphere and $100^{\circ} \mathrm{F}$, with steel liner and protective insulation between the floor liner and concrete. Heat flow paths were upwards through the cell ceiling to the containment sphere air and then to the atmosphere. The paths through the walls and floor were to a smeared mass model of the remaining concrete, and then to earth as a sink.

The accident condition spilled 20 tons of primary sodium at $1200^{\circ} \mathrm{F}$ on the HTS cell floor and this marked time zero for running the transient problem. It was postulated that one third of core fission products were released to the cell producing a decay heat load. Twenty-one percent of this decay heat load was entered to the cell gas node directly, representing gaseous fission products in the form of noble gases, halogens and volatiles. The remaining decay heat was entered at the sodium node along with ${ }^{24} \mathrm{Na}$ activity and chemical reaction energy from the pool burning of sodium in $2 \%$ oxygen. 
BNWL - 1133

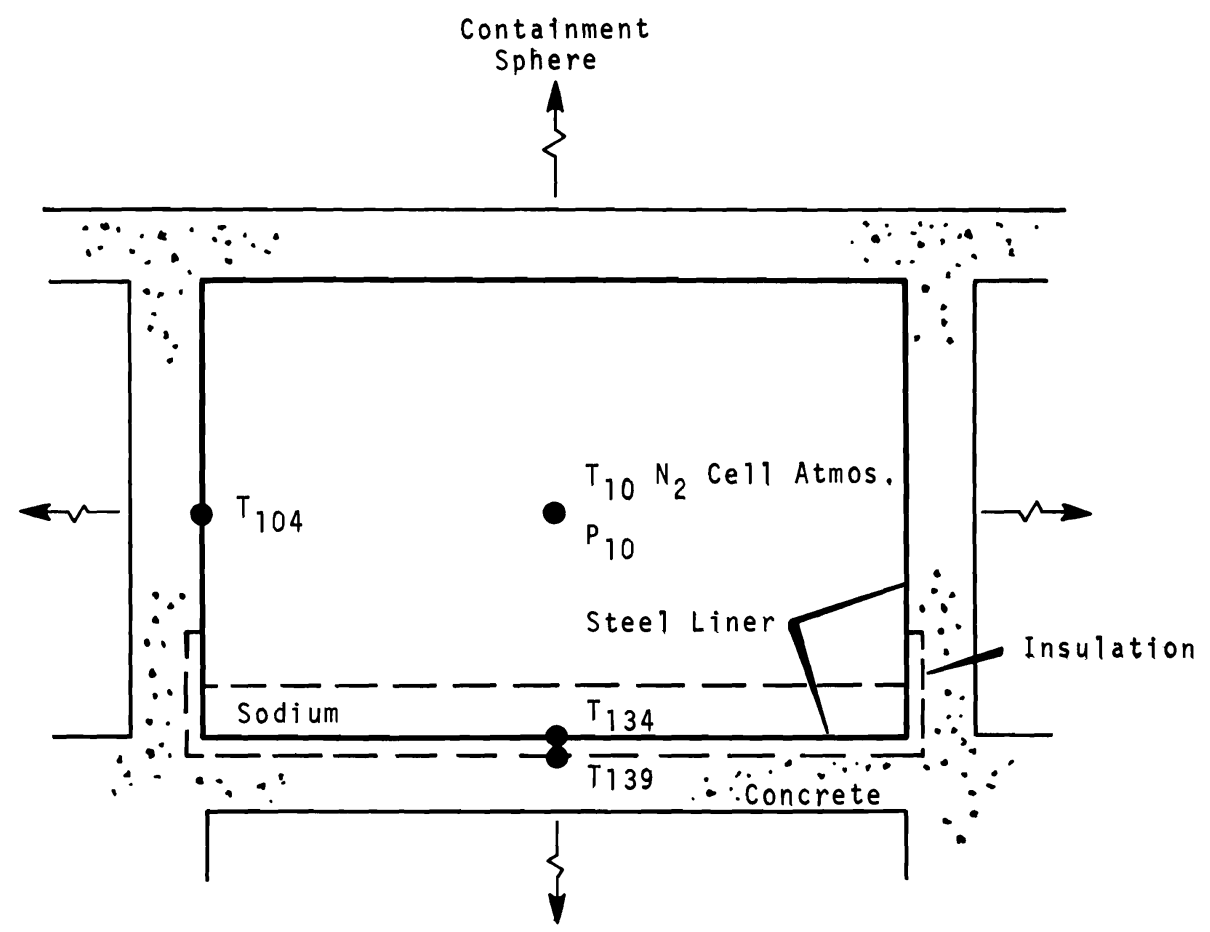

$\begin{array}{ll}\text { FIGURE 3.C.1. } & \text { HTS Cell Features Included in Model } \\ & \text { for Transient Temperature Analysis } \\ & \text { Folzowing DBA + Loss-of-Coolant } \\ & \text { Accident }\end{array}$

Output for the transient calculation is shown in

Figure 3.C.2, temperature and pressure versus time. Cell temperature and pressure rose rapidly to its maximum $638^{\circ} \mathrm{F}$ at $14.6 \mathrm{psig}$ in less than $2 \mathrm{~min}$, then dropped to $571^{\circ} \mathrm{F}$ and $12.8 \mathrm{psig}$ at 10 hours. From 10 to $100 \mathrm{hr}$ cell temperature was decreasing at $1{ }^{\circ} \mathrm{F}$ per 15 hours. The steel floor liner in contact with sodium responded almost instantly to $1195^{\circ} \mathrm{F}$, then continued upward to its maximum of $1330^{\circ} \mathrm{F}$ at $3 / 4 \mathrm{hr}$, then declined to $880^{\circ} \mathrm{F}$ at 100 hours.

The concrete face temperature under the floor insulation responded slowly but surpassed the side wall temperature at $20 \mathrm{hr}$ and $400^{\circ} \mathrm{F}$; at $100 \mathrm{hr}$ it was $588^{\circ} \mathrm{F}$ and still rising. The wall temperature $472^{\circ} \mathrm{F}$ was still rising slowly at 100 hours. 


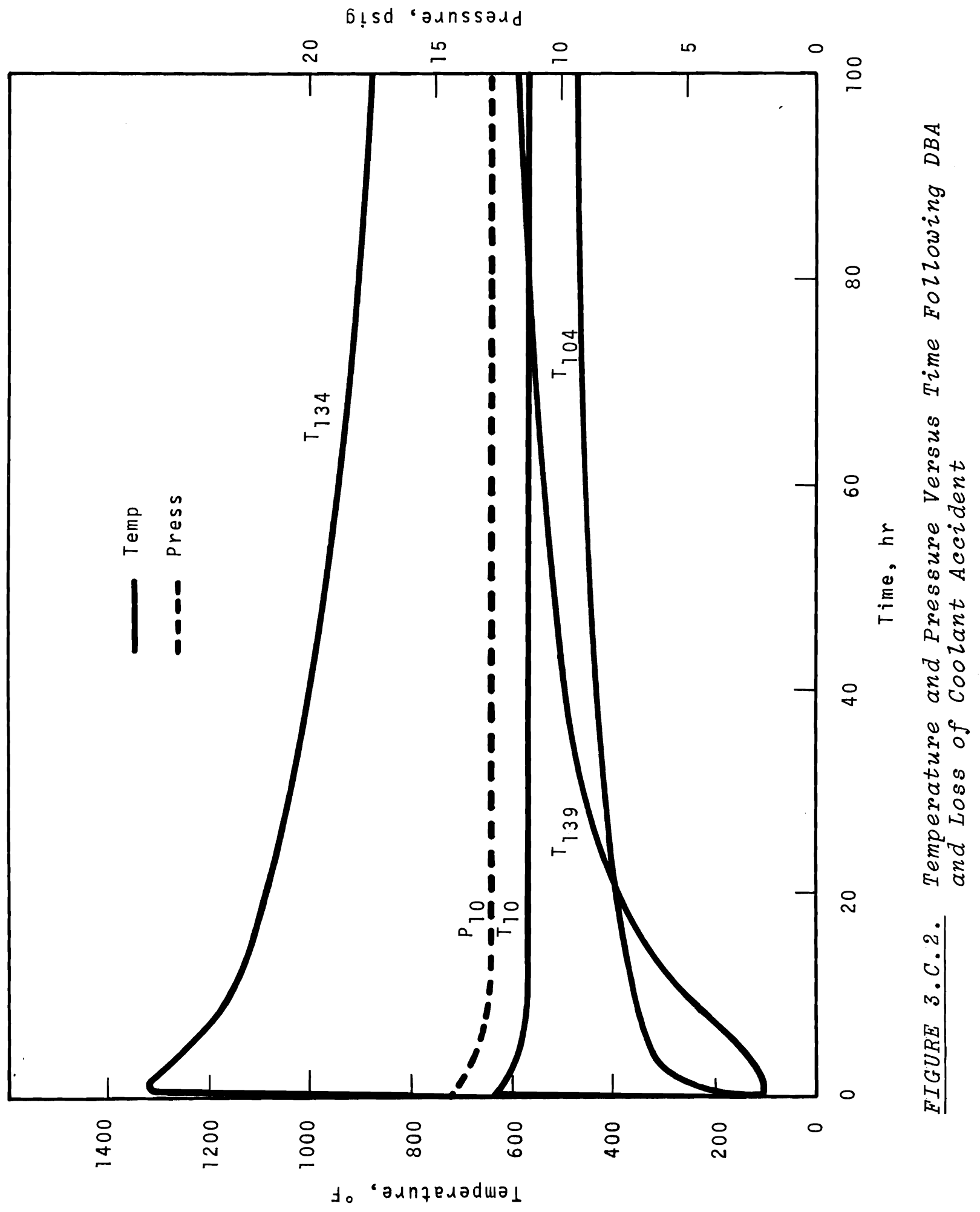


to a sink at $418^{\circ} \mathrm{F}$ using a film coefficient of $100 \mathrm{Btu} / \mathrm{hr} \mathrm{ft}^{2}$ ${ }^{\circ} \mathrm{F}$ between the bottom of the oxide insulating slab and the coolant. The radiation cooling case results in a limiting fuel layer thickness of 1.2 inches. In any event, the 1 -in. fuel layer case was used in subsequent analyses.

A transient heat transfer analysis was performed for the geometry discussed above using NUTIGER. The 1 in. of fue 1 and 3 in. of oxide insulator were divided into 40 internal nodes of 0.1-in. thickness. The fuel nodes had internal heat generation which decreased from a maximum of $28 \% / \mathrm{cm}^{3}$ to $13.5 \mathrm{~W} / \mathrm{cm}^{3}$ at $1 \mathrm{hr}$ and to $7.5 \mathrm{~W} / \mathrm{cm}^{3}$ at 10 hours. The temperature history of the system is shown in Figure 3.C.4. This figure shows that the insulator melts into a maximum depth and then resolidifies as the power level decreases. Figure 3.C.5 shows the heat flux variation from the upper fuel surface and lower oxide surface.

Three inches of oxide is shown to be a very effective barrier which limits the heat flux through the cavity floor. This means temperature gradients through the steel 1 iner and cooling system may be kept to a reasonable level. The analysis given here disregards the effects of convection within the $\mathrm{s} 1 \mathrm{ab}$.

C. Machinery Dome - Reactor Cavity Venting

G. L. Fox

In one variation of the FFTF Containment Design Basis accident, the sodium-in case, it is postulated that the reactor vessel cover is lifted and releases vaporized core materials to the machinery dome. Previous calculations (P. R. Shire) show an initial peak pressure of 86 psia occurring in the dome. It is desirable to reduce this peak by venting to the reactor cavity and possibly to other cells within the first containment barrier of the plant system. 
BNWL -1133

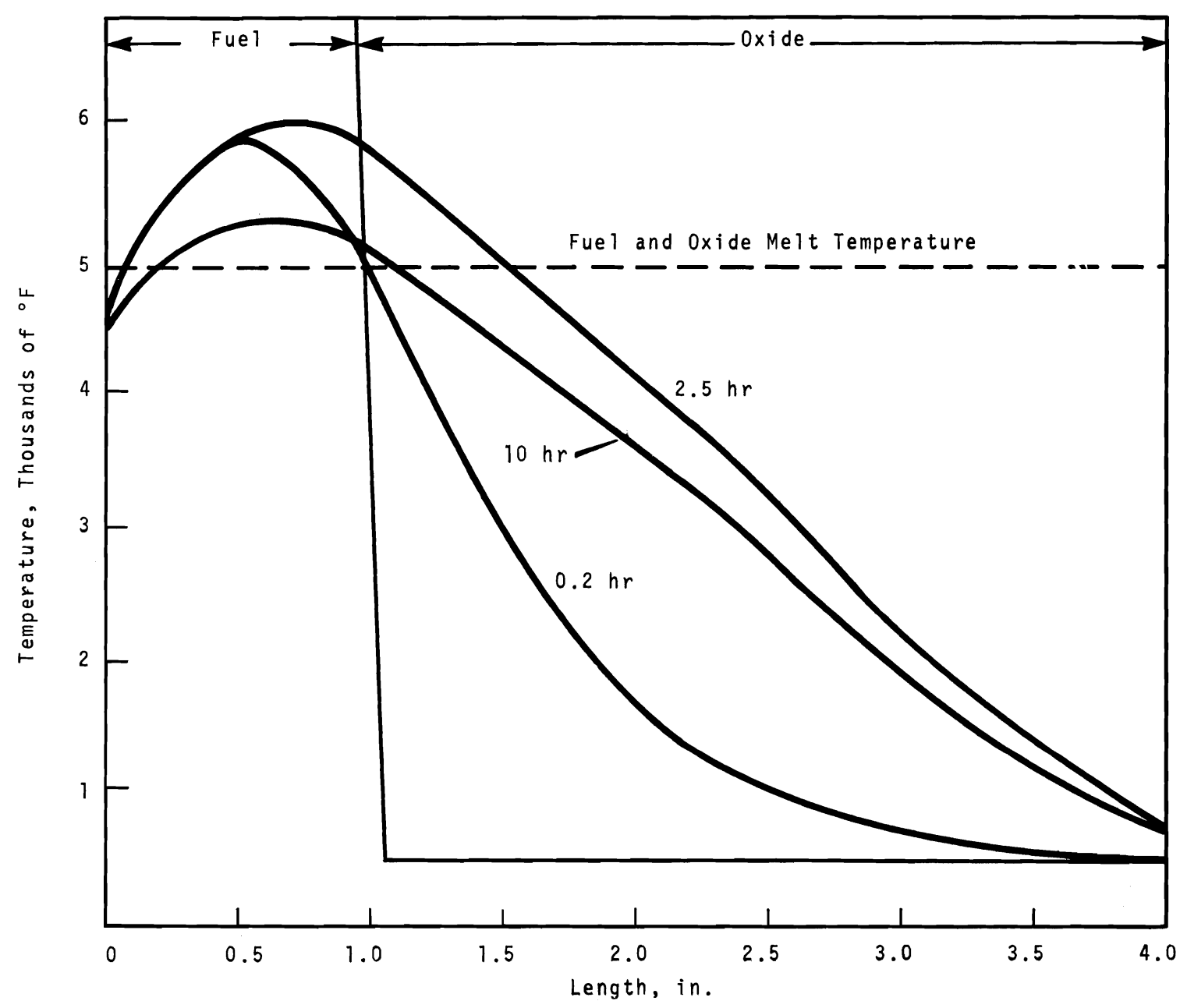

FIGURE 3.C.4. Temperature History of Oxide-Fuel System (Upper surface cooled by boiling stainless steel layer, Tboil $=4400^{\circ} \mathrm{F}$; lower surface cooled by sink, Tcoolant $=500^{\circ} \mathrm{F}$ ) 


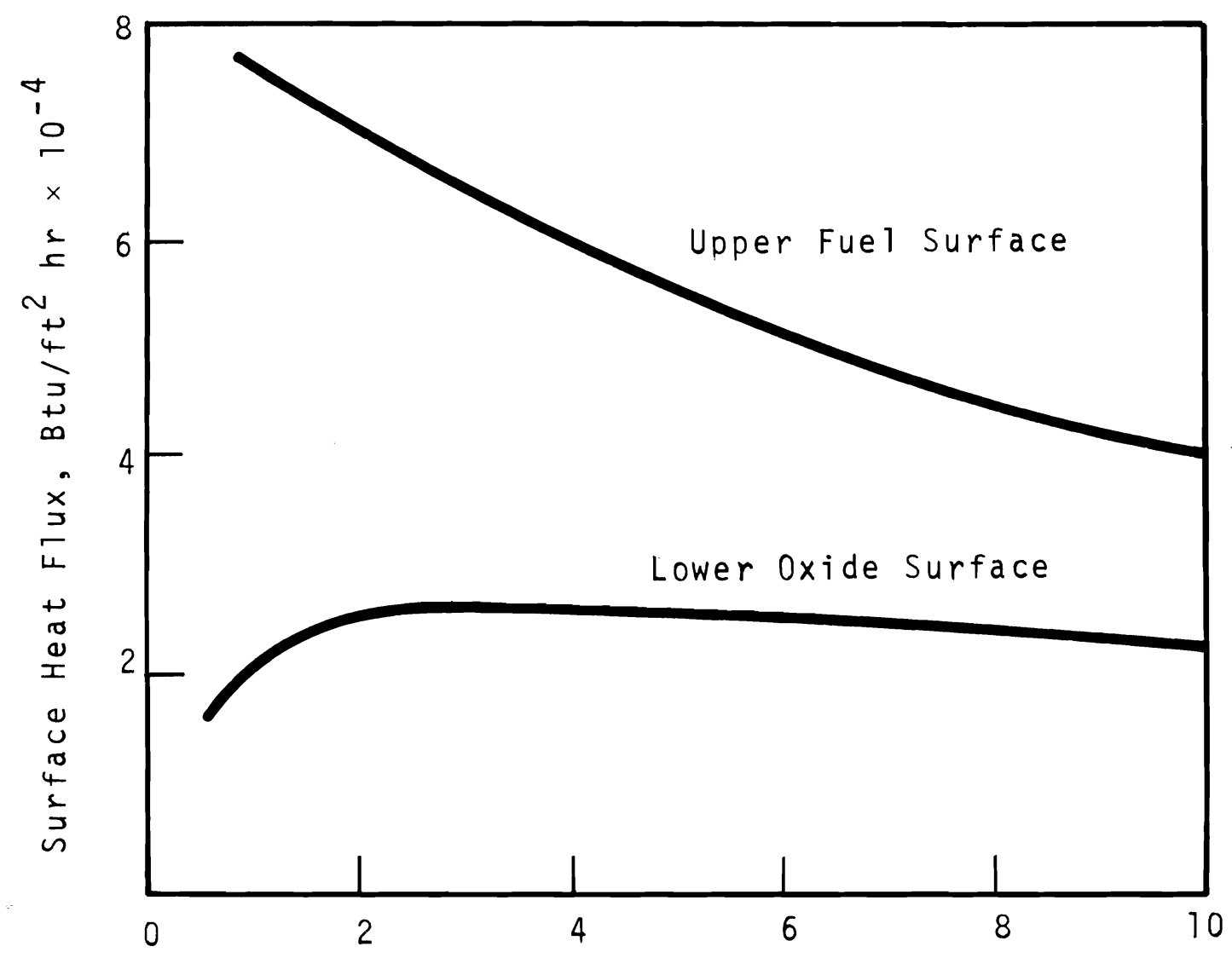

Time, $h r$

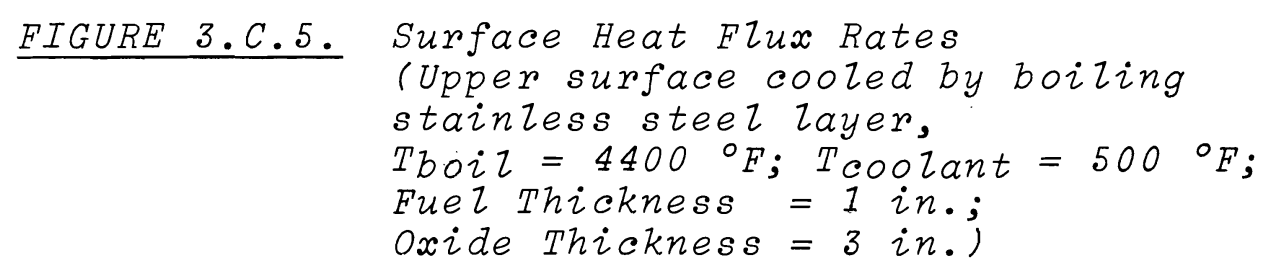


A computer program was written to solve for transient pressures and temperatures when gas flows from one cell volume to another during a Design Basis Accident venting situation. The program is written in MIMIC, an analog simulation language, and will handle up to four cells connected in series by three flow ducts. Heat transfer within the cells and entrance and discharge coefficients are included. The following assumptions app1y:

(1) Fixed composition gas, i.e., constant isentropic exponent and gas constant.

(2) Quasi-static flow condition, (i.e., equilibrium equations apply at each instant).

(3) Friction and heat transfer within flow ducts is negligible.

(4) Sonic flow exists if pressure ratio between cells is greater than critical.

(5) Bernoullis compressible flow equation applies for subsonic flow.

(6) Gas flow will be in same direction for all flow ducts. The program has been debugged and is ready for operation.

Sample calculations which represent venting from the machinery dome to the reactor cavity which is connected in turn to equipment cells is shown in Figure 3.C.6. The first case considers all flow duct areas to be $10 \mathrm{ft}^{2}$. The initial pressure of $86 \mathrm{psia}$ corresponds to the maximum machinery dome pressure, while the other cells begin at atmospheric pressure. Only the pressure in Cells 1 and 2 , the machinery dome and reactor cavity, respectively, are shown for simplicity. From the figure it is apparent that pressure is equalizing at 30 psia in about one second for the $10 \mathrm{ft}^{2}$ venting area. 
BNWL - 1133

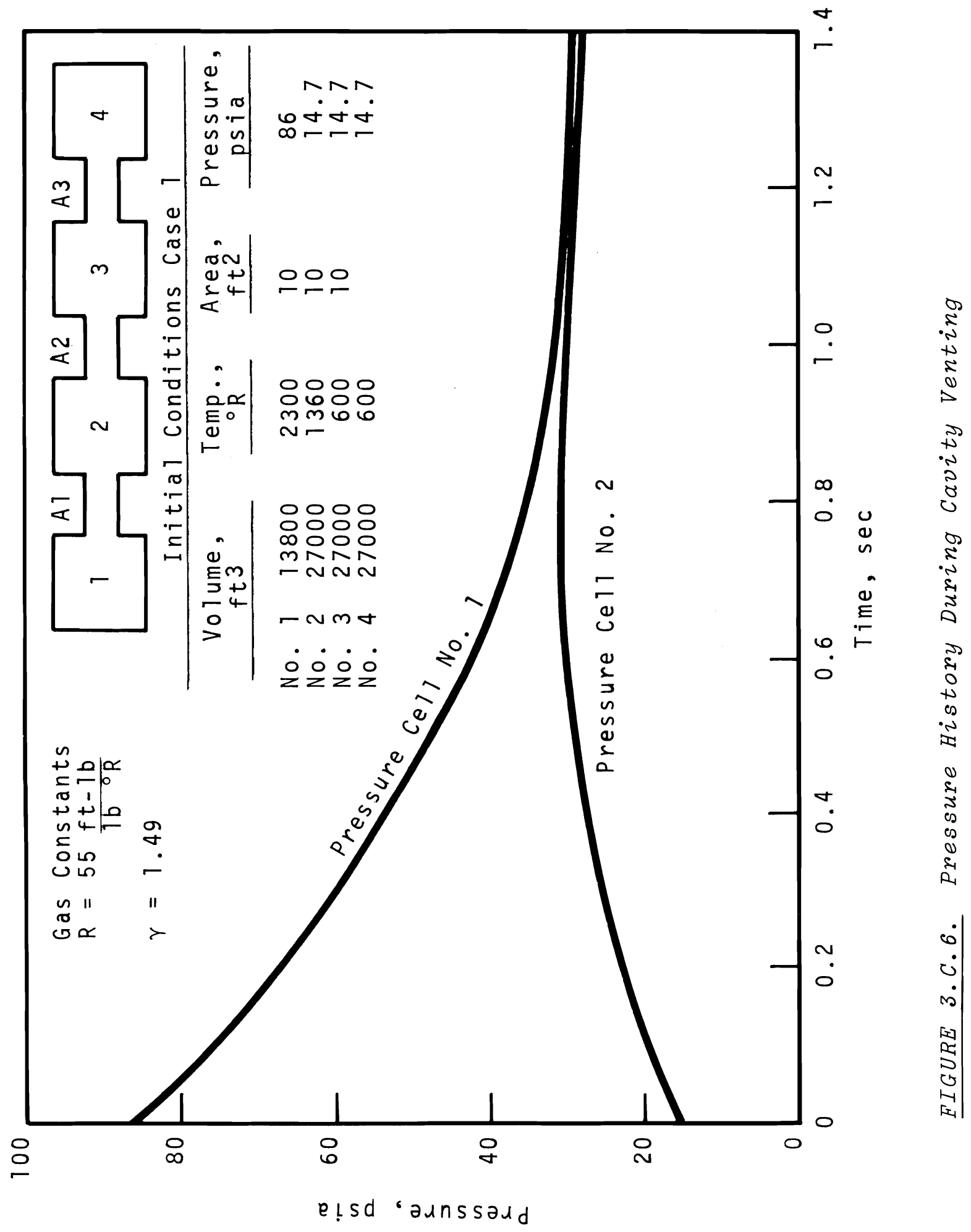


d. Transient Analysis of Reactor Cavity Response to DBA

R. D. Peak

A digital computer program has been prepared for the determination of transient temperatures and pressures within the reactor cavity following the unlikely occurrence of a core melt-through accident. This work has involved the conversion of the digital computer program CONTEMPT. This program, described in IDO-17220, analyzes the energy-mass-pressuretemperature responses of a single containment which can be described by a vapor region (nitrogen and sodium vapor), a liquid region (sodium liquid), and up to 20 heat conducting regions (such as reactor vessel wall, guard vessel wa11, radial shield, bottom shield, cavity wall, floor, and roof). This program was originally prepared to analyze the blowdown-loss of coolant accidents of water reactors in air containments. The main conversion was to substitute sodium and nitrogen properties for the water and air properties used by the program.

The converted code will be used to analyze conceptual designs of the reactor cavity cooling system as shown on SK-3-14636 (1) and variations of this system.

e. Reliability Analysis of the Plant Protection System (PPS)

0 . B. Monteith

The analysis of the PPS is continuing. During this reporting period the rod scram release circuit design has been revised to include additional relays for the purpose of increasing the independence of the logic from failures in the relays. The revision presents a complicated arrangement of components for establishing its reliability diagram and math mode1.

1. Not shown in this report. 
BNWL -1133

The long term availability of the revised rod scram release circuit for various testing intervals is shown in the accompanying table. These data will be used in the reliability analysis of the overall plant protection system. As a result of the circuit revisions, circuit unavilability has been reduced somewhat, as compared to the original results for comparable conditions.

\section{ROD SCRAM LOGIC CIRCUIT UNAVAILABILITY}

Hours Between Test

$\begin{array}{llll}\begin{array}{c}\text { Failure Rate } \\ \text { Range }\end{array} & 8 \mathrm{hr} & 168 \mathrm{hr} & 1500 \mathrm{hr} \\ \text { Worst } & 1.2 \times 10^{-6} & 8 \times 10^{-4} & 0.06 \\ \text { Nominal } & 1.2 \times 10^{-8} & 5.4 \times 10^{-6} & 6 \times 10^{-4} \\ \text { Optimistic } & 1.2 \times 10^{-12} & 5.2 \times 10^{-10} & 4 \times 10^{-8}\end{array}$

2. Systems Analysis

H. G. Johnson

a. Heat Transport System Analysis

(1) Dump Heat Exchanger Analysis. The DHX digital simulation using only six nodes each for the sodium, metal and air portions of the DHX is operational, and has been checked for steady-state operation. Transient operation is still being checked and compared to the reference model. This simulation predicts a steady-state heat transfer rate of $140.8 \mathrm{MW}_{t}$ for the 258 tubes/pass DHX for flow and temperature conditions for which the TAP DHX-simulation calculates a rate of $135.5 \mathrm{MW}_{t}$ and the ADOPT code, $133.3 \mathrm{MW}_{t}$. Comparison of temperature versus distance plots for the three cases shows the six-node model agrees very well for about the first third of the distance through the DHX for both the air and sodium fluids, then a slight but steady departure from the reference values occurs. This behavior, together with the long distance (25 ft) spanned by one node in the simple model, may indicate that the $4 \%$ error 
here is entirely in the coarseness of the nodal mesh used. In order to check this hypothesis the model is currently being expanded to 12 nodes.

Both the reference TAP model and the six-node model were set up to compute coefficients and thermophysical properties on the basis of both local temperatures and on the arithmetic average of the end temperature conditions. A comparison of exactly the same case using both the TAP model and the sixnode representation for both local and average conditions indicated that there were no significant differences in end conditions for steady-state calculations. (Node temperatures in the center of the exchanger differ in the two cases by a maximum of about $5{ }^{\circ} \mathrm{F}$.) This feature still must be checked for transient runs, but indications are that the use of average properties is quite satisfactory. The great advantage to using average properties with the six-node model is that the computer run time is about halved over the case using local properties.

3. Control Analysis

R. A. Harvey

a. Driver Channel Instrumentation Analysis J. J. Regimbal and G. H. Dickerson

The TIGER $V$ code, used for studying the effectiveness of thermocouples and flowmeters in preventing sodium boiling, was modified to utilize previously computed information more effectively. The code change permits magnetic tape storage and retrieval of initializing data so that a coolant flow loss ramp can be extended beyond that of a previous run without the need to recompute the previous run. Alternative solutions, depending upon the mode of scram or power cutback, may also be computed from channel conditions stored at the time sensor trip settings are reached. 
Limiting conditions for coolant boiling prevention by protective action were found for a variety of postulated flow loss occurrences. The flow is reduced steadily to an arbitrarily chosen final level, and temperature transients of the fuel, coolant, and thermocouples are computed. Safety system action occurs automatically when trip settings for flow or thermocouple temperatures are exceeded.

A typical solution is presented in Figure 3.C.7 for the case of flow reduction at a rate of $30 \% / \mathrm{sec}$ to a level of $30 \%$ flow. Safety rod release occurred $100 \mathrm{msec}$ after the thermocouple junction temperature reached $30^{\circ} \mathrm{F}$ above the steadystate value. Disregarding effects of superheating and the sodium static head, boiling would have barely occurred at the core outlet despite protective action. If flow reductions to a level somewhat smaller or greater than $30 \%$ occurred at this same rate, the maximum SAFE thermocouple response time to prevent boiling is also smaller or greater, respectively (Figure 3.C.8).

4. Safety Technology and Practices J. W. Hagan

\section{ANL Participation in FFTF Safety Programs}

Specific areas have been identified for more direct participation by ANL in the FFTF safety programs to ensure that the LMFBR safety technology at ANL is utilized to its fullest extent in the FFTF studies. The areas of immediate concern for the PSAR and its supporting information include: (a) Performance of the maximum accident studies which establish the DBA, and (b) Evaluation and specification of the fuel/cladding design bases and, correspondingly, damage criteria for the fuel.

The ANL SASIA accident analysis code is being incorporated in the FFTF studies to identify fuel failure thresholds and locations under hypothetical accident conditions. Adaptability 


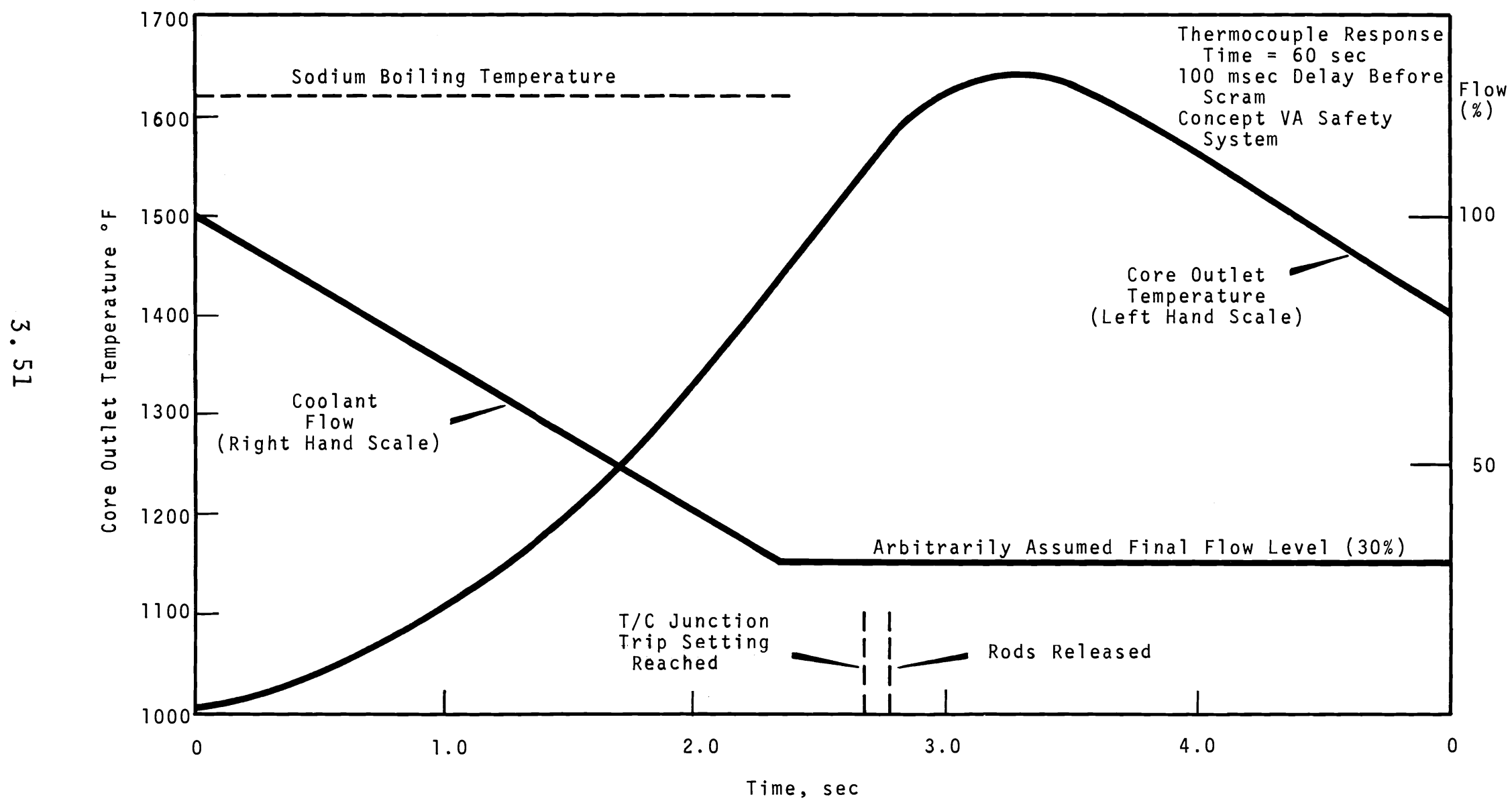

FIGURE 3.C.7. Core outzet Temperature Due to $30 \% / \mathrm{sec}$ Flow Reduction with Protective Action 


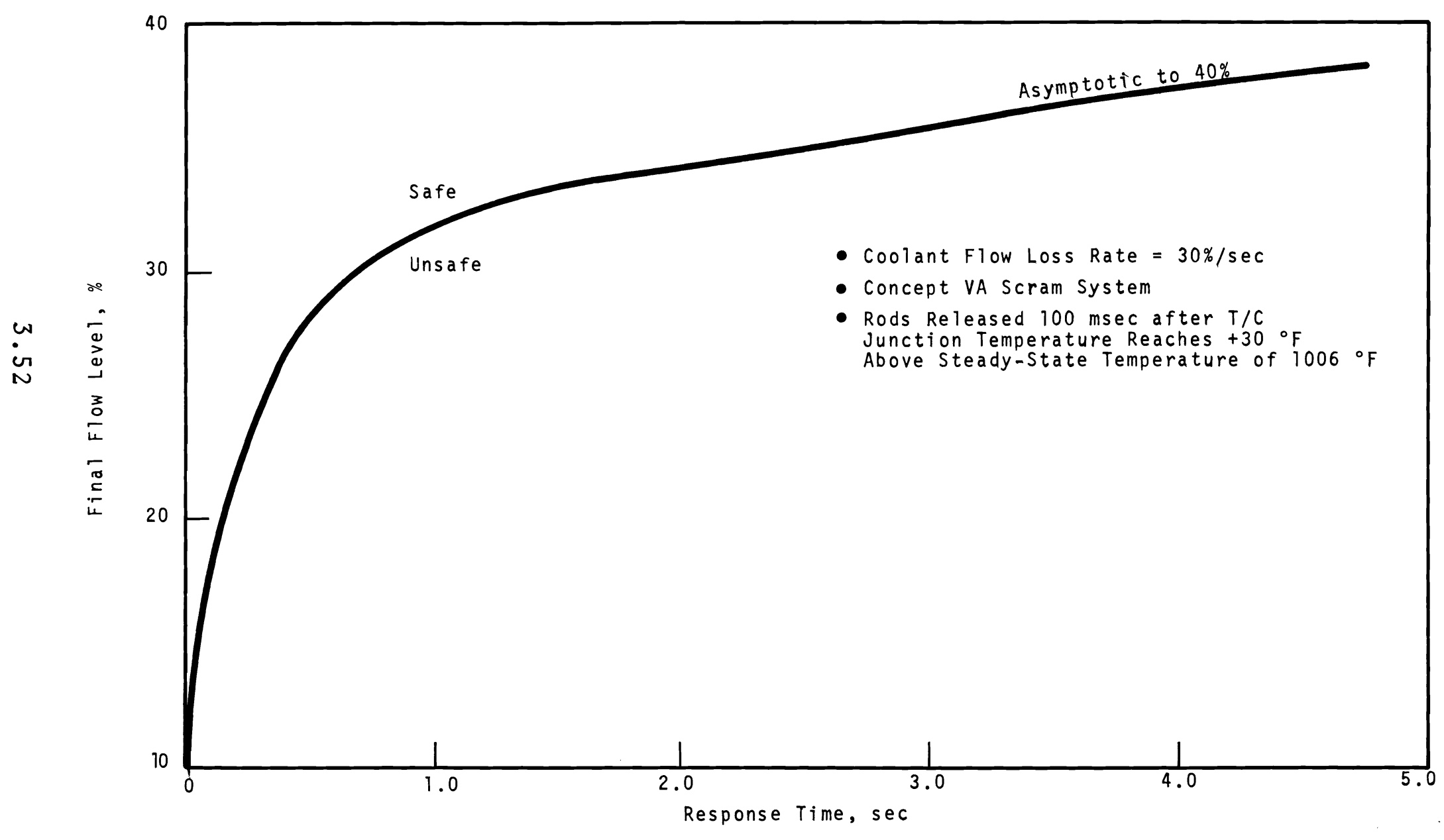

FIGURE 3.C.8. Maximum Sensor Response in Time Permitted to Prevent Boiling at Core outlet 
of the code to an additional pin failure model is being considered an ANL prior to the actual runs for the PSAR input. The initial faulted conditions assumed for these runs have been tentatively established and are now being evaluated. 


\section{ENGINEER ING DEPARTMENT \\ D. L. Condotta}

\section{A. REACTOR SYSTEMS}

1. Reactor Design

S. O. Arneson and R. C. Walker

a. Reactor Core

J. F. Wett

BNW Configuration Control Board approval has been obtained and the following Design Description was transmitted for RDT review and approval:

- CCDD-35 - First Core Fuel Assembly Component

b. Reactor Vessel and Shield R. C. Walker and 0. W. Priebe

The Request for Proposal package for the reactor vessel, head, guard vessel and associated equipment was issued to Babcock, Wilcox, Combustion Engineering, and Chicago Bridge and Iron on May 27. Proposals are requested to be submitted to Westinghouse on July 7 .

The scope of work for continuation of reactor vessel studies by Babcock and Wilcox was approved by RDT.

2. Reactor Equipment

S. 0. Arneson and C. A. Munro

a. Control Mechanism Development

J. C. Noakes, P. K. Telford

(1) Roller Nut Testing. Agreement was received to use the replacement $N$. W. Savannah roller nut CRDM for the initial test at LMEC.

(2) CCDD No. 33 Support. A document is being issued recommending that the roller nut concept be used for the control 
and secondary safety systems; the magnetic jack concept be used for the primary safety system; and the BNW pneumatic drive be used as the alternate concept in the event that either of the other drives fails to meet the design requirements.

\section{b. Reactor Hardware}

J. W. Kolb, B. G. Smith, L. R. Bese1, R. F. Gilmore

Removable Driver Fuel Instrument Assembly. A Development Work Statement draft for verification of the removable driver fuel instrument assembly concept has been completed with internal FFTF comments incorporated. The purpose of this program is to determine, by testing, the feasibility of remotely removing and re-installing the removable instrument assembly through a curved guide tube during reactor operation. The draft is being forwarded to Westinghouse and the BNW Laboratory for comment and preliminary planning.

\section{c. Closed Loop Nozzle Closure Program}

R. F. Gilmore, J.W. Kolb

Welding and Cutting. The primary objective of this task is to evaluate methods to reliably separate the welded closed loop nozzle closures by remote control. The current design approach is the trepanning method using two single-point groove-cutting tools and two facing tools. The remote cutting machine is designed to separate completely the closed loop tube from the nozzle and prepare the joint for subsequent rewelding in a single cutting operation. Alternative methods to separate the welded nozzle closures are also being studied.

Shop fabrication drawings of the remote cutting machine are completed. Final tool bit design configurations have been established. Module testing of the remote cutter head assembly is being planned to verify positive chip control, confirm cutter speed and feed rates, and to determine actual cutter loads and the vacuum system necessary to exhaust the chips away from the cutting surface. 
3. Core Development and Analysis

S. 0. Arneson and J. R. Carrel1

a. Sodium Flow, Hydraulic and Mechanical Testing of FFTF Fuel Assemblies (CFD-3) J. M. Yatabe

(1) Coolant Mixing and Flow Distribution. Continued evaluation of the absolute resistance technique for flow mixing determinations has identified a strong temperature sensitivity effect averaging $1.25 \%$ of measured resistance per degree Fahrenheit. Therefore, it has been concluded that the water temperature in the mixing tests must be controlled to $\pm 1^{\circ} \mathrm{F}$ in order to produce adequate data. Using careful temperature control and other appropriate operation techniques, mixing data reproducible within $\pm 4 \%$ was obtained in trial runs.

(2) Sodium Flow Testing. The Mark I ássembly (a full-sized fabrication prototype) has now been tested to approximately $3600 \mathrm{hr}$ at full flow and temperature conditions (400 gal/min, $1060^{\circ} \mathrm{F}$ in the Core Component Test Loop at Argonne National Laboratory. The fuel assembly was removed from the facility, cleaned and returned to BNW for detailed inspection as previously reported. The assembly appeared to be in excellent condition, except for a slight loosening of the wire wrap spacers on the outer pins.

Seventy pins have now been removed from the test assembly, and the surface conditions of the pins appear to be excellent. However, by visual examination, the degree of wire wrap looseness appears to be decreased in the central pins of the assembly. Planned quantitative measurements of wire stretching on a number of individual pins are required before any conclusions can be derived on the relationship between spatial position and wire loosening. 
BNWL -1133

(3) Loose Wire Wrap Effects. It has been postulated that wire wraps may loosen during reactor operation because of differential swelling. If movement of this slack wire could occur relative to the bundle, the coolant channel configuration could change, giving rise to hot spots. In addition, increased vibration amplitudes in the assembly could result, leading to more rapid wear rates.

To identify potential wear problems, a 7-pin fuel assembly model has been fabricated (three pins with wire stretched 0.020 in. and three pins with wire stretched 0.030 in.) and tested in the Small Components Test Loop. The conditions for the life test are steady sodium flow velocities of $30 \mathrm{ft} / \mathrm{sec}$ and temperature of $1150^{\circ} \mathrm{F}$. Sodium purity was maintained at below $10 \mathrm{ppm}$ oxygen and $20 \mathrm{ppm}$ carbon as measured by analytical chemistry performed on samples. The assembly has been exposed to these conditions for approximately $800 \mathrm{hr}$ before removal for an interim examination.

The interim examination results are qualitative since no destructive examination could be permitted on the test assembly. Photographic and direct visual examination indicated no evidence of wear on cladding or wire wrap surfaces. The assembly was re-inserted into the loop and life test conditions re-established. The duration of the final phase of the test will be 3,000 hours.

b. Heat Transfer Characteristics of FFTF Fuel Assemblies

The Small Heat Transfer Loop modification to permit 7-pin bundle testing was completed and checkout tests demonstrated that all added components (e.g., pump, power supply, and heat dump addition) are performing properly. During the modification, a test on a single pin in water was run to give greater validity to the quality assurance being applied to the pins to be used for 7-pin bundle testing. A heat flux of 
$1,700,000 \mathrm{Btu} / \mathrm{hr}-\mathrm{ft}^{2}$ (water temperature $300^{\circ} \mathrm{F}$ ) was achieved without failure. However, the internal thermocouple was found to have shorted to the cladding. This situation will be rectified in the 7-pin bundles by having the vendor pre-oxidize the bare thermocouple wires to provide additional insulation.

c. Development Facilities Management K. G. Toyoda

(1) Hydraulic Core Mockup Test Program (H. Leigh, J. Muraoka, D. L. Ballard, D. M. Jackson, L. R. Sweetin, J. Spalek, G. W. Riedeman). The objective of the HCM test program is to provide development and testing support for resolution of the FTR vessel and core hydraulic and mechanical design problems, The inlet feature model is a part of this program. Currently the original inlet model is being modified to more closely simulate the vertical core concept $\mathrm{V}-\mathrm{a}$. The complete modification will be made in steps and testing will proceed after each step. The initial model modifications include the following:

- The inlet end of all flow ducts were cut off, leaving an open end entry

- The ducts were anchored to the upper tubesheet to simulate a single tubesheet configuration

- The original inlet basket was reinstalled and used until the concept $\mathrm{V}$-a basket is available

- The new steel eliptical head and a safety support were installed.

(2) Sodium Core Development Facilities (CM-3) (K. D. Hayden, R. R. Wyer). Construction work is progressing on the FFTF Sodium Facilities Building (B1dg. 335). The contractor has placed all underground piping and conduit and has completed the pouring of building footings. The two 750 VA surplus 
electrical transformers and $440-\mathrm{V}$ motor control center from the deactivated reactor areas have been transferred to J. A. Jones warehouse for overhaul and storage. Vitro design work has been progressing on the LMFBR Core Segment Development Facility.

Preliminary design criteria and conceptual flow diagrams were prepared for the HTSF Sodium Receiving and Processing System and the HTSF Inert Gas Systems. The sodium system provides storage and cold trap purification for approximately 30,000 gal of sodium. The inert gas system provides storage for approximately 45,000 SCF of gaseous nitrogen and 90,000 SCF of gaseous argon at 750 psi.

(3) Sodium Facilities Operation (J. D. Berg, L. J. Defferding). The objectives of this section and description of equipment were given in BNWL-915. (1) The status of the sodium facilities is given in the following:

- Sma11 Component Evaluation Loop: The FFTF fuel subassembly was removed, cleaned, examined and reinstalled in the loop for an additional $600 \mathrm{hr}$ run. During the downtime a new temperature-power controller was installed on the main $12 \mathrm{~kW}$ heater.

- Small Heat Transfer Loop: Following the loop upgrading, checkout, and operator training, operation was initiated (utilizing a dummy test section) to clean up the sodium. A single pin test assembly was installed 5-19-69 and testing initiated on 5-22-69. For this series of tests, the simulated fuel pin power and loop temperature were increased simultaneously from zero power at $400^{\circ} \mathrm{F}$ to about $30 \mathrm{~kW}$ at $800^{\circ} \mathrm{F}$ with the system flow rate at $20 \mathrm{gpm}$. The flow was then reduced to establish the prototypical temperature rise across the test pin. The pin power and test section

1. FFTF Monthly Informal Technical Progress Report, BNWL-915. 
discharge temperature were cycled four times. The test section was removed from the loop and steam-cleaned according to standard procedures. After cleaning, the test section was leak checked and reinstalled on the loop for the second phase of this test. The second phase of the test included the determination of the performance limits for this test pin. During this phase of the test, a sodium leak and fire started in the test section enclosure when a break occurred in the end regions of the test assembly. The sodium ignited immediately on contact with the air in the metallic test section safety enclosure; the Dowtherm in the system used to cool the electrical leads also contributed to the fire. The fire was completely restrained within the test section safety enclosure. No delay to the program resulted.

- Static Sodium Pots: Testing (cycling pressure and temperature) of the pressure transducer in Pot No. 3 continued. Pots 1,2 and 4 remained shut down, however, a pressure transducer is being readied for installation in Pot No. 4.

- Sodium Purification Loop: The cold trap inlet line trace heater was replaced (failure reported last month) by 5-2-69 and 1oop started up on 5-3-69. This system has remained in operation at $600^{\circ} \mathrm{F}$ bulk temperature with direct reading $0_{2}$ and carbon probes in service.

- Fission Product Screening Loop: A new primary pump throat (failure reported last month) was fabricated and delivered 5-22-69. Installation of the pump throat and flow meter tube holders is in process.

- Mechanical Properties Loop: Idle this month, test section being fabricated.

- FFTF Sodium Facilities Building: A new $60 \times 100 \mathrm{ft}$. building is under construction (completion about 12-15-69) to 
house the Small Component Evaluation Loop, Small Heat Transfer Loop, and the Static Sodium Pots. In addition, spare parts and equipment storage space is provided along with a maintenance shop area.

4. Refueling and Radioactive Maintenance Systems

S. O. Arneson and W. E. Cawley

a. Conceptual System Design Descriptions E. J. Ruane

System 42 - Nonirradiated Fuel Handling (E. D. Grazzini). The system 42 CSDD has been revised to include additional requirements for pre-irradiation testing equipment and has been resubmitted to the BNW Configuration Control Board for review and approval. 
B. FLUID SYSTEMS

B. M. Johnson

1. Heat Removal System

T. W. Withers

a. Sodium Pumps

W. Babcock

The Westinghouse Design Study is on schedule. Contractual limitations of time and money did not permit pursuit of the following problems in this study identified as follows:

- An uncertainty exists regarding the impeller capability to resist creep at temperatures over $900^{\circ} \mathrm{F}$.

- An inner tank liner is subject to cracking in the combination of high temperatures and transients.

- Shaft dynamic problems indicate that a second sodium bearing may be required for damping. At $500 \mathrm{rpm}$, the shaft deflection exceeds the bearing clearance. The torsional critical speed is too close to operating speed.

- The NPSH requirements have not been achieved.

- Very little substantive work was accomplished on vortexing problems.

The revised pump program and testing plan was completed and is being prepared for internal comment before submittal to RDT .

The revised state-of-the-art report on sodium pumps was published and distributed.

1. W. B. Babcock. State of Technology Study-- Pumps, Experience With High Temperature Sodium Pumps in Nuclear Reactor Service and Their Application to FFTF, BNWL 1049 (OUO). Battelle-Northwest, Richland, Washington, June 1969 . 


\section{b. Intermediate Heat Exchangers \\ L. A. Whinery}

Babcock and Wilcox Company work activity on the FFTF IHX design study contract (BNW Contract No. BDR-571) was devoted primarily to development and evaluation of alternative IHX design layouts. This work progress is reported in a preliminary draft of Babcock and Wilcox Report No. BAW-BDR-571-1, FFTF IHX Exploratory Design Studies - Interim Report - Concept Selection. Twenty-two alternative IHX concepts were qualitatively evaluated by Babcock and Wilcox and two interim designs were selected as recommended bases for follow-on study. Table 4.B.I. summarizes major design parameters.

Concept I features a helical coil tube bundle with floating lower head. Secondary sodium inlet and outlet piping are routed concentrically through an overhead shield plug and must be cut prior to tube bundle removal. Tubes are attached to tubesheets using a crevice-free and backside weld capable of being ispected. Other than flow impingement baffles at the primary inlet, no shellside flow distribution baffles are proposed, thus leading to a low-pressure drop unit.

Concept II utilizes a straight tube bundle with floating lower head. The tube bundle is removable after cutting secondary inlet and outlet piping. Also, a rotatable upper shield plug is provided with index holes permitting access for in-place tube plugging using an explosive welding technique being developed by Babcock and Wilcox. Tube-to-tubesheet welds are of the partial penetration, J-groove type.

In addition to the on-going Babcock and Wilcox design studies, NYO has also negotiated work scopes with Westinghouse and Foster-Wheeler for performing LMFBR Program IHX design studies of a nature generally supporting the FFTF needs. 
BNWL -1133

TABLE 4.B.I. IHX Design Parameters Resulting from Preliminary Calculations

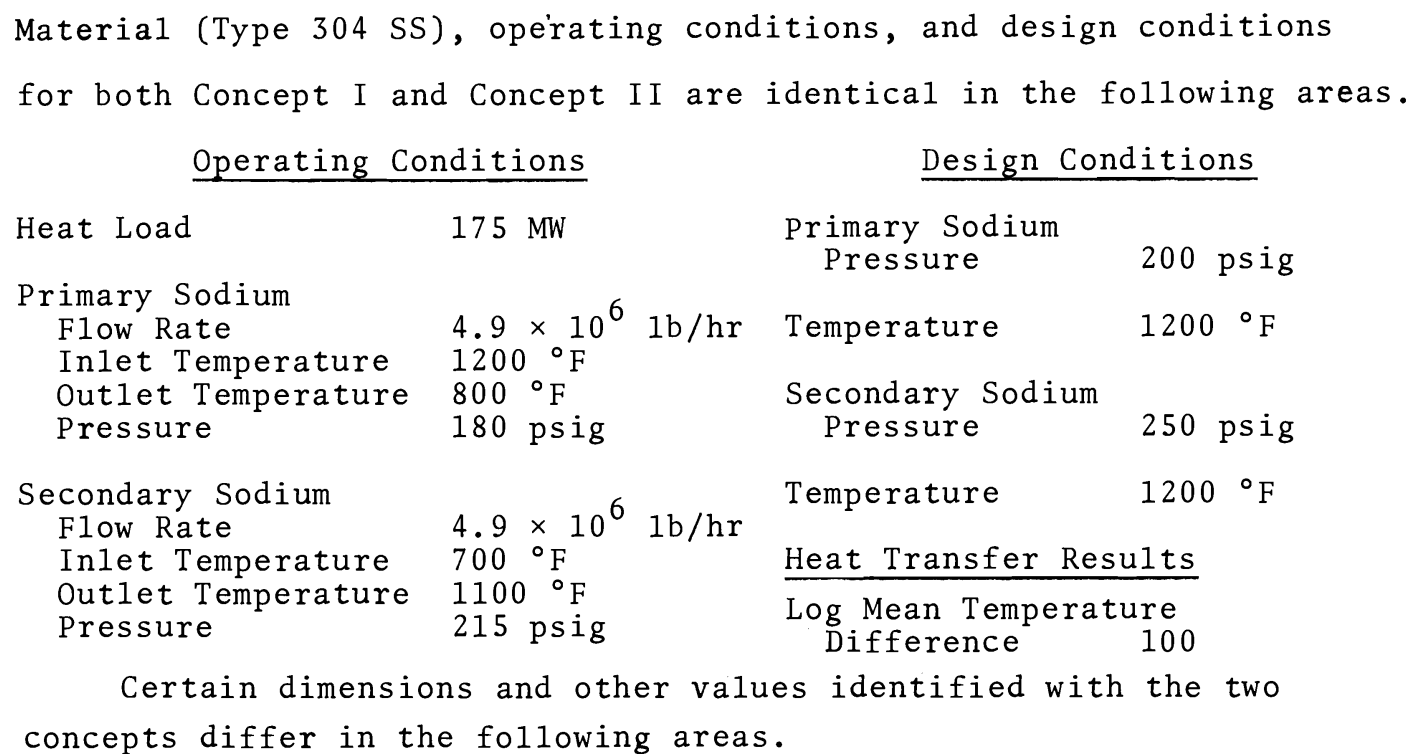

$\frac{\text { CONCEPT I I }}{S-3581-700} a^{a}$

Tube Bundle Dimensions

$\begin{array}{lll}\text { Bundle Outer Diam, in. } & 80 & 55 \\ \text { Bundle Inner Diam, in. } & 42 & 26 \\ \text { Tube Size and No. } & & \\ \text { Quantity } & 300 & 1500 \\ \text { Diameter, OD in. } & 1.5 & 0.75 \\ \text { Pitch, in. } & 3.5 \text { (on tubesheet) } & 1.25 \\ \text { Minimum Wall Thickness, in. } & 0.060 & 0.035\end{array}$

Heat Transfer Results

Overall Heat Transfer Coefficient Heat Transfer Surface (min.)

$1050 \mathrm{Btu} / \mathrm{hr}-\mathrm{ft}{ }^{2}-{ }^{\circ} \mathrm{F}$ $6300 \mathrm{ft}^{2}$ $\frac{\text { CONCEPT II }}{\mathrm{S}-3581-100}$ Rev. $?^{\mathrm{a}}$

Pressure Drop Calculations

Tota1 Primary Pressure Drop, psi 3.5

Total Secondary Pressure Drop, psi 6

Major Dimensions

She11 Length, ft

She11 OD, in.

36.5

93.5

Sodium Inventory

Shellside

Tubeside

Removable Bundle Weight

a. These SK drawings not shown in this report.
32.5

62.5

5

$1440 \mathrm{Btu} / \mathrm{hr}-\mathrm{ft} \mathrm{t}^{2}-{ }^{\circ} \mathrm{F}$ $4800 \mathrm{ft} 2$

$\begin{array}{ll}33,0001 \mathrm{~b} & 13,0001 \mathrm{~b} \\ 30,0001 \mathrm{~b} & 16,0001 \mathrm{~b} \\ 137,0001 \mathrm{~b} & 73,0001 \mathrm{~b}\end{array}$




\section{Auxiliary Systems}

R. V. Dulin

a. System 81 - Sodium Receiving and Processing

The CSDD has been approved and issued for this system. The document is being revised currently to incorporate the approved Design Safety Criteria. The architech-engineer (AE) has completed review of the conceptual design and is proceeding with design studies on mixing tees, freeze traps, and sodium pumps. LASL is in the process of analyzing design and perfor-. mance characteristics of various cold trap configurations in support of FFTF.

BNW is providing study results on the following studies:

Contaminated Sodium Disposal Method

Cross Contamination Potential

Material Selection for Sodium Services

Material Surveillance Methods

Impurity Removal and Control Methods

Controlled Addition of Impurities

b. System 82 - Inert Gas Receiving and Processing

The CSDD for this system has been approved and final issuance is awaiting incorporation of the approved Design Safety Criteria. The AE has completed review of the conceptual design and is proceeding with design studies on sodium vapor traps.

BNW is directing a design study by GE on the impact of failed and vented fuel operation on plant design.

c. System 83 - Auxiliary Heating and Cooling

The AE is preparing the CSDD for this system, which is to include those process cooling functions requiring liquid metal as the heat transfer medium as well as the heating function for a11 sodium-containing equipment. The CSDD is in early draft status. 


\section{d. System 84 - Decontamination and Cleaning}

This system will include primarily the decontamination and cleaning of installed sodium piping systems and large components removed for maintenance. The equipment and processes required for such cleaning and decontamination present a number of technical problems, and a CSDD is considered the best way to bring these technical problems into project focus. The CSDD is in preparation.

e. System 85 - Chemical Analysis Facility

This facility is to include all of the radioactive and nonradioactive analysis required at the FFTF site. The AE has completed a final issue of the CSDD to be submitted for BNW comment, approval, and submission for RDT approval.

Since the Auxiliary Systems are primarily service systems for the major FFTF systems, detailed concepts are affected by concepts for those major systems. Thus, it will probably be necessary to make a final "round" of Auxiliary Systems concept revisions when major system concepts are finally established.

3. Irradiation Facilities

B. M. Johnson and J. R. Carre11

a. Short-Term Irradiation Facility - (STIF)

P. F. Shaw and M. K. Mahaffey

The STIF CSDD was approved by CCB. A justification for the facility was prepared for transmittal to RDT. 


\section{PLANT SYSTEMS}

E. M. Johnston

1. Structure and Utilities

F. A. Shadel

a. Reactor Containment System (System No. 27)

C. C. Steele and N. Vieli

Representatives of BNW, Bechte1, Westinghouse, Atomics International, Aerojet-Genera1, and RDT met at AEC Headquarters in May to review the conceptual design of the FFTF containment system described in CSDD No. 27. The following essential features of the containment system were agreed upon:

- A two-barrier containment arrangement.

- A spherical outer containment vessel.

- Closed loop equipment cells located within the reactor outer containment vessel.

- Primary sodium systems located within the reactor containment vessel.

- An effectively flat operating deck, with deviations from this objective individually justified.

CSDD No. 27 for the Reactor Containment System was approved subject to RDT comments.

b. Seismic Consultant Agreement F. H. Shade 1

BNW has retained John A. Blume and Associates, San Francisco, as the FFTF Consultant for seismic design and earthquake engineering . 
2. Electrical Systems

G. H. Strong

a. Primary Electric Power System (System No. 11)

M. F. Wiitala

The Bonneville Power Administration submitted a drawing showing proposed protective relaying for the $115 \mathrm{kV}$ system. The relaying scheme is based on information contained in CSDD-11 and Bechtel Engineering Report No. 24, CSDD-11. The scheme utilizes carrier current transfer tripping on the circuit breakers at the Midway-Benton tieline terminals and the FFTF sectionalizing circuit breakers to obtain circuit breaker reclosing in approximately 35 cycles $(0.58 \mathrm{sec})$ after a transient fault. A review of the past history of the frequency of occurrence of transient faults on the tieline and an analysis of the effects of such faults on the operation of FFTF indicated that the fast reclosing was not necessary. BPA has been requested to revise their protective relaying diagram on the basis of a 1 -sec reclosure time. The new diagram will be used by Bechtel as a basis for design.

3. Fue1 Examination System

C. L. Boyd

Recommended Methods of Gas Cooling Driver and Test Fuel Assemblies

E. B. Ramsey

BNW submitted the following recommended methods to RDT for concurrence on the gas cooling of driver and test assemblies:

- Axial suction recommended for gas cooling during transfer, storage, examination and disassembly-reassembly operations with the fuel assembly flow duct in place.

- Transverse suction recommended for gas cooling during examination and disassembly-reassembly operations with the fuel assembly flow duct removed. 
- A combination of axial and transverse suction recommended for transition gas cooling during removal and replacement of the fuel assembly flow duct.

The major advantages of the recommended methods are better control of sodium vapor, contamination, and hot exhaust gas; and easier monitoring of cooling gas outlet temperatures.

An additional consideration in the selection of the transition gas cooling method is the need for similarity of axial and transverse cooling methods; that is, a combination of either axial and transverse pressurized cooling or axial and transverse suction cooling. This requirement is based on data from transition cooling tests reported in BNWL-1062, (1) where a combination of pressurized axial flow and transverse suction flow resulted in sharp cladding temperature peaks indicative of poor flow distribution. Preliminary analysis showed that changing of the axial flow to suction would significantly reduce the temperature peaks occurring during simulated liner removal. Both GE and ORNL, who are engaged, respectively, in conceptual studies for Axial Gas Cooling Hardware and Disassembly-Reassembly Equipment are in agreement with the recommendations . 1. FFTF Monthly Informal Technical Progress Report, BNWL-1062, 


\section{INSTRUMENTATION AND CONTROL}

C. D. Swanson

1. Plant Instrumentation

J. W. Mitche11

a. Centra1 Contro1 and Data Handling - System 91

G. L. Waldkoetter, D. W. Hartmann

Bechtel's estimates run as high as 2800 preheat thermocouples as compared with the estimate of 1500 in CSDD 91. Until piping layout and pipe heating design are firmer, the higher number will be used for sizing the system.

A brief study on the feasibility of using two computers instead of the planned three for the CC\&DH was completed. In the study, it was concluded that the identified system requirements can be met with either a 24 or 32 -bit word size, 2 -computer configuration. However, since the expected increase in computer usage will be in the area of calculations, the 32 -bit word size computer appeared to be the better choice. Further study of this subject will continue during preliminary design.

b. Process Data Displays B. E. Dozer

The 20-channe1, field-effect transistor multiplexer has been received from Interstate Electronics and testing is nearly completed. In general, most of the tests meet the manufacturer's specifications.

\section{Instrumentation Development}

M. R. Wood

a. Low-Leve1 Neutron Flux Instrumentation

C. N. Jackson, N. C. Hoitink, and D. C. Thompson

This task encompasses the developmental test and evaluation of sensors, cables, and other components for highsensitivity, low-level neutron counting systems. Both the 
reactor startup and subcriticality instrumentation channels will experience severe enviromental conditions of up to $10^{6} \mathrm{R} / \mathrm{hr}$ gamma at temperatures (initially) of $900^{\circ} \mathrm{F}$ and finally of $1200^{\circ} \mathrm{F}$.

Engineering developmental tests were conducted during the reporting period to determine the performance of hightemperature coaxial cables at temperatures up to $1200^{\circ} \mathrm{F}$. Measurements employed the integral bias curves technique and involved the components and instrumentation previously used for the high level gamma and temperature tests of the sensors. For direct comparison, spurious noise signals were measured using the same technique.

Transmission of the high voltage and signal through the heated zone of the cable encountered no operational problems over the full range of test temperatures. Preliminary shortterm measurements, using short cable sections, revealed a cable noise problem at temperatures of about $600^{\circ} \mathrm{F}$ and higher. As observed, lower detector voltages reduced the magnitude of the noise problem. Further characterization of the noise generation problems and methods for miniumization or elimination will require further investigation.

Future plans include testing the detector and a greater length of cable (approx. $20 \mathrm{ft}$ ) to both temperature and gamma radiation fields. The silica-insulated cable will be placed in a furnace for up to one month to determine whether a timedependent noise component is present.

b. Pressure $\triangle \mathrm{P}$ Flow and Level Sensors for Sodium Service R. D. Crosier, K. O. Creek

The objective of this task is to develop pressure and level instrumentation for FFTF applications. Pressure testing of the Consolidated Electrodynmics Corp. transducer 4-361-0001 SN-2260 (an unbonded strain-gage type rated at 
$600^{\circ} \mathrm{F}$ and $250 \mathrm{psi}$ has been completed successfully at temperatures of $625^{\circ} \mathrm{F}$ and $650^{\circ} \mathrm{F}$ in the sodium pots being tested at $675^{\circ} \mathrm{F}$.

c. Driver Test Position Connector Concepts R. D. Crosier, S. K. Meyers and K. O. Creek

A specification for an improved prototype closed loop connector including quality assurance requirements was sent to seven connector manufacturers to obtain their proposals, but no bids were received. The vendors are being. questioned to determine their objections and to work out a suitable specification.

d. Surveillance Sensors

R. L. Brown and K. O. Creek

The objective of this task is to evaluate the Sperry wheel ultrasonic inspection unit for temperature and radiation tolerance and for application in inspecting FFTF vessel and piping welds.

A Sperry wheel unit has been procured, and initial evaluation of the components and materials in the wheel has been completed. A list of materials expected to fail because of radiation or temperature damage has been prepared. As originally delivered, the wheel transducer could not withstand the projected FFTF environments. The unit was intended to inspect a piping surface at $500^{\circ} \mathrm{F}$ while the remainder of the wheel unit was maintained at a much lower temperature by artificial cooling.

Alternative materials for the components subject to damage are being investigated in order to recommend rep1acements . 
e. Subassembly Instrumentation Testing in Sodium M. J. Rieb

The task objective is to perform tests in sodium on ful1size driver and open test position developmental instrumentation at reactor core subassembly flow and temperature conditions. Authorization to start negotiations with Westinghouse will start design of the test section as soon as contract negotiations are completed. This new loop is now filled with sodium and is undergoing the initial startup process. 


\section{E. SODIUM AND GAS TECHNOLOGY \\ B. M. Johnson}

1. Corrosion and Chemistry

D. W. Shannon

a. Evaluation of Radioisotope Transport and Deposition

W. F. Brehm, E. A. Kovacevich, J. J. McCown

Sections of the dismantled Radioisotope Transport Loop were submitted for study of composition gradients near the metal-sodium interface. Preliminary results indicate a decrease in $\mathrm{Cr}, \mathrm{Ni}$, and $\mathrm{Mn}$ concentration near the metal surface of hot-leg samples. This is expected. The study is still underway.

Thermal convection 1oop TC-8 was shut down after $816 \mathrm{hr}$ operation at $1300^{\circ} \mathrm{F}$ maximum temperature, with $900^{\circ} \mathrm{F}$ minimum. The distribution patterns for ${ }^{51} \mathrm{Cr},{ }^{54} \mathrm{Mn}$, and ${ }^{60} \mathrm{Co}$ are being measured using a germanium diode detector. This is the third of the five different maximum temperature runs p1anned for TC loops.

b. High Leve1 Analytical Facility Design J. F. Jarosch, L. F. Lust

A study of the pros and cons of making the inert atmosphere portion of the hot cell mockup evacuable has been completed. It was concluded that the costs and inconvenience of an evacuable cell were not warranted. Design of a non-evacuable cell is continuing and purchase of associated equipment has been initiated.

Laboratory tests of cleaning methods for sample tubes are continuing. Preliminary data indicate that mechanical abrading increases the oxide contribution of the tube rather than decreasing it as had been supposed. 
A paper entitled "Techniques for Determining Impurities in Sodium Coolant" authored by R. F. Keough, K. C. Kno11, L. F. Lust and E. L. Osborne was presented at the Northwest Regional Meeting of the American Chemical Society on June 12.

c. Selection and Testing of FFTF Sodium-Sampling Methods

K. C. Knol1

Discovery and elimination of "bugs" in the prototype bypass loop sampler continues. Considerable difficulty has been encountered in maintaining the sample tube furnace at a uniform temperature. Several minor modifications have been made to improve temperature control and other performance characteristics. Plans are being made for the installation of smoke detector actuated solenoid operated valves and other necessary safety features to allow unattended operation of the sampler.

d. Selection and Testing of Cover Gas Instruments and Sampling Systems

G. B. Barton

Gas Sampling System Development. A new vapor trap design has been conceived and a prototype constructed. The new trap design is based on the premise that the bulk of the sodium which escapes conventional traps does so as an aerosol mist. The new trap design breaks the aerosol through a re-vaporization followed by a second condensation. The prototype is designed for three re-vaporization thermal cycles. Initial tests show considerable promise.

Theoretical calculations leading to scale factor recommendations for packed and baffle traps are underway and should be completed early in the next report period. 
e. Selection and Testing of In-Line Sodium Analysis Instruments J. J. McCown

(1) Oxygen Meter. The UNC oxygen meter continues to operate satisfactorily on the sodium purification 1oop. Several attempts to add carbon compounds to the loop had no effect on the oxygen meter. Chemical analysis indicated no change in the oxygen or carbon content of the loop

(2) Carbon Meter. A spectrographic grade carbon rod was placed in a bypass addition tube on the sodium purification loop and contacted with $600^{\circ} \mathrm{F}$ sodium for $40 \mathrm{hr}$. The carbon meter did not show any change in output signal during the test. Upon removal from the loop the carbon rod was found to be intact with no sign of erosion, etc. Chemical analysis showed no change in the total carbon content of the sodium ( $5 \pm 2 \mathrm{ppm})$.

f. Decontamination

G. R. B1oom

Chemical cleaning procedures used for decontaminating water reactors are being tested for the decontamination of sodium reactors. One proposed procedure would (1) oxidize a layer of stainless steel about $0.1 \mathrm{mils}$ deep, and (2) removed the oxidized layer with a standard water reactor decontamination process. The activation products diffused into the stainless steel would be oxidized along with the stainless steel. They would then be removed in the second step of the decontamination process along with the oxide film.

Samples from the dismantled Radioisotope Transport Loop were processed with a one cycle steam and citrate method and the results reported last month. One of the samples 
was recycled through the oxidation and the decontamination step, and recounted. Both the new and the old data are given below to give a comparison.

\begin{tabular}{ccc}
\multicolumn{2}{c}{$\begin{array}{c}\text { Decontamination } \\
\text { 1 Oxidation } \\
\begin{array}{c}\text { Decontamination } \\
\text { Cycle }\end{array}\end{array}$} & $\begin{array}{c}\text { 2 Oxidation } \\
\text { Decontamination } \\
\text { Cycles }\end{array}$ \\
\cline { 2 - 3 } $\mathrm{Co}^{60}$ & 2.4 & 2.1 \\
$\mathrm{Mn}^{54}$ & 1.1 & 1.9 \\
$\mathrm{Cr}^{51}$ & 1.6 & 2.4
\end{tabular}

The Co ${ }^{60}$ decontamination factor did not change, the apparent decrease was attributed to counting error. The $\mathrm{Mn}^{54}$ and $\mathrm{Cr}^{51}$ decontamination factors increased as another layer of metal was removed during the second oxidationdecontamination cycle. Calculated uniform penetrations from weight loss data were $0.3 \mathrm{mils}$ for the first cycle and $0.6 \mathrm{mils}$ for two cycles.

F. METALS, MATERIALS AND CODES

J. C. Tobin

1. Materials Applications

J. E. Irvin

a. Weldment Studies A. L. Ward, A. J. Love11

The objective of this study is to describe the effects of fast-reactor irradiation and environment on the tensile and creep-rupture properties of weldment materials. Information gained in this study will be used to specify welding mate. rials and procedures to provide optimum compatibility 
with the projected service conditions for the FTR vessel and core structural components.

Tensile testing of the as-fabricated Type 304 SS weldments has been completed to produce a testing matrix which includes four different welding processes (TIG, Submerged-Arc, Stick Electrode, and MIG), three specimen types (weld, fusion 1ine, and base meta1), and four testing temperatures. This matrix constitutes a base of tensile property information to be used in support of the weldment irradiation effects experiment.

After tensile testing, each specimen was macro-etched to distinguish weld metal from base metal. It was observed that, of the approximately 35 specimens containing base metal in the gage length, $75 \%$ fractured in the base metal. From a statistical view, it would appear that the base metal properties are limiting the test-to-failure behavior of the composite (weld, fusion line, HAZ, and base) weldment material. Of those facturing in weld metal, most had been tested at $900^{\circ} \mathrm{F}$ or previously annealed at $1200^{\circ} \mathrm{F}$, thus suggesting the possible effect of some transformation of de1ta ferrite to sigma phase in the weld metal. Metallographic examinations are in progress to confirm to confirm the presence of sigma phase in those specimens exposed to temperatures in the range of 800 to $1600^{\circ} \mathrm{F}$.

A cooperative study with ORNL is continuing to characterize the effect of delta ferrite in weld metals and also to develop reliable methods of measuring ferrite contents. The results of independent ferrite determinations on the TIG weldment by the QTM (ORNL) method and point count analysis (BNW) are in sufficient agreement to be consistent with nationally published error bands. 
A limited number of specimens are being tensile tested at $1100^{\circ} \mathrm{F}$ to support the creep-rupture portion of this work. All four weld processes will be tested in addition to the base metal test. In order to facilitate comparisons with literature data, a few tensile tests are being conducted at room temperature.

The design of a new tensile specimen with a 0.250 in. gage diameter and 1.125 in. gage length has been completed. Weldment specimens will be fabricated to this design and tested to confirm the properties data obtained from the subsized specimens.

Creep-rupture tests on Submerged-Arc specimens at $1100^{\circ} \mathrm{F}$ are in progress. The preliminary results from two short term tests indicate lower rupture lives by a factor of 15 when compared to Type 304 SS rod stock specimens in the $1950^{\circ} \mathrm{F}$ solution annealed condition. Additional creep-rupture tests are in progress to evaluate this gross difference in rupture properties.

b. Subcritical Crack Growth E. B. Schwenk, L. A. James

The objective of this program is to determine the slow crack extension behavior (i.e. subcritical crack growth) of the Fact Test Reactor Primary Piping system material. Such data will provide a basis for estimating the life expentancy of flaw-containing piping components for simulated environment and service conditions.

Initial work in this program centers on determining the fatigue crack growth behavior of Type 304 SS with respect to analysis by the crack propagation power law for temperatures and environments expected to be characteristic of piping system operation. This information will provide a basis for reasonable estimation of the remaining fatigue life in piping system components using fracture mechanics analysis techniques. 
Tests now in progress are being conducted on $1 / 2$ inch thick Type 304 SS characterized under the Irradiation Effects to Reactor Structural Materials Program.

Figure 4.F.1 shows a plot of average crack length, a, (average of measurements on both sides of specimen) versus cycles, N, to failure and Figure 4.F.2 is the corresponding $\Delta \mathrm{K}$ versus $\mathrm{da} / \mathrm{dn}$ curve. The data shown in Figure 4.F.2 have not yet been corrected for plasticity effects. Thus the magnitude of $\Delta K$ for crack growth rates greater than about $10^{-4}$ in./cycle probably does not reflect the actual crack tip stress state.

c. Radiation Effects on Absorbing Materials for Control Rods

A. L. Pitner

Profilometry tests were performed on the cladding of the boron carbide capsules BC-1 and BC-4 which were irradiated in EBR-II. Measurements were made on three indexed axes $120^{\circ}$ apart, just as in the pre-irradiation measurement. No change in the cladding profile of either capsule was detectable. Following the profilometry, the capsules were each sectioned into five equal seqments approximately 1.2 in. 1 ong. The compacted powder was removed with considerable effort from each section using a vibra-tool. The $\mathrm{B}_{4} \mathrm{C}$ appeared to be sintered in the cladding, but once the sample was removed it again had the appearance of a fine powder. A sieve analysis will determine whether any sintering did occur.

The first assembly of the Hanford $\mathrm{B}_{4} \mathrm{C}$ irradiation, designed to operate at sample temperatures of 1100 and $1300^{\circ} \mathrm{F}$, increased in temperature so that it is now operating at 600 to $1200{ }^{\circ} \mathrm{F}$. The second assembly, designed for 700 and $900{ }^{\circ} \mathrm{F}$ operation, was running at temperatures from 500 to $700^{\circ} \mathrm{F}$ just after startup was accomplished. Behavior of the first assembly, however, would indicate that these temperatures will increase 


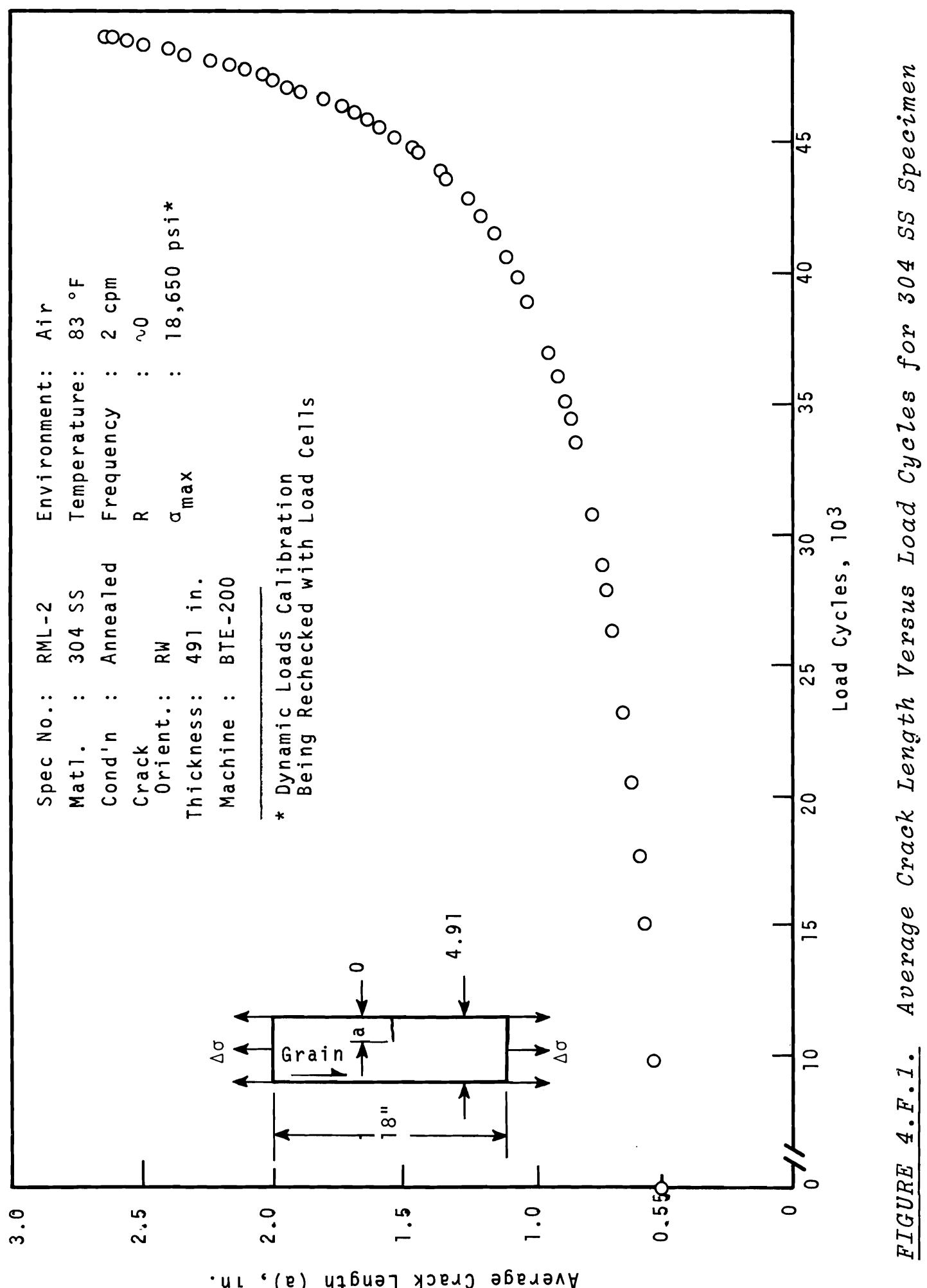


BNWL -1133

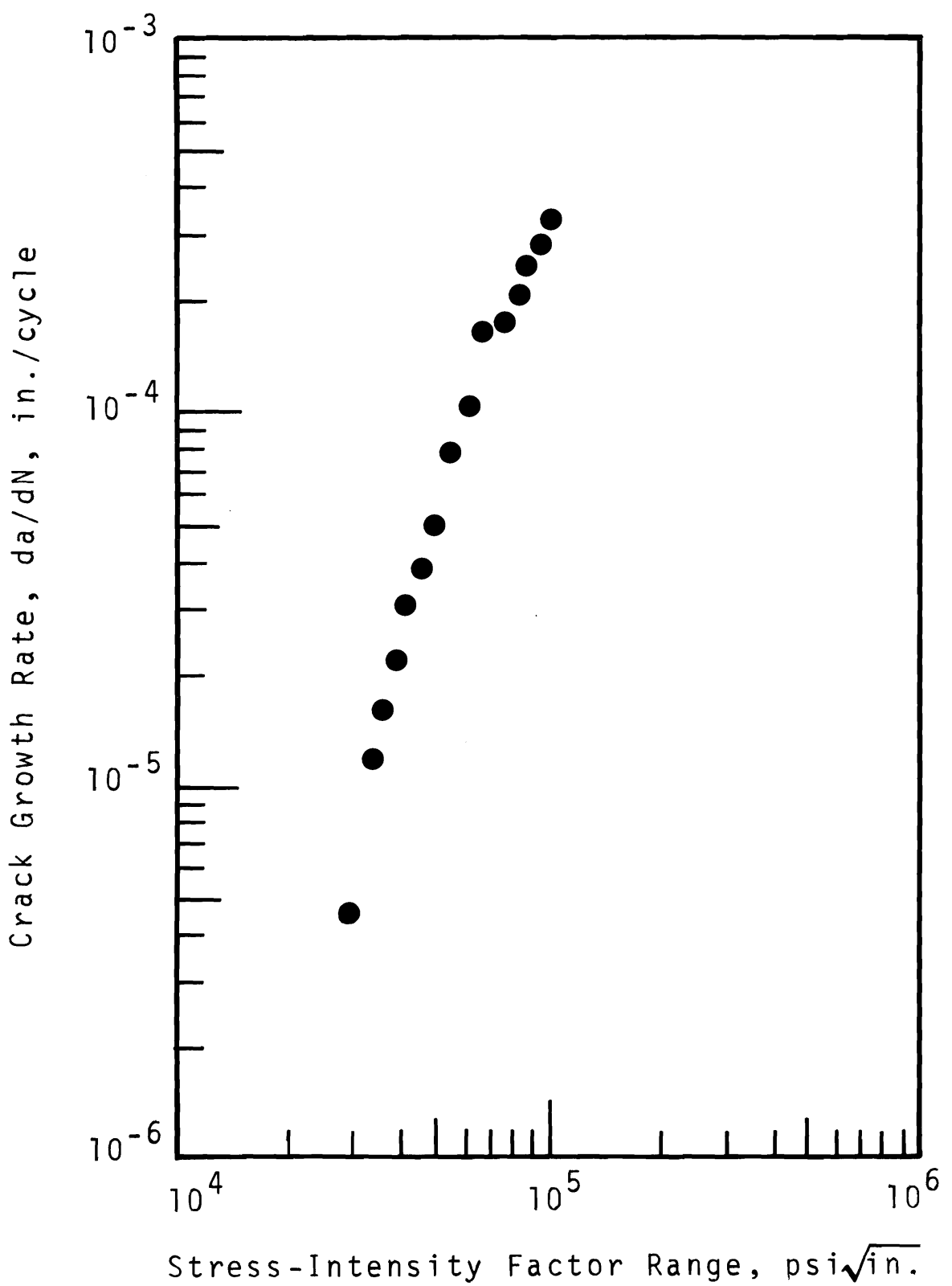

Specimen No.: RML-2

Temperature: $83^{\circ}$

Maximum Stress: 18,650 ps $i^{*}$

Thickness : 0.491

Material : 304 SS Annealed

Stress Ratio: $\sim 0$

Width : 4.91

Specimen Type: SEN

Frequency : $2 \mathrm{cpm}$

Environment : Air

Orientation : RW

Date Tested : $5,6 / 69$

* Dynamic Loads Calibration

Being Rechecked with Load Cells

FIGURE 4.F.2. Crack Growth Rate of 304 SS Plotted Versus Stress Intensity Factor 
gradually with time. It is felt that the lower-than-design temperatures are probably resulting from the additional flux depression evident in the irradiation assemblies. Considerably more $\mathrm{B}_{4} \mathrm{C}$ "poison" is present in the irradiation assemblies than was in the Snout-capsule heat transfer test performed last year.

2. Fabrication Development

R. N. Johnson

The objective of this program is to develop and evaluate fabrication processes required to produce components for the FTR. Development, evaluation, and qualification of commercial sources of supply is a program goal; and where components such as fuel ducts and test loops must be routinely replaced, the establishment of two or more competitive and continuing sources of supply is an additional objective.

a. Duct Welding Development

W. F. Brown

The automatic tube welding machine was inspected by BNW representatives at the Vendor's plant on May 22-23, 1969. The machine did not perform in accordance with the purchase specifications.

In order to determine the feasibility of making simultneous spot welds on opposite faces of the hex duct, a series of simultaneous welds were made between pairs of unaged Inconel 718 and Type 304 SS with 4-in.-thick solid copper back-up and current conducting bar. Peel tests and tensile-shear tests were used for preliminary evaluation to establish a starting weld schedule. The results indicated that simultaneous welds can be made with the proper fixtures. For further tests, an adjustable copper back-up and current conducting fixture was made. This fixture will be inserted inside the hex tubes to conduct welding current to opposite faces and to prevent tube distortion. 
b. Duct Gaging and Characterization

R. N. Johnson, R. H. Todd

A Request for Proposal for the duct gaging and characterization system was sent to twenty potential vendors on May 16, 1969. Nine of the 20 vendors so far have declined to submit proposals and one has replied that he will definitely submit a proposal. No replies have yet been received from the other 10 vendors.

c. Duct Procurement Activities

R. N. Johnson

A Request for Proposal for the fabrication of the prototype fuel ducts was sent to 12 potential vendors on May 26, 1969.

d. Closed Loops - Procurement Activities S. M. Gill

Present plans call for the off-site manufacture of two prototypical closed loop tube assemblies, with delivery to BNW by July 1971 and installation in the Prototypical Closed Loop Test Installation by January 1972. Activity is currently underway on preparation of a Request for Proposal with the intent of contracting with a supplier for these assemblies within three to four months.

Preliminary effort has involved vendor evaluation to determine interest and to ensure adequate and competitive proposals. As a result of specific contacts and advertising, a list of eight probable qualified firms is available.

At the present time specifications and drawings for the RFP are being finalized and reviewed. The proposed design has been discussed with WARD personnel and their concurrence received. 


\section{Component Surveillance}

J. W. Helm

\section{a. Inservice Inspection Requirements}

J. H. $\operatorname{Cox}$

The report Surveillance and Inservice Inspection

Requirements for the FFTF has been issued to the project for comments.

The purpose of this report is to recommend specific surveillance and inspection requirements, methods to perform examinations to meet the requirements, design requirements to permit the inspections, and the necessary development of the methods. The report is based on the ASME (N-45) Code for Inservice Inspection, (1) and on requirements studies by Westinghouse Advanced Reactors Division (2) and Southwest Research Institute. (3) In some cases, discussions from the latter two reports are used without modification.

b. FFTF Periscope W. J. Coleman, J. D. Jensen

The conceptual design of an optical periscope suitable for use in inspection of the FFTF reactor vessel is continuing. The periscope assembly will consist of a head which contains the viewing prism and collecting optics, an objective section, an extendor section, and the eye piece section. Conceptual design of the periscope head has been completed.

(1) ASME,USA Standard Code for Inservice Inspection of Nuclear Reactor Coolant Systems, october 1968.

(2) Buggy, J.J., D. L. and Paxson, E., Surveillance and Inservice Inspection Recommendations for the FTR: Techniques, Program Development, Westinghouse Electric Corp. Advance Reactors Division Report, WARD-3977-1, February 1969.

(3) Wylie, R. D., et al, Criteria for Surveillance and Inspection of the Fast Flux Test Facility, Southwest Research Institute, Report SWRT 17-2552-01-A, May 1969. 


\section{FFTF FUELS DEVELOPMENT}

\section{E. A. Evans}

\section{A. FUEL ELEMENT DEVELOPMENT}

C. A. Burgess

1. Subassemb1y Development Section

J. W. Thornton

a. Project Status

(1) BCP-034 - Subassemb1y Assemb1y. BNW received a directive from AEC-RL during the week of May 18, to proceed with the construction phase of this project. The design work of the facility is $100 \%$ complete. The demolition work in Room 138 is $90 \%$ complete while the overall project is $8 \%$ complete.

The cleaning tanks to be installed under this project have been designed and are being fabricated in the Technical Shops .

(2) BAP-022 - High Bay Addition. This project was approved at AEC Headquarters in May. A directive was received by BNW from AEC-RL to proceed with the design phase of this project.

2. Process Development and Demonstration

R. E. Bardsley

a. Fabrication of 300 Fuel Pins for Criticality Studies C. A. Strand, G. E. Sammis, H. T. Blair

Fabrication of the 300 FFTF type fuel pins for criticality studies is continuing in the FFTF fuel pilot line. A total of 98 fuel pins has been assembled. A total of $27 \mathrm{~kg}$ of mixed oxide powder has been processed and $14 \mathrm{~kg}$ of mixed oxide fue 1 pellets were debound and sintered. The $0 / \mathrm{M}$ results obtained 
from these sintering runs indicate that the $0 / M$ may be a function of the furnace load mass as well as the sintering temperature. An average of $4.1 \mathrm{wt} \%$ of the pressed green pellets is lost as volatiles in the debinding process. Another $0.9 \mathrm{wt} \%$ is lost as volatiles during sintering.

The pellet grinding, pellet gauging, and fuel pin loading hoods and their associated equipment became operational during the month.

The capability for sintering fuel pellets to size through control of die size and forming pressure was demonstrated. Two different process lots involved in this demonstration were debonded and sintered in separate runs. Debonding and sintering conditions were held constant for the two runs involved. Table 5.A.I shows some of the pertinent data concerning each of the batches. Figure 5.A.1 is a frequency distribution of the sintered pellet diameters measured at both ends of the pellets. The minor difference between batches A-6-S18 and B-2-S19 is probably because they originated as two separate processing lots.

\section{TABLE 5.A.I. Fuel Pellet Debonding and Sintering Run Data}

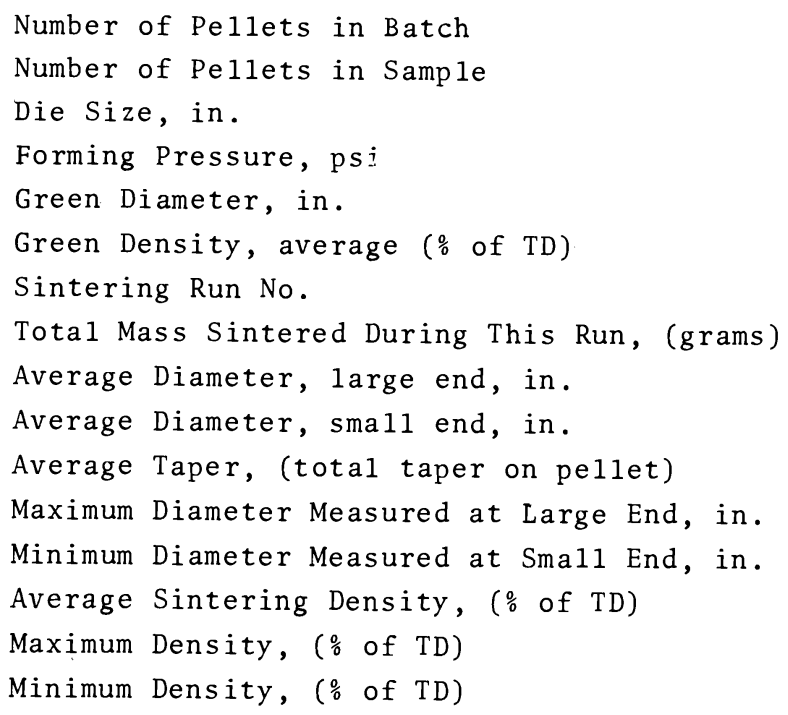

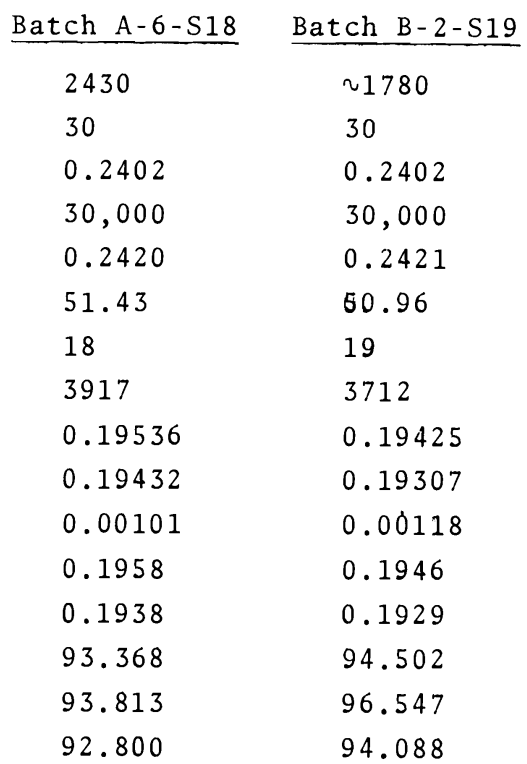



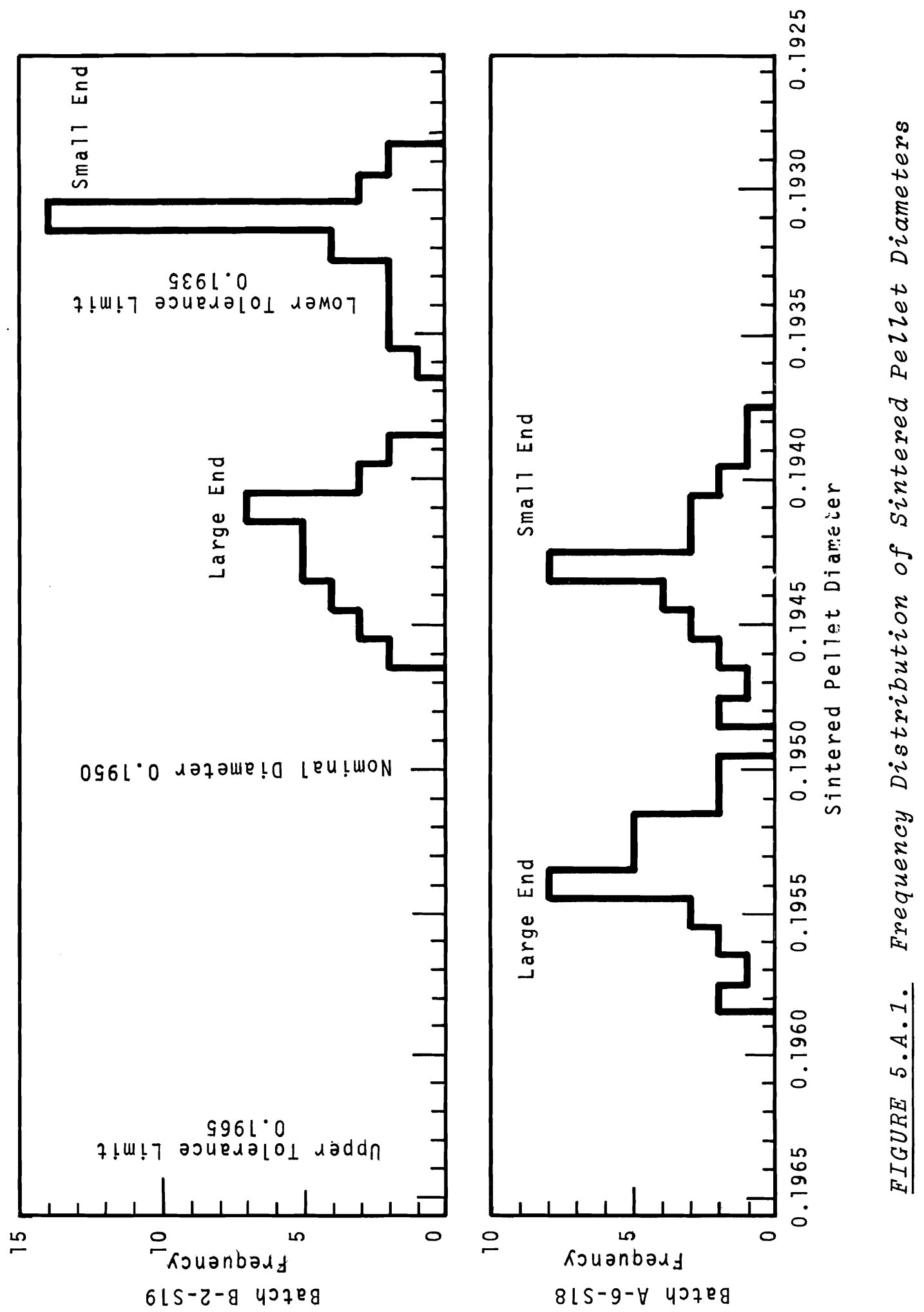
b. Process Development M. J. Barr

(1) Fractional Factorial Experiment. Approximately 10 sintering runs remain to be completed. Current priorities permit one run per week with possibilities of two runs per week after July 1, 1969.

(2) $\mathrm{PuO}_{2}$ Sinterability Tests. Additional oxalate precipitated and calcined plutonia (ARHCO Lot 28-10-31) was obtained for evaluation. Preliminary data indicate sintered densities similar to those previously obtained with ARHCO Lots 28-3-7, 28-9-8, and 28-9-26 were produced. Test data were obtained on as-received powder for ARHCO-calcined to $425{ }^{\circ} \mathrm{C}$ and PNL-calcined to $625{ }^{\circ} \mathrm{C}$. Powders were pressed without binder or additional processing and were sintered in dry $\mathrm{Ar}-8 \% \mathrm{H}_{2}$ atmosphere to $1640{ }^{\circ} \mathrm{C}$ for 4 hours. A11 densities are given in percent theoretical. Data for Powder Lot 28-10-31 are as follows :

\begin{tabular}{|c|c|c|c|c|}
\hline $\begin{array}{c}\text { Calcined } \\
\text { Temperature, } \\
{ }^{\circ} \mathrm{C} \\
\end{array}$ & $\begin{array}{c}\text { Green } \\
\text { Density, } \\
\frac{o}{0} \text { TD } \\
\end{array}$ & $\begin{array}{c}\text { As-Sintered } \\
\text { Density, } \\
\frac{0}{0} \text { TD } \\
\end{array}$ & O/M Ratio & $\begin{array}{c}\text { Sintered } \\
\text { Density } \\
\text { After } \\
\text { Oxidation, } \\
\frac{0}{0} \text { TD } \\
\end{array}$ \\
\hline 425 & 50.47 & 77.59 & 1.83 & 79.15 \\
\hline 625 & 57.15 & 77.78 & 1.83 & 79.41 \\
\hline
\end{tabular}

The as-sintered density was calculated using a theoretical density of $11.46 \mathrm{~g} / \mathrm{cm}^{3}$. When lattice parameters at the $0 / \mathrm{M}$ ratio of 1.83 are considered, the actual theoretical density of the as-sintered pellets is approximately $82.5 \%$. The discrepancy between the theoretical $82.5 \%$ and observed $79.3 \%$ (average after oxidation to an $0 / M$ of 2.00 ) is being investigated. 
3. Special Products Fabrication Section

E. T. Weber

a. Assembly of Test Pins for Irradiation in EBR-II

R. M. Crawford

Forty-five fue 1 pins for PNL-7 were completed and are ready for final visual inspection and shipping. This number constitutes the total requirement of 37-pins for immediate assembly, plus eight spares for PNL-7.

The xenon tagging of the first 20 pins for PNL-7 was witnessed by a representative of ANL. All pins in this subassembly were xenon tagged.

Fifty percent of the fuel pellets for PNL- 8 were characterized and are ready for loading. Fifty percent of the cladding tubes for PNL-8 were air gaged, bottom closure welds completed, radiographed, and made ready for loading.

b. Fue1 Fabrication for Test Pins for Irradiation in EBR-II

W. E. Warden

Fuel fabrication for EBR-II subassembly PNL- 6 is in process. This fuel consists of $30 \%$ enriched $\left({ }^{235} U\right)$ in the EBR-II test composition of $75 \% \mathrm{UO}_{2}-25 \% \mathrm{PuO}_{2}$. Five $\mathrm{kg}$ of PNL- 6 mixed oxide fuel pellets have been sintered to the required density range $(93 \pm 2 \% \mathrm{TD})$. Two additional $\mathrm{kg}$ of fuel pellets have been pressed and are in the sintering process.

Fue 1 fabrication for EBR-II subassembly PNL-17 is in process in Line No. 2 of the FFTF Fuel Process Demonstration Facility. This fue 1 consists of $65 \% 235_{\mathrm{U}}$ enrichment in the EBR-II test composition of $75 \% \mathrm{UO}_{2}-25 \% \mathrm{PuO}_{2}$. Seven $\mathrm{kg}$ of PNL-17 mixed oxide were processed through the powder preparation operations. 


\section{c. Fabrication of Fuel and Special Test Pins for Irradiation Tests Under Task FP-3 W. E. Warden}

Fue 1 pellet fabrication for one density range ( $94 \%$ TD) has been completed. This fuel is normal $\mathrm{UO}_{2}$ and oxalate $\mathrm{PuO}_{2}$ of composition $75 \% \mathrm{UO}_{2}-25 \% \mathrm{PuO}_{2}$. Three $\mathrm{kg}$ of this fuel were sintered to the required density in producing $0.320-$ in. diam fuel pellets.

Seven of the eight fuel pins requested for 2-pin calibration test capsules were completed. Eight fuel pins for capsule FP-33 (Gap Closure Experiment) were assembled. The two fue 1 pins requiring a helium atmosphere were completed and the six fuel pins requiring various helium-xenon mixtures were processed to the xenon tagging operation.

\section{B. FUELS QUALITY ASSURANCE}

N. G. Powers

1. Development and Control of Inspection and Testing

a. U1trasonic Cladding Tester

J. Ryden Jr., E. F. Perrizo, A. C. Callen

The laboratory ultrasonic cladding tester has been set up to inspect $0.230-i n$. OD tubing. On a recently-fabricated standard made of $20 \%$ cold worked TP 316 cladding, EDM notches as small as $0.7 \mathrm{mil}$ in depth were detected.

b. Fue1 Pin Tubing Thickness Measurement J. L. Thompson, F. M. Coffman, A. C. Callen

A Branson Vidigage was examined to determine whether it could resolve wall thickness of 0.230 -in. OD by nominal $0.015-$ in. wall tubing to $0.0001-i n$. A special transducer and oscillator were procured, as recommended by Branson Instruments, and evaluation performed on a piece of tubing with a measured ring of wall varying from 0.01470 to 0.01505 in. No difficulty 
was encountered in recording the thickness to $2 \times 10^{-5}$ in. resolution, the approximate accuracy of the precision mechanical measurement of the tube wall thickness. Thermal drift of the Vidigage is noticeable over a long period (i.e., tens of minutes) but has not yet been accurately measured for determination of test statistics.

In the actual tubing test to be used early in the month of June, the tubing will be rotated at $1450 \mathrm{rpm}$. The Vidigage capability for measuring at a rate of 1800 per minute will provide thickness readings every $0.1 \mathrm{in}$. on the circumference of the tube. The resulting change of thickness occurring each 16 msec requires a circuit to hold each value for the maximum possible time to permit even a high speed recorder to indicate each value. Such a circuit has been built to do this and will be incorporated into the overall test.

\section{c. Particle Size M. W. Urie, W. L. Delvin}

The cooperative work between Urie and Daniel, reported last month, was completed. The electron micrographs obtained by Daniel of the $\mathrm{PuO}_{2}$ dispersions made by Urie showed reasonable correlation with the distribution curves obtained by Urie using the MSA particle size analyzer. The data show that the higher $\mathrm{PuO}_{2}$ is fired and the longer the dispersion time, the finer the particles will be.

\section{d. X-Ray Fluorescence D. S. Skeie, W. L. Delvin}

Initial results to determine the $\mathrm{U} / \mathrm{Pu}$ in solid, mixed oxide were both encouraging and discouraging. Good straightline calibration curves were obtained using standards prepared in the laboratory. Those curves were reproducible to within $5 \%$. However, when a sintered pellet was crushed and measured, the $\mathrm{U} / \mathrm{Pu}$ obtained was 5 to 1 instead of the actual 3 to 1 
BNWL -1133

make-up value confirmed by laboratory analysis. A1so, the unsintered, mixed oxide powder from which the pellet was made showed a 5 to 1 ratio. Plans call for assaying the standards by the laboratory to check their make-up.

e. Emission Spectrography

A. S. Wilson, K. M. Maloney, R. R. Rhodes,

R. Ko, W. L. Delvin

A UO $\mathrm{U}_{2}$ sample was analyzed by the emission spectrograph and by the spark source mass spectrograph. The following tabulation compares the results. Only those elements detected by one or both of the instruments are shown. The results are good to within a factor of 2 and 3 for the emission spectrograph and spark source, respectively.

Element Emission Spec, ppm Spark Source, Detection Limit (a)

$\begin{array}{lllc}\mathrm{Al} & ---(\mathrm{b}) & 3 & 5 \\ \mathrm{~B} & <0.1 & --- & 0.1 \\ \mathrm{Ca} & <2 & 1 & 2 \\ \mathrm{Cr} & 5 & 5 & <5 \\ \mathrm{Cu} & 0.5 & --. & 0.2 \\ \mathrm{Fe} & 100 & 50 & 50 \\ \mathrm{Mg} & 100 & 30 & <5 \\ \mathrm{Mn} & 5 & 0.2 & 1 \\ \mathrm{~K} & --- & 1 & 20 \\ \mathrm{Na} & -- & 4 & 2 \\ \mathrm{Ni} & <5 & 0.5 & 5 \\ \mathrm{Sb} & <10 & --- & 10 \\ \mathrm{Si} & <10 & --- & 10 \\ \mathrm{~V} & <50 & --- & 50\end{array}$

a. Detection limits have not been established yet in a $\mathrm{UO}_{2}$
matrix for spark source. b. Not detected. 
An estimate of detection limits for six elements in $\mathrm{UO}_{2}$ by spark source was made. Estimates of these elements, not determinable by emission spectrograph, are as follows:

Estimated

Element Detection Limit, ppm

$\begin{array}{lr}\text { W } & 2 \\ \mathrm{C} 1 & 2 \\ \mathrm{~S} & 10 \\ \mathrm{~F} & 1 \\ \mathrm{~N} & 1 \\ \mathrm{C} & 1\end{array}$

No work has been done yet to check the validity of those estimates.

2. Quality Assurance Systems and Procedures

a. Follower and Data Card System D. A. Stranik

A complete description of the card system and the cards has been written along with a flow diagram showing the flow of the data. The cards are at present being upgraded and finalized. The system description has been incorporated into the draft of the Fuels Quality Assurance Manual.

b. Fue1s Quality Assurance Manual

J. D. Schaffer, D. A. Stranik, W. F. Stevenson

A completed draft of the Fuels Quality Assurance Manual was distributed for comment. This manual (in three volumes) adheres to the following outline:

FFTF Fuels Quality Program

Introduction

Scope

Objectives

Organization and Administration

Quality Organization and Interfaces

Supporting Documents/Procedures/Systems 


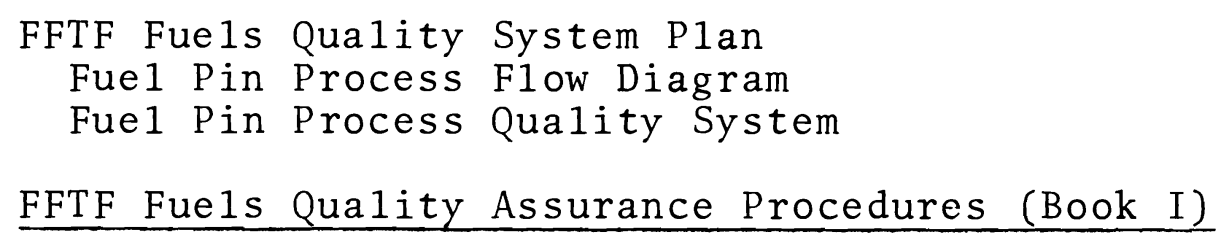

Statistica1 Quality Program

Calibration and Standards

Qualification and Certification

Design Reviews

Control of Suppliers

Inspection and Test

Inspection and Test Methods (See Book II)

Nonconforming Material

Data Card System

Handling, Packing, Storing, Shipping

Audits

FFTF Fue1s Quality Assurance Procedures (Book II)

Inspection and Test Methods

Analytical Chemistry Methods

Nondestructive Test Procedures

Helium Leak Testing

Sinterability Performance Test - UO

Sinterability Performance Test - $\mathrm{PuO}_{2}$

Reference Standards

A program of comments collection, accuracy upgrading, and trial application is underway.

C. CLADDING DEVELOPMENT

T. T. Claudson

1. Cladding Development and Processing

J. C. Tverberg

a. Procurement Activities

R. J. Lobsinger

(1) Plenum Springs. Incone $1 \mathrm{X}-750$ plenum springs were ordered from an alternative vendor after the original vendor failed to produce acceptable springs. These springs will be used in EBR-II subassemblies PNL-9, 10, and 11 , as well as the prequalification subassemblies. 
(2) FFTF Fue1 Cladding. Carpenter Technology Corporation, while producing tubing conforming to the ultrasonic inspection specification, has indicated a desire to produce fuel clad tubing far exceeding the specification requirements. To this end, the mandrels will be polished to an extremely fine surface finish and all cutting will be done with an electrolytic cutoff saw to avoid introducing metal chips into the system.

b. Vendor Development J. C. Tverberg

Work has begun with three contractors on the Vendor Development Program. Tube drawing is well underway at Sandvik Stee1, Incorporated. Wolverine Tube has placed an order for a special 4000-1b heat of 316 stainless steel with Allegheny Ludlum, delivery of which has been promised for August 15, 1969 at the latest. Carpenter Technology has made the basic vacuum induction heat of $8000-1 b$ of 316 stainless steel and is awaiting analyses before making the final consumable arc remelt ingot.

\section{c. Parameter Studies}

R. C. Aungst, R. J. Lobsinger, R. R. Studer

General Electric, at Cincinnati, Ohio is on schedule in preparing a series of ingots to study the effect of variations in chemistry and melting practice on tubing quality. Four master heats of 400-1b each have been cast from which smaller test heats will be made by remelting and the chemistry adjusted.

The basic fabrication parameter study conducted by ORNL has yielded the instrumented extrusion of six billets into tube hollows. The next portion of the work will include melting of ingots in which the nitrogen and carbon will be varied within specified limits and the instrumented reduction of tube hollows on the special tube reducer and draw bench will be provided. 
Initial results with the nondestructive cold work-grain size device were very encouraging. Specimens with known cold work and known grain size were distinguishable. Work is now starting using tube specimens with known levels of cold work.

Use of X-ray diffraction to distinguish different levels of cold work also have been quite successful. It is possible to obtain a better degree of resolution on varying degrees of cold work than earlier thought. Work is now underway to determine whether a texture difference exists between tube reduced and drawn material.

2. Cladding Evaluation

J . J. Holmes

\section{a. Biaxial Stress-Rupture Studies}

R. W. Barker

The objective of this program is to determine the effects of fast reactor irradiation on the biaxial stress-to-rupture properties of candidate fast reactor cladding alloys.

Biaxial stress-rupture tests on AISI Type 316 SS irradiated in EBR-II to $0.18 \times 10^{22} \mathrm{n} / \mathrm{cm}^{2}$ ( $\mathrm{E}>0.18 \mathrm{MeV}$ ) were initiated during the May, 1969 reporting period. Tests at short rupture times and $1200^{\circ} \mathrm{F}$ were completed and data reported. The rupture strain for one test was omitted due to the timing of the test failure with respect to the reporting period. The measured strain for this specimen (test conditions were 30,000 psi hoop stress and $1200^{\circ} \mathrm{F}$ ) was $2.4 \%$ as shown in Table 5.C.I.

The irradiation temperature for the biaxial stressrupture specimens irradiated in EBR-II subassembly X-022, previously estimated to be about $1000^{\circ} \mathrm{F}$ based on $\mathrm{X}$-rays of fusible metal alloys in stainless steel capsules after irradiation, has been re-examined. On the basis of Oak Ridge National Laboratory gamma heat experiments in EBR-II, Row 7, the irradiation temperature is calculated to be $815^{\circ} \mathrm{F} \pm 20$. 


\section{TABLE 5.C.I. Biaxial Stress-Rupture Tests on AISI Type 316 SS Irradiated to vo.8 $1022 \mathrm{n} / \mathrm{cm}^{2}$ ( $E>0.1 \mathrm{MeV}$ ) in EBR-II. Test Temperature was $1200^{\circ} \mathrm{F}$. The Irra- diation Temperature was $815^{\circ} \mathrm{F} \pm 80$.}

Unirradiated Data (a)

\begin{tabular}{|c|c|c|c|c|c|c|}
\hline $\begin{array}{c}\text { Hoop } \\
\text { Stress, } \\
\text { psi }\end{array}$ & $\begin{array}{c}\text { Rupture } \\
\text { Time, } \\
\mathrm{hr} \\
\end{array}$ & $\begin{array}{c}\text { Rupture } \\
\text { Strain, } \\
\frac{o}{0} \\
\end{array}$ & $\begin{array}{l}\text { Irradiated } \\
\text { Test No. }\end{array}$ & $\begin{array}{c}\text { Hoop } \\
\text { Stress, } \\
\text { psi }\end{array}$ & $\begin{array}{c}\text { Rupture } \\
\text { Time, } \\
\text { hr } \\
\end{array}$ & $\begin{array}{c}\text { Rupture } \\
\text { Strain, } \\
\frac{\%}{0} \\
\end{array}$ \\
\hline 42,000 & 0.1 & 15 & & & & \\
\hline 36,000 & 1.0 & 10 & 12 & 36,000 & 2.1 & 1.9 \\
\hline 30,000 & 10.0 & 7 & 13 & 30,000 & 32 & 2.4 \\
\hline 24,500 & 100.0 & 5 & & & & \\
\hline
\end{tabular}

a. Stress and strain values were taken from unirradiated test curves at rupture times shown.

The test rigs are developing leaks through repeated use, and operation has become difficult. Especially difficult has been maintenance of high pressures for long periods of time. Similar problems are also common at other laboratories.

In order to alleviate the problem of gas leakage, a new group of test rigs is being constructed. The rig design will be modified slightly by utilizing Aminco high pressure fittings wherever possible, rather than the Swagelok brand fitting, to obtain greater reliability.

Anomalies in test specimen behavior were observed in 316 specimens at a test temperature of $1400^{\circ} \mathrm{F}$. Three short term biaxial stress tests were initiated on irradiated material at this temperature and all three failed at the lower plug cladding-weld interface. It is not completely understood whether this phenomena is a function of the postirradiation condition or the welding process. In either case, specimens are being mounted with mechanical seals only. Biaxial stressrupture testing using the mechanically sealed specimens is continuing. 
BNWL - 1133

b. Damage Analys is

J. L. Straalsund and H. R. Brager

The objectives of this effort are to establish the irradiation induced swelling characteristics of FFTF alloys, to relate fast reactor induced substructural changes in microstructure to corresponding changes in mechanical properties, and to develop means for data extrapolation using both microscopic modeling and empirical approaches.

Density measurements on sections from an EBR-II safety rod thimble were reported with the corresponding exposures in a previous monthly report. Further consideration of the data available indicates that the specimens were at a different position with respect to the mid-plane than had been reported. The corrected data are given in Table 5.C.II.

\section{TABLE 5.C.II. Irradiation Induced Swelling in EBR-II Safety Rod Thimble}

Distance from Mid-Plane, in.

20.8
15.0
10.0
8.0
5.5
3.0
0.5
-2.0
-4.0
-9.0
-14.8
-19.8

F1uence $\times 10^{-22}$ $\mathrm{n} / \mathrm{cm}^{2}, \mathrm{E}>0.1 \mathrm{MeV}$

$$
0.36
$$

1.28

2.62

3.46

4.80

5.89

6.40

6.14

5.57

2.62

1.34

0.601
Temperature, ${ }^{\circ} \mathrm{F}$

872

852

826

810

786

756

732

718

710

700

700

700
Swe11ing, $\Delta \rho / \rho, \frac{\circ}{\circ}$

0.14

0.41

0.93

1.55

2.44

3.09

2.41

1.53

0.87

0.47

0.27

0.11 
BNWL -1133

In the previous monthly report, a least mean square fit was made to selected swelling data for annealed 304 stainless stee1. The equation used in developing a swelling equation for design guidance was based partly on the safety rod thimble data, and the analysis was repeated using the corrected data. Although the revised equation indicates slightly more fluence and temperature dependence, the differences are quite small in comparison with the uncertainties involved and change of the interim design equation reported last month does not presently appear necessary.

The classical theories of homogeneous nucleation have been reviewed and applied to the formation of voids in the presence of an irradiation produced vacancy supersaturation to compare predicted with experimentally observed trends.

The variation in nucleation rate with flux predicted with classical nucleation theory is as follows:

$$
I=A^{\prime}(\phi)^{3-6}
$$

where

$$
\begin{aligned}
I & =\text { nucleation rate } \\
A & =\text { constant } \\
\phi & =\text { flux }
\end{aligned}
$$

The observed void production rate, however, varies in an approximately linear fashion with flux. Thus, the classical nucleation theory appears to predict a much higher flux dependency for the nucleation rate than is observed where typical experimental values for the pertinent parameters are used.

c. Mechanical Testing of Fuel Pin Cladding

R. L. Fish

The purpose of this program is to provide a basis for evaluating the combined effects of fuel-cladding interaction, fluence, and operating temperature on the postirradiation 
burst and stress-rupture properties of the cladding. Specimens cut from irradiated PNL fueled subassembly pins are mechanically sealed and pressurized in a totally enclosed test vesse 1 in the hot cell facilities of the 324 Building.

Three specimens have been successfully burst tested thus far. The history and test results for these specimens are tabulated in Table 5.C.III. Additional burst tests on specimens taken from the PNL-1 subassembly are planned for temperatures of 1000 and $1200^{\circ} \mathrm{F}$. These tests will be used for determining subsequent stress-rupture test pressure values for the other PNL-1 subassembly specimens.

\section{TABLE 5.C.III. Specimen History and Burst Test Results}

\begin{tabular}{|c|c|c|c|c|c|}
\hline Specimen & $\begin{array}{c}\text { F1uence } \\
\mathrm{E}>0.1 \mathrm{MeV}\end{array}$ & $\begin{array}{l}\text { Operating } \\
\text { Temp, }{ }^{\circ} \mathrm{F} \\
\end{array}$ & $\begin{array}{l}\text { Test } \\
\text { Temp, }{ }^{\circ} \mathrm{F} \\
\end{array}$ & $\begin{array}{l}\text { Hoop } \\
\text { Stress } \\
\text { at Inside } \\
\text { Diam, psi } \\
\end{array}$ & $\frac{\Delta \mathrm{D}}{\mathrm{D}, \%}$ \\
\hline $\begin{array}{l}\text { Unirradiated } \\
\text { Lot "E" } \\
\text { Cladding }\end{array}$ & $\ldots$ & $\ldots$ & 900 & $\begin{array}{l}57,700 \\
\text { psi }\end{array}$ & 19.2 \\
\hline $\begin{array}{l}\text { PNL 1-6 } \\
\text { Plenum } \\
\text { Region }\end{array}$ & $\sim 1.2 \times 10^{21}$ & $\sim 890$ & 900 & $\begin{array}{l}59,800 \\
\text { psi }\end{array}$ & 18.4 \\
\hline $\begin{array}{l}\text { PNL 1-6 } \\
\text { Fue 1ed } \\
\text { Specimen }\end{array}$ & $i 3.2 \times 10^{21}$ & $840-850$ & 899 & $\begin{array}{l}73,100 \\
\text { psi }\end{array}$ & 9.6 \\
\hline
\end{tabular}


BNWL -1133

\section{FUELS EVALUATION}

J. E. Hanson

1. Task FP-2

a. Thermal Irradiation of $\mathrm{UO}_{2}+\mathrm{PuO}_{2}$ Fuel Pins

G. E. Culley, E. O. Ballard, S. H. Christensen and N. D. Mills

A section was cut from the fuel pin at the position of the lower axial fuel motion restrictor, 10.3 in. from the bottom of the fuel column. In addition to the fuel restrictor interface, this section shows what appeared on the neutron radiographs as a pellet separation that had been bridged with fuel. The fuel in this region operated at approximately $12.7 \mathrm{~kW} / \mathrm{ft}$ and shows a well formed central void, columnar grains, and apparently a lesser degree of cracking than the lower-powered sections. The perturbation in the heat transfer path caused by the presence of the floating type axial fuel motion restrictor is readily apparent. It is also apparent that the pellet separation has been bridged by fuel. The bridge occurs only in the grain growth region and, by the shape of the central void, the mass transfer to provide the bridge material was from both the upper and lower pellets. The beta-gamma autoradiograph, showing the typical outline of the grain-growth region, indicates an accumulation of fission products in this region.

The next section taken was the peak power $(13.7 \mathrm{~kW} / \mathrm{ft})$ transverse section. It is characterized by a slightly off center central void, columnar grain growth, and fuel in contact with the cladding. The fuel is not as badly cracked as the lower power sections, although some fallout did occur in this section during preparation. The beta-gamma autoradiograph also shows the ring outlining the grain growth region. 
The last section to be taken was cut at the upper central void terminus. The micrograph shows the terminus of the central void, although the grinding of the sample was slightly skewed and some additional central void is evidenced by the beta-gamma autoradiograph. Aside from the normal grain structure and central void, the most predominant feature of this sample is the presence of a rather large pellet separation through which the cladding can be seen. This separation did not appear on the neutron radiographs. However, the gamma scan taken of the capsule and the one taken of the fuel pin gave conflicting indications of pellet separations in this area. Judging from the appearance of the cut ends, it appears that the bottom end of the fuel had moved with respect to the cladding after the cutting operation. This is significant in that, although the fuel-cladding gap appears to have been completely closed, the fuel pellets did move.

When all the photomicrographs are available, more detailed analyses will be made to correlate predictions and observations.

(2) Transient Irradiations. Permission to perform the TREAT calibration test has been received from ANL-TREAT. The calibration capsule was inserted into a TREAT capsule and preirradiation testing performed. The capsule is presently awaiting shipment to TREAT. Arrangements have been made to perform radiochemical burnup analysis on the fuel after irradiation in TREAT.

\section{Task FP-6}

a. Thermal Flux Irradiation of Hypostoichiometric $\mathrm{UO}_{2}-\mathrm{PuO}_{2}$

R. D. Leggett, L. A. Pember, and J.W. Weber

Pins BNW-1-1, 2, 3 and 5 were recovered from their respective capsules in the BNW hot cells, cleaned in Dowanol 
and water, visually examined and photographed. The four pins appear to be in excellent condition with no indication of a breach in the cladding. Negative results of sampling the inner capsules for fission gas supports the indication that all pins are intact. All pins were tightly bound inside this inner capsule. Thus, it was necessary to slit the inner capsules longitudinally in order to remove the pins without damaging them. The pins are now measured with a profilometer. Preliminary results from BNW-1-2 indicate that a maximum average diameter increase of about 0.008 in. occurred on the bottom 2 in. of the fuel column. This increase corresponds to about 3\% $\Delta \mathrm{D}$. Some ovality was also noted. Following this, the pins will be gamma scanned, punctured for plenum gas collection and analysis, and sectioned for ceramography.

b. Electron Microprobe Examination

R. D. Leggett and E. D. Jenson

A section from pin BNW-1-8 (failed) is being studied to determine the location of fission products, the concentration profiles of uranium and plutonium, and the extent and nature of fuel-cladding interaction. Preliminary results indicate a very large depletion (factor of 10 to 20) of plutonium and a buildup of uranium (approximately $20 \%$ ) at the fuel surface.

The plutonium depletion is thought to be largely the result of burnup effects in the thermal flux, while the uranium buildup is attributed to migration. Very few fission products appeared to be present in this section.

3. Task FP-7

a. Fue1 Pin Irradiations in EBR-II

L. A. Pember, J. W. Weber, E. O. Ballard, and

S. H. Christensen

Five PNL-X pins are undergoing postirradiation examination in the LASL hot cells. Two of these pins PNL-X-6 and X-7, 
operated at an estimated $10.6 \mathrm{~kW} / \mathrm{ft}$ to a burnup of $8500 \mathrm{MWD}$, while the other 3 PNL-X-1, X-3, and X-4, operated at an $\overline{\text { MTM }}$ estimated $6 \mathrm{~kW} / \mathrm{ft}$ to $4800 \frac{\mathrm{MWD}}{\mathrm{MTM}}$.

On opening, PNL-X-1 showed some peculiar markings in the cladding in the plenum region which, although not completely explained, appear to have had no influence on pin performance. The markings consisted of a network of dark lines appearing reddish-brown when viewed in air at low magnification. A qualitative analysis of some of the fine particulate brushed from these markings showed $\mathrm{Fe}, \mathrm{Cr}$, and $\mathrm{Ni}$ as the major constituents. The marks on the cladding are probably sites of preferential oxidation at light scratches placed on the surface of the pin during fabrication. Analysis of the $\mathrm{Na}$ from the PNL-X-1 and X-6 capsules showed slightly higher concentration of $\mathrm{Fe}, \mathrm{Ni}$, and $\mathrm{Cr}$ in $\mathrm{X}-1$. PNL-X-6 exhibited none of the reddish-brown markings.

Examination of the PNL-X pins through profilometry and collection and analysis of the internal pin gas has been completed at LASL. Results from analysis of the profilometer data are shown in Table 5.D.I. Comparison of the maximum diameter in the fuel section with the average diameter through the gas plenum indicates a maximum diameter increase of $0.0005 \mathrm{mil}$ on the higher power, higher exposure fuel pins. Ovality of the cladding $O D$ was limited to 0.0004 in. or less.

Results from the plenum gas measurements and analysis are shown in Tables 5.D.II and 5.D.III. The volume of fission gas formed and the percent released is based on the estimated burnups. A comparison of the PNL-X-6 and $\mathrm{X}-7$ percent gas release with results previously obtained from the PNL-1-19 fuel pins with similar design parameters, and irradiated under similar conditions, indicates the exposure estimate to be reasonable. 


\section{TABLE 5.D.I. PNL-X CZadding Diameters}

\begin{tabular}{cccc} 
Pin Number & $\begin{array}{c}\text { Maximum } \\
\text { Cladding OD }\end{array}$ & & \multicolumn{2}{c}{ Diameter Increase } \\
Compared to Plenum
\end{tabular}

(1) Maximum from four diameter measurements around circumference at $0^{\circ}, 45^{\circ}, 90^{\circ}$, and $135^{\circ}$ made at 1-in. increments along longitudinal axis.

\section{TABLE 5.D.II. Gas Measurements on PNL-X Pins}

\section{Fission Gas}

Total Fission Est. Burnup, Formed, Fission Gas

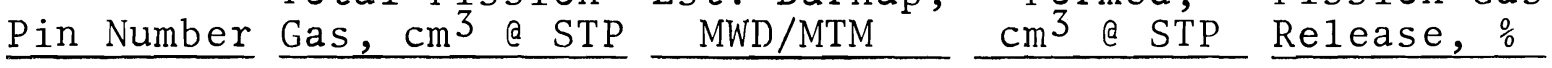

$\begin{array}{rlrrr}\text { PNL }-X-1 & 0.0272 & 4800 & 8.9 & 0.31 \\ \text { PNL-X - 3 } & 0.0251 & 4800 & 8.9 & 0.28 \\ \text { PNL-X - } & 0.01185 & 4800 & 8.9 & 0.13 \\ \text { PNL - X-6 } & 3.592 & 8500 & 15.68 & 22.91 \\ \text { PNL -X - 7 } & 3.386 & 8500 & 15.81 & 21.42\end{array}$

TABLE 5.D.III. Gas Analysis on PNL-X Pins

\begin{tabular}{|c|c|c|c|c|c|c|}
\hline Pin Number & $\% \mathrm{Xe}$ & $\% \mathrm{Kr}$ & $\% \mathrm{He}$ & $\frac{N_{2}}{2}$ & $\% 0_{2}$ & $\%$ Ar \\
\hline$P N L-X-1$ & 0.327 & 0.033 & 99.5 & - & -- & 0.10 \\
\hline PNL-X - 3 & 0.307 & 0.029 & 99.6 & -- & -- & 0.09 \\
\hline PNL - X - 4 & 0.146 & 0.011 & 99.6 & 0.03 & 0.01 & 0.20 \\
\hline PNL - X - 6 & 28.32 & 3.61 & 67.6 & - & -- & 0.50 \\
\hline PNL - X - 7 & 27.04 & 3.50 & 68.9 & - & - & 0.50 \\
\hline
\end{tabular}


b. Electron Microprobe Examination of Irradiated Fue1s

E. D. Jenson

Fuel pin sample PNL-1-6F was examined in the shielded electron microprobe for variation in plutonium and uranium across the pin and identification of metallic-appearing ingots. This pin, irradiated to $8140 \mathrm{MWd} / \mathrm{T}$ with PNL-1-3, has exposure characteristics similar to those reported last month for PNL-1-3.

All ingots found near the central void of PNL-1-6 showed the presence of the fission product molybdenum. None of those examined showed the presence of iron. In contrast, all particles in the outer third of the pin showed the presence of iron, but no molybdenum. Of four particles located about halfway between central void and cladding, two showed the presence of iron and molybdenum, as well as an element tentatively identified as phosphorus and a probable trace of tungsten, but no technetium nor ruthenium.

c. EBR-II Instrumented Subassembly (PNL-17)

M. K. Millhollen

Components for the fuel pins are now being fabricated from the approved drawings under the direction of the Special Products Fabrication Section. Since it is not possible to ascertain when EBR-II will be raised to the 62.5 MW power level, the decision has been made to fabricate fuel pellets in which the uranium enrichment is reduced from 93 to $65 \%$. If the reactor power is raised before the test is installed, the maximum linear heat generation rate will not exceed $12 \mathrm{~kW} / \mathrm{ft}$. If the power is not raised, the pin power generation will be approximately $25 \%$ less. 


\section{d. Transient Fuel Pin Analysis}

F. E. Bard and D. S. Dutt

As was stated in the month of February, (1) the codes PECT-I and INEQ did not provide a dilatation creep and plasticity mode1. During the past four months, the dilatation element has been formulated and programmed. The code INEQ was then used to analyze a TREAT experiment. The results of the computer run showed INEQ to require too much computing time to be of any use. The code INEQ consists of 269 first order simultaneous differential equations with respect to time. Also for each time point, a matrix equation consisting of 22 simultaneous algebraic variables must be solved.

e. Dosimetry and Damage Analysis for Fue1s

R. E. Dah1, Jr. and R. D. Bourquin

Development of a computer method suitable for use in selecting neutron spectra and flux at any radial or axial position in the EBR-II from calculated or measured data has been completed. This effort will enable rapid evaluation of fuel element behavior for any position in EBR-II within the accuracy of the spectral information (from reactor analyses and/or experimental measurements). For example, behavior of the highest average and the lowest power pins in a subassembly or the peak-to-average values for any pin can be calculated.

Documentation of the method of analysis used to relate cladding damage and fuel element burnup during the course of extended irradiations in fast reactors has been partially completed. This documentation includes a description of the methods and use of BURN BABY BURN.

(1) FFTF Monthly Report, BNWL-1006, February 1969. 


\section{4. $\quad$ Task CFD - 3}

\section{a. CCTL Flow Test Examination}

M. K. Mi11ho11en

During the removal of the 217 pin flow test element from the CCTL, a steel cable previously exposed to sodium vapor during the test, was found to have a much lower breaking strength than was anticipated. Samples of the exposed cable and of new, unused cable were prepared metallographically and studied to determine the reason for the low strength.

There was also an opportunity to examine samples of 201 SS (1) unexposed to sodium, (2) submerged in liquid sodium, and (3) exposed to sodium vapor. The liquid sodium was at a temperature of $1060^{\circ} \mathrm{F}$ for at least $3600 \mathrm{hr}$ and at lower temperatures for an additional $1000 \mathrm{hr}$. The sodium vapor was that in the test vessel above the liquid level. Evidence of some limited surface attack was disclosed by a 500X magnification of the sample immersed in liquid sodium. Evidence of an accelerated surface attack in the sample exposed to sodium vapor was very obvious, and indicates that 201 SS cannot be regarded as a satisfactory material for extended periods of use in sodium atmospheres. 


\section{E. OFFSITE FUEL PROGRAMS}

G. A. Last

\section{LMFBR Fue1 Development}

B. R. Hayward and F. M. Smith

Additional work scope was added to the NUMEC and UNC process development contracts to determine the weight per unit length of the FTR fuel pellets and fuel columns. The purpose of this work is to evaluate alternate methods of specifying the fuel loading characteristics required in the FTR fuel pin design.

The design of two NUMEC 61-pin subassemblies for test in EBR-II will be based on $85 \%$ smear density. BNW has recommended the use of $68 \%$ enriched $\mathrm{UO}_{2}$ in these tests to minimize the handling of these subassemblies at the time EBR-II goes to 62.5 MW operating level. Additional fuel pin hardware and certifications were forwarded to NUMEC, including fuel tubes and 0.250-in. diam end cap stock.

The total effort on Phase II of the Analytical Chemistry Program was about $70 \%$ completed by the first week of June. Four sites, AI, B\&W, BNW, and UNC will have completed their analytical work before June 30. Two sites, GE and NUMEC, may have to carry the program beyond June 30 because of equipment difficulties. Late arrival and necessary checkout of the C.P. coulometer will delay the uranium and plutonium assays from GE. NUMEC is having difficulty in getting their gas evolution apparatus operable.

Kerr-McGee was offered an opportunity to join the Analytical Chemistry Program under a no-cost-to-fFTF contract. All data will be evaluated on the same basis as the other participants. 
Burnout of the sintering furnace in the plutonium process line has compelled AI to abandon their efforts to complete the Task C-2 Scrap Recycle program. BNW has given AI permission to retain about $3 \mathrm{~kg}$ of the pellets and powdered material from the scrap recycle task for use in making some reactor physics measurements on a non-FFTF project. Any costs associated with returning this retained material after June 30 will be at no cost to BNW.

General Electric's proposal to extend Task F-2 work to improve homogeneity determination methods through alphaautoradiography and neutron radioagraphy has been accepted. The contract has been signed and the work started.

Extension of the Analytical Chemistry Program, Task G-2, to source or raw materials required for FFTF fuel fabrication is being initiated. The formulation of detailed plans and scheduling of discussions with Dr. C. F. Metz of LASL and other interested personnel in BNW, AEC and ARHCO to lay out an optimum course of action are under way. Shipper-receiver differences in analysis of nuclear raw materials used for FFTF fuel fabrication, along with product quality and types of products have pointed out the need for standardized analyses, sampling procedures, and specifications. Thus far, analytical methods to define the quality of the raw materials are somewhat uncertain. The recent work done in Phases I and II of the Analytical Chemistry Program will be extended to raw materials to ensure comparable standardization of methods and evaluation of precision and accuracy of the methods. 


\section{DISTRIBUTION}

No. of

Copies

OFFSITE
AEC Chicago Patent Group G. H. Lee, Chief

AEC Division of Reactor Development and Technology

M. Shaw, Director, RDT

Asst Dir for Nuclear Safety

Analysis \& Evaluation Branch, RDT:NS

Environmental \& Sanitary Engineering Branch, RDT:NS

Research \& Development Branch, RDT:NS (2)

Asst Dir for Plant Engineering, RDT

Facilities Branch, RDT:PE

Components Branch, RDT:PE

Instrumentation \& Control Branch, RDT:PE

Liquid Metal System Branch, RDT:PE

Asst Dir for Program Analysis, RDT

Asst Dir for Project Management, RDT

Liquid Metals Projects Branch, RDT:PM

FFTF Project Manager, RDT:PM (3)

Asst Dir for Reactor Engineering, RDT

Contro1 Mechanisms Branch, RDT:RE

Core Design Branch, RDT:RE (2)

Fue1 Engineering Branch, RDT:RE

Fuel Handiing Branch, RDT:RE

Reactor Vessels Branch, RDT:RE

Asst Dir for Reactor Technology, RDT

Coolant Chemistry Branch, RDT:RT

Fuel Recycle Branch, RDT:RT

Fuels \& Materials Branch, RDT:RT

Reactor Physics Branch, RDT:RT

Special Technology Branch, RDT:RT

Asst Dir for Engrg Standards, RDT

1 AEC Idaho Operations Office

C. W. Bills, Director

1 AEC San Francisco Operations Office

Director, Reactor Division

AEC RDT Site Representatives

Argonne National Laboratory

Atomics International

Atomic Power Development Associates, Inc.

General Electric, Sunnyvale 
No. of

Copies

Argonne National Laboratory

R. A. Avery

R. A. Jaross

A. Trave11i

G. F. Popper

N. J. Swanson

LMFBR Program office (2)

M. Levenson, Director, EBR-II Project

1 Argonne National Laboratory (Idaho Falls)

F. W. Thalgott

2 Atomic Power Development Associates, Inc.

Document Librarian

$7 \quad$ Atomics International

D. J. Cockeram (5)

Liquid Metal Information Center - J. J. Droher (2)

3 Babcock \& Wilcox Company

S. H. Esleek

G. B. Garton

P. J. Kovach

1 Battelle-Northwest Representative

N. A. Hill (ZPR-II Rep)

8 Bechtel Corporation

J. J. Teachnor

1 Combustion Engineering

1000 MWe Follow-On Study

W. P. Staker, Project Manager

5 General Electric Company

K. Cohen (3)

Bertram Wolfe

Nuclear Systems Programs - D. H. Ahmann

2 Gulf General Atomics, Inc.

General Atomics Division

D. Coburn

1 Idaho Nuclear Corporation

D. R. DeBoisblanc

1 Liquid Metal Engineering Center

Director

2 Los Alamos Scientific Laboratory

D. B. Hall

R. D. Baker - University of California 
No. of

Copies

1 Nuclear Materials and Equipment Corporation (AEC) C. S. Caldwe11

2 Oak Ridge National Laboratory

H. G. Duggan

W. 0. Harms

1 Southwest Research Institute

A. G. Pickett

1 Stanford University

Nuclear Division

R. Sher

1 United Nuclear Corporation

Research and Engineering Center

R. F. DeAnge 1 is

10 Westinghouse Electric Corporation

J. C. R. Ke11y

ONS ITE-HANFORD

1 AEC Chicago Patent Group

R. K. Sharp (Richland)

3 AEC RDT Site Representative

P. G. Holsted

3 AEC Richland Operations Office

J. M. Shivley

4 Battelle Memorial Institute

1 Bechte1 Corporation

M. 0. Rothwe11 (Rich1and)

2 Douglas United Nuclear

O. C. Schroeder

C. W. Kuhlman

1 Westinghouse Electric Corporation

R. Strzelecki (Richland)

129 Batte11e-Northwest

F. W. Albaugh

G. J. Alkire

S. 0. Arneson

E. R. Astley

J. M. Batch

A. L. Bement, Jr.

R. A. Bennett 
No. of

Copies

Batte11e-Northwest

T. K. Bierlein

L. D. Blackburn

C. L. Boyd

D. C. Boyd

R. L. Brown

W. L. Bunch

C. A. Burgess

J. J. Cadwe11

A. C. Callen

C. M. Cantre11

J. R. Carrell

W. E. Cawley

W. L. Chase

T. D. Chikalla

T. T. Claudson

J. C. Cochran

P. D. Cohn

D. L. Condotta

J. H. Cox

G. M. Dalen

J. M. Davidson

C. T. Davis

F. G. Daws on

D. R. de Halas

A. W. DeMerschman

D. R. Doman

G. E. Driver

K. Drumheller

R. V. Dulin

J. F. Erben

E. A. Evans

T. W. Evans

P. L. Farnsworth

L. M. Finch

J. C. Fox

E. E. Garrett

F. C. Gronemeyer

W. L. Hamps on

J. E. Hans on

K. M. Harmon
R. A. Harvey

J. J. Hauth

B. R. Hayward

R. E. Heineman

J. W. Helm

R. J. Hennig

G. M. Hesson

P. L. Hofmann

J. J. Holmes

B. M. Johns on

H. G. Johnson

E. M. Johnston

J. N. Judy

F. J. Kempf

D. D. Knowles

D. D. Lanning

G. A. Last

D. C. Lehfeldt

H. D. Lenkersdorfer

C. W. Lindenmeier

W. W. Little, Jr.

C. E. Love

B. Mann

W. B. McDonald

D. Marinos

J. S. McMahon

C. A. Munro

R. E. Nightingale

L. T. Pedersen

G. S. Peterson

R. E. Peterson

H. G. Powers

H. L. Pringle

W. D. Richmond

W. E. Roake

R. L. Roske

F. H. Shade 1

D. W. Shannon

F. R. Shober

D. E. Simpson 
No. of

Copies

Batte11e-Northwest

C. R. F. Smith

R. J. Squires

D. D. Stepnewski

G. H. Strong

C. D. Swanson

J. W. Thorton

J. C. Tobin

K. G. Toyoda

J. C. Tverberg

C. E. Voge1

M. Voge 1

R. C. Walker

E. T. Webber

J. H. Westsik

J. F. Wett

R. G. Wheeler

F. J. Williams

N. G. Wittenbrock

T. W. Withers

M. R. Wood

F. W. Woodfield

D. C. Worlton

H. H. Yoshikawa

FFTF Reference File (10)

Technical Information (5)

Technical Publications (3)

FFTF Technical Reports Office 